\title{
2008 Annual Report
}

\section{Steelhead Kelt Reconditioning and Reproductive Success}

\author{
Prepared by: \\ Ryan Branstetter \\ Jeff Stephenson \\ Douglas R. Hatch (Principal Investigator) \\ John Whiteaker \\ Saang -Yoon Hyun \\ Columbia River Inter-Tribal Fish Commission \\ 729 NE Oregon Street, Suite 200 \\ Portland, OR 97232 \\ Bill Bosch \\ Dr. David Fast \\ Joe Blodgett \\ Todd Newsome \\ Yakama Nation \\ Department of Natural Resources \\ Fish and Wildlife \\ 401 Fort Road \\ Toppenish, WA 98948 \\ Lisa M. Hewlett-Dubisar \\ Jen Graham \\ Confederated Tribes \\ Of the \\ Warm Springs Reservation \\ Department of Natural Resources \\ Fish and Wildlife \\ P O Box C \\ Warm Springs, OR 97761 \\ Rhonda Dasher \\ Chris Fisher

\section{Colville Confederated Tribes} \\ Department of Natural Resources \\ Fish and Wildlife \\ Fish \& Wildlife Department \\ PO Box 150 \\ Nespelem, WA 99155 \\ Prepared for: \\ U.S. Department of Energy \\ Bonneville Power Administration \\ Division of Fish and Wildlife \\ P.O. Box 3621 \\ Portland, OR 97283-3621 \\ Project Number: 2007-401-00 \\ Contract Number: 0030769
}




\begin{abstract}
Iteroparity, the ability to repeat spawn, is a natural life history strategy that is expressed by some species from the family Salmonidae. Current rates of observed steelhead Oncorhynchus mykiss iteroparity rates in the Columbia River Basin are severely depressed due to anthropogenic development which includes operation of the hydropower system and other habitat degradations. Artificial reconditioning, which is the process of culturing post-spawned fish (kelts) in a captive environment until they are able to reinitiate feeding, growth, and redevelop mature gonads, is evaluated in this study as method to restore depressed steelhead populations. To test the efficacy of steelhead kelt reconditioning as a management and recovery tool different scenarios were investigated ranging from very low intensity (collect and transport fish) to high intensity (collect and feed fish in captivity until rematuration). Examinations of gamete and progeny viability were performed for first-time spawners and reconditioned kelt steelhead. We have continued to examine reproductive success of reconditioned kelt steelhead in Omak Creek using microsatellite loci to perform parentage analysis on juvenile O. mykiss. The groundwork has also begun on developing a genetic analysis of the Yakima subbasin in order to determine steelhead kelt contribution by utilizing parentage analysis on a larger scale. A research and study plan has been developed cooperatively with the University of Idaho to determine the feasibility of steelhead kelt reconditioning program in the Snake River Basin. Analysis of management scenarios indicated that while no-term and short-term reconditioned kelts continue to perform well outmigrating to the ocean but returns from these groups have been low ranging from $0-12 \%$ during $2002-2008$. Survival (56\%) of fish in the long-term treatment in 2008 was the highest we have observed in this project. Analyzing the three different management scenarios within the Yakima River subbasin we determined that long-term reconditioning contributed the highest numbers of fish to the spawning run, and short-term reconditioning overall was the best of the transport releases to the ocean. However contributions to the spawning run by no-term or short-term groups was low in all years. This is the second successful year of kelt gamete and progeny analysis. Initial limited results suggest that reconditioned kelts may have shown limited improvement in both egg quantity and/or quality. There is further evidence to support the successful spawning of steelhead kelts in the wild at Omak Creek. Yakima kelts have been successfully identified to stream origin using genotypes.
\end{abstract}




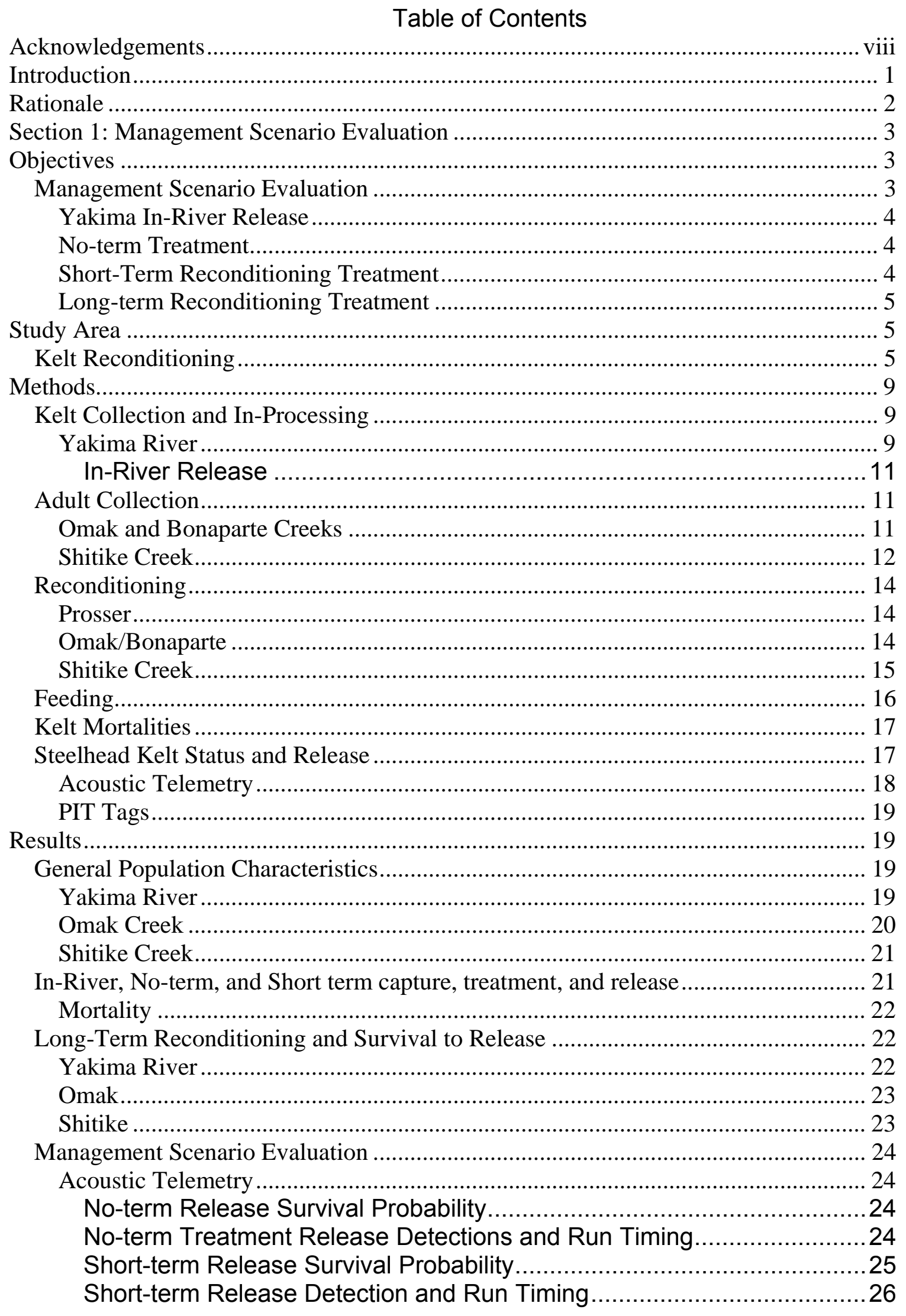


Acoustic Telemetry Return Detections ................................................................... 27

Long-term Reconditioning................................................................................... 27

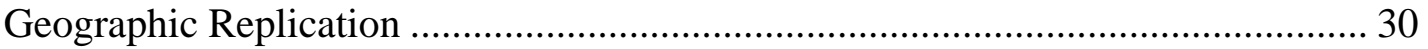

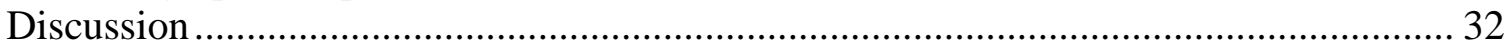

Management Scenario Evaluation ............................................................................. 32

Steelhead Kelt Returns........................................................................................ 35

Geographic Replication .................................................................................... 38

Section 2: Gamete and Progeny Viability...................................................................... 39

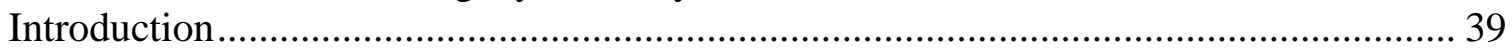

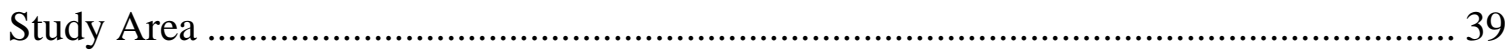

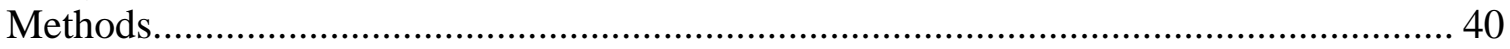

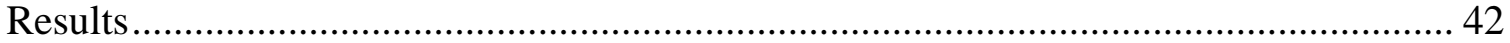

Adult Collection, Spawning and Reconditioning ………........................................... 42

2009 Broodstock First-time Collection, Spawning ..................................................... 42

2008 Broodstock First-time Collection, Spawning, and Reconditioning .................. 42

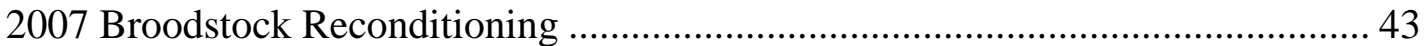

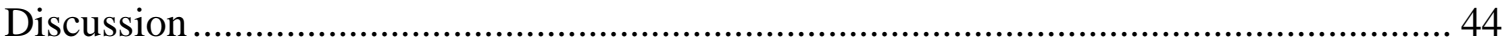

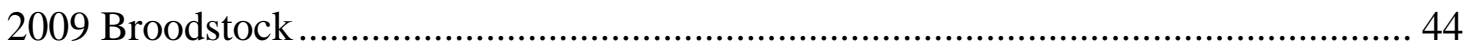

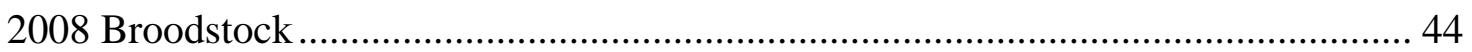

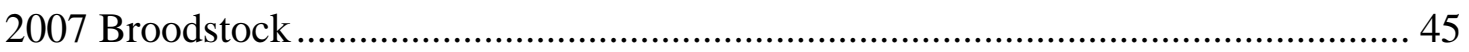

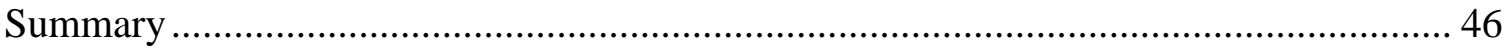

Section 3: Reproductive Success ............................................................................. 47

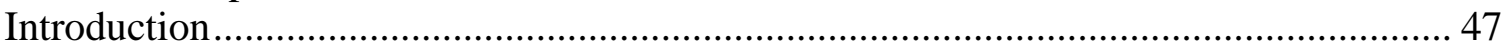

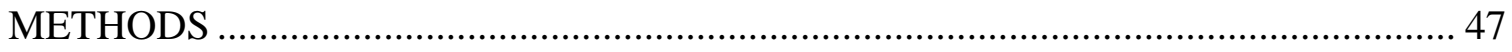

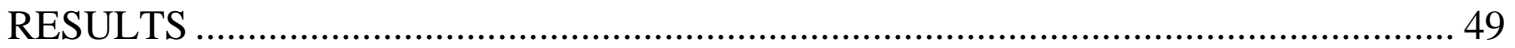

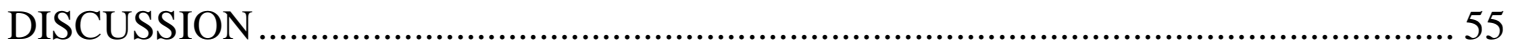

Section 4: Genetic Analysis of Yakima Subbasin Oncorhynchus mykiss ....................... 56

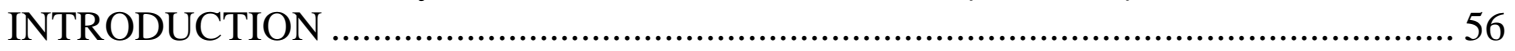

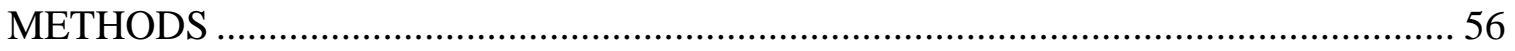

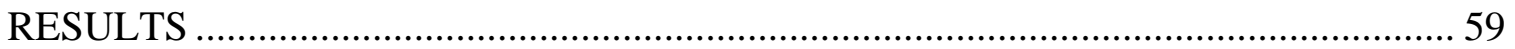

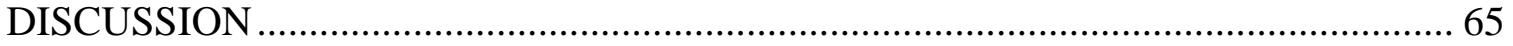

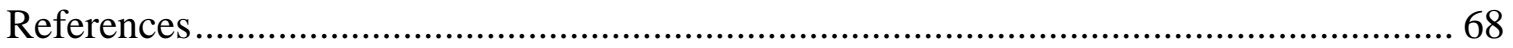

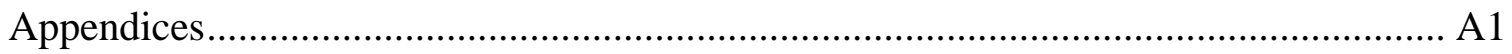

Appendix A. Snake River Study Plan....................................................................... A1

Appendix B. Lower Columbia River Array Locations ...................................................B1

Appendix C: Likelihood functions of parameters...........................................................

Appendix D. Detections History by Treatment and Release Year For Yakima River

Steelhead Kelt Releases......................................................................................... D1

Appendix E. First Time Spawner Analysis for Steelhead Captured at Parkdale 2008. 


\section{Figures}

Figure 1. Reconditioning site (Prosser, WA) and release site (Hamilton Is. Boat Ramp) for No-term and Short-term reconditioning experiments.

Figure 2. Lower Columbia River acoustic receiver deployment 2008 ................... 7

Figure 3. Map showing the locations of Omak Creek as well as the Confederated

Tribes of the Colville Reservation.

Figure 4. Map showing the location of Shitike Creek and the Confederated

Tribes of the Warm Springs Reservation

Figure 5. Chandler Juvenile Evaluation Facility adult separator. ........................... 10

Figure 6. Photograph of the resistance board weir located on Omak Creek........ 12

Figure 7. Shitike Creek weir March 2008............................................................... 13

Figure 8. Shitike Creek weir upstream box............................................................. 13

Figure 9. Steelhead kelt reconditioning tanks Prosser, WA ..................................... 14

Figure 10. Steelhead kelt reconditioning facilities w/ sampling area at Cassimer

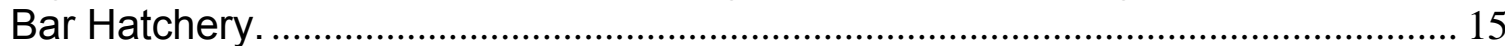

Figure 11. New placement of kelt reconditioning tank in 2008 at WSNFH.......... 16

Figure 12. Steelhead kelt collection dates and numbers of fish removed from the

CJEF in 2008.

Figure 13. Steelhead kelt outmigration survival as a function of travel time (in days) for no-term (NT) and short-term (ST) treatment releases from 2004 through 2008

Figure 14. No-term (NT) and short-term (ST) release groups from 2004 through 2008 survival as a function of Columbia River flow ( $\mathrm{kcfs}$ ) measured at Bonneville Dam. The one point not included within an ellipse is from 2006.

Figure 15. Survival of No-term (NT) and short-term (ST) release groups, in the lower Columbia River, from 2004 through 2008 as a function river temperature. One NT release from 2007 and one ST release from 2006 did not group in their respective ellipses.

Figure 16. Location of Parkdale Fish Facility and Powerdale Dam/ Fish Trap. ... 40 Figure 17. Ln Probability of Data. For each value of $K=1-10$, three In Probability values are graphed. The large increase between $K=1$ and $K=2$ is considered to be the only one of significant interests.

Figure 19. Length Frequency Histograms for fish sampled in 2007 and 2008. Percent of run for each length classes is reported for known age (via parentage) juveniles captured in the screwtrap. Range of putative kelt progeny is displayed to demonstrate relationship with known age fish.

Figure 20. Neighbor joining dendrogram of Cavalli-Sforza Edwards genetic distance among studied populations. Numbers at nodes represent bootstrap percentage from 1000 replicates (only those greater than 50 percent shown).... 63 Figure 21. Ln Probability of Data. For each value of $K=1-10$, the average of three In Probability values is graphed.

Figure 22. Proportional mixed stock assignments. The percentage of each collection of unknown fish assigned to the reference populations. Unknown fish consist of adults collected at either Prosser Dam during first spawning migration, or 
as outmigrating kelts at the Chandler fish trap. Reference populations consist of the five tributary collections of juveniles.

\section{Tables}

Table 1. Summary of upstream migrating hatchery and wild summer steelhead captured at picket weir, Shitike Creek March- June 2008.

Table 2. Condition of hatchery (AD) and wild (NM) steelhead caught in the upstream trap at the Shitike Creek weir (\%).

Table 3. Release group results by treatment........................................................ 22

Table 4. Long-term reconditioning results by tank 2008......................................... 23

Table 5. Survival rate and detection probability of No-term release 1 on 4/25/2008 and No-term 2 on May 25, 2008. The lambda term is the product of survival and detection probability, this term cannot be decomposed in the reach 3 estimate.

Table 6. Number detected, travel time and average travel speed to detection array from time of release of No-term release group 1, $N=24$. Released $4 / 25 / 2008$

Table 7. Number detected, travel time and average travel speed to detection array from time of release of No-term kelt release group 2, $\mathrm{N}=25$. Released May $12,2008$.

Table 8. Survival rate and detection probability of Short-term release on $4 / 25 / 2008$. The lambda term is the product of survival and detection probability, this term cannot be decomposed in the reach 3 estimate...................................... 26 Table 9. Number detected, travel time and travel speed to detection array from time of release of Short-term kelt release $N=50$. Released on 4/25/2008.......... 26 Table 10. Acoustic tag return migration detection in the lower Columbia River. . 27

Table 11. Prosser Management Strategy Results. .................................................. 29

Table 12. Long-term Reconditioning by Release Site ........................................... 31

Table 13. Total PIT- tag Detection By Release Year at Prosser 2004-2008 w/ Bonneville Comparison. .......................................................................................... 36

Table 14. 2008 McNary Dam Detections ............................................................... 37

Table 15. Female kelt 2828: Successful keel development (\%) as an estimate of initial fertilization 2009

Table 16. Female Kelt 94: Successful keel development (\%) as an estimate of initial fertilization.

Table 17. Spawner \#: 2828 keel comparison between first time spawning in 2008 and kelt spawning in 2009 .

Table 18. Steelhead (94) keel comparison between first time spawning in 2007 and kelt spawning in 2009.

Table 19. Population Statistics. Each collection is reported in terms of sample size $(n)$, expected heterozygosity $\left(H_{E}\right)$, observed heterozygosity $\left(H_{O}\right)$, average number of alleles per locus (A), allelic richness (AR), number of loci out of HardyWeinberg equilibrium (HW), and number of pairwise loci comparisons showing linkage disequilibrium (LD).

Table 20. Population assignments by structure. Percentage of each collection assigning to the group labeled as anadromous (Anad), Resident (Res), or Mixed. 
Mixed is defined as having intermediate values of less than 0.90 or 0.70 for both the anadromous and resident groups.

Table 21. Population Statistics. Each collection is reported in terms of sample size $(n)$, number of samples removed due to evidence of cutthroat sampling or introgression (cut), number of microsatellite alleles (A), microsatellite allelic richness (AR), microsatellite private allelic richness (PAR), expected heterozygosity $\left(\mathrm{H}_{\mathrm{E}}\right)$, and observed heterozygosity $\left(\mathrm{H}_{\mathrm{O}}\right)$, average number of alleles per locus (A), allelic richness (AR), number of loci out of Hardy-Weinberg equilibrium (HW), and number of pairwise loci comparisons showing linkage disequilibrium (LD).

Table 22. Hardy-Weinberg equilibrium. Each collection is reported in terms of the number of comparison (comp), the number and proportion of loci showing departures from Hardy-Weinberg (Probability), and the number and proportion showing evidence of Heterozygote Deficit (Deficit) or Excess (Excess). Table 23. Linkage Disequilibrium. Each collection is reported in terms of the number of pairwise comparisons made (comp), and the number (n) and proportion (prop) of pairwise comparisons showing evidence of linkage disequilibrium (LD).

Table 24. Pairwise Fst values and number of Loci with $P<0.05$. Fst values greater than 0.02 are highlighted. Number of Loci with $P<0.05$. For each population pairwise comparison, the number of loci showing evidence of population differentiation is shown. Numbers greater than 25 are highlighted

Table 25. Individual assignments to reference populations. The number of fish assigning to baseline collections is listed. Each row lists where samples are from. Columns list where individuals were assigned to. Assignments are given for both collection level, and reporting group with all Naches tributaries treated as a single reporting group. Bold numbers are assigned to their population of collection. .... 64 Table 26. Chi-squared tests for comparisons between each unknown collection of adult steelhead. P-values for each pairwise comparison are given. 65 


\section{Acknowledgements}

The authors of this report would like to thank the following individuals and organizations for providing time and expertise toward this project: The Bonneville Power Administration for providing funding for this research project and to its staff for their assistance. Hatchery staff for the care provided to this important species: Parkdale Fish Facility (Jim Gidley, Albert Santos and Chuck Gehling), Prosser Fish Hatchery (Bill Fiander, Mark Johnston, Jake Aleck, Michael Fiander, Carrie Skahan, OJ Davis, and Bob Gleason), Cassimer Bar Fish Facility (Tony), and Warm Springs National Fish Hatchery. The trapping crews for the long hours worked carefully capturing steelhead: Chandler Juvenile Fish Facility, Shitike Creek, Omak and Bonaparte Creeks, and Parkdale Dam Trap (Megan Heinrich and Crew). Thanks to the vigilant work of the virology staff at Oregon Department of Fish and Wildlife (Tony Amandi, John Kauffman, Mark Engelking, and Sharon Vendshus), Washington Department of Fish and Wildlife (Joan Thomas), Lower Columbia Fish Health Center (Eric Pelton and Ken Lujan), and Eagle Creek Fish Health Center (Doug Monson). We would also like to thank the following individuals for providing valuable expertise, information and supplies: Matt Mesa, Penny Swanson, Roy Sampsel, Marla Chaney and Colleen Weiss at the Bonneville Captive Brood Program, Dr. Robert Flecker (Hillsdale Veterinary Group), Bob Rodgers (WDFW), Rod French (ODFW) and Greg Davis (ODFW). Thanks to the following Columbia River Inter-Tribal Fish Staff for their technical expertise, suggestions, and assistance: Bobby Begay, Shaun Narum, Phil Roger, Denise Kelsey, David Graves, Rob Lothrop, Christine Golightly, Richard Sampson, Peter Galbreath, Jeff Fryer, Gabe Sheoships, David Liberty, Winfred Perez and Charles Torbeck. 


\section{Introduction}

Oncorhynchus mykiss are considered to have one of the most diverse life histories in Salmoninae (Behnke 1992) with variants that include resident, estuarine, and anadromous ecotypes, widely ranging ages, timing of juvenile and adult migrations, and various reproductive strategies including precocity, semelparity, and iteroparity. This complex array of life history variation is possibly a compensating or bet hedging device for life in stochastic environments (Taborsky 2001). Overlapping generations provide resources especially for small populations in the event of failure of any brood year due to brief catastrophic events (Seamons 2006). While fluctuating populations and overlapping generations may reduce the effective population size ( $N_{e}$; Waples 2002), retention of genetic diversity and persistence of the species may be favored due to these compensating life histories (Seamons 2006 and Narum et al. 2008).

Populations of wild steelhead $O$. mykiss have declined dramatically from historical levels in the Columbia and Snake rivers (Nehlsen et al. 1991; NRC 1996; US v. Oregon 1997; ISRP 1999). In 1997, steelhead in the upper Columbia River were listed as endangered under the Endangered Species Act (ESA) (NMFS 1997). Those in the Snake River have been listed as threatened since 1997 (NMFS 1997). Stocks originating in the mid-Columbia were listed as threatened in 1999 (NMFS 1999). The causes of the species decline are numerous and well known. The two that have had the biggest impact are hydropower operations and habitat loss (TRP 1995; NPPC 1986; NRC 1996; ISRP 1999). Regional conservation plans recognize the need to protect and enhance weak upriver steelhead populations while maintaining the genetic integrity of those stocks (NPPC 1995).

Iteroparity, the ability to repeat spawn, is a natural life history strategy that is expressed by 0 . mykiss, with repeat spawner rates estimated to be as high as $79 \%$ for populations in the Utkholok River of Kamchatka, Russia 1994-96 (Savvaitova et al. 1996) and as high as 30\% for British Columbia (Withler 1966). Historical rates for the Columbia River have not been readily documented but adult emigrating steelhead averaged $58 \%$ of the total upstream runs in the Clackamas River from 1956 to 1964 (Gunsolus and Eicher 1970). Current iteroparity rates for Columbia River Basin steelhead are considerably lower, due largely to high mortality of downstream migrating kelts (post-spawn steelhead) at hydropower dams (Evans and Beaty 2001), and potentially inherent differences in iteroparity rate based on latitudinal and inland distance effects (Withler 1966; Bell 1980; Fleming 1998). The highest recent estimates of repeat spawners from the Columbia River Basin were in the Kalama River (tributary of the unimpounded lower Columbia River) that exceeded 17\% (NMFS 1996). At the Hood River, return summer run steelhead kelt at an average rate of $5.7 \%$ (above only one mainstem dam) based on scale pattern analysis (Olsen 2008). 
Iteroparity rates for Klickitat River steelhead were reported at 3.3\% from 1979 to 1981 (Howell et al. 1984). Summer steelhead in the South Fork Walla Walla River have expressed $2 \%$ to $9 \%$ iteroparity rates (J. Gourmand, ODFW, pers. comm.). Initially it was thought that repeat spawners composed only $1.6 \%$ of the Yakima River wild run (from data in Hockersmith et al. 1995) but new data may suggest otherwise.

\section{Rationale}

Post-spawn steelhead represent a portion of the population that have successfully survived through an entire life cycle culminating with spawning. Artificially reconditioning these kelts may counter the negative selective forces against iteroparity associated with the hydrosystem, thereby helping to preserve the evolutionary legacy of the species. Kelt reconditioning starts with the introduction of feed which encourages the reinitiation of feeding, thereby enabling kelts to survive and rebuild energy reserves required for gonadal development and repeat spawning. Techniques used in kelt reconditioning were initially developed for Atlantic salmon Salmo salar and sea-trout S. trutta. A review of these studies and those applicable to steelhead kelts are summarized in Evans et al. (2001). Additional reviews of this subject (Hatch et al. 2002 and 2003b) provide strong support of the benefits of kelt reconditioning to address population demographic and genetic issues in steelhead recovery. The ultimate success of kelt reconditioning should be assessed based on the number of individuals that successfully reproduce in the wild following reconditioning and release. Although it is difficult to witness individual fish spawning in the wild, and even more difficult to assess the viability and quality of gametes, we are conducting experiments (reproductive success and gamete/progeny viability) to determine the extent to which reconditioned kelts are contributing to subsequent generations. Additionally we are estimating survival and return rates of artificially reconditioned kelt steelhead subjected to various management treatments ranging from low to high intensity efforts.

This report is divided into four sections. The first section describes the evaluation of various management strategies that could be used as tactics for steelhead restoration programs. The second section includes an evaluation of progeny and gamete viability of Skamania stock steelhead in the Hood River. The third section is a field study of reproductive success of reconditioned kelt steelhead. The last section is the genetic analysis of $O$. mykiss population structure within the Yakima River subbasin to determine the reproductive success of steelhead kelts in the wild. 


\section{Section 1: Management Scenario Evaluation}

The premise of this group of studies is to develop and evaluate potential strategies that fishery managers could use for steelhead restoration. We attempt to include measures that span from low intensity and cost through relatively high intensity with greater associated costs. Most of the year our efforts were focused on studies in the Yakima River, however, the signing of the Columbia River Accords in May 2008 expanded the project to include the Snake River. Work associated with the Snake River has included development of a research and project implementation plan (Appendix A).

\section{Objectives}

1. Investigate and develop approaches to utilize the steelhead kelt life stage to increase steelhead populations.

Rationale: Providing assistance to post-spawn steelhead in the forms of transportation, feed, and prophylactic measures may increase the probability that individual steelhead repeat spawn and contribute to population growth. In this objective we measure the variation in steelhead response to intervention methods. Further we attempt to identify locations that are particularly

problematic to steelhead kelt migrations in the lower Columbia River and estuary.

2. Apply kelt steelhead reconditioning techniques at selected streams to postspawners for release back into study streams.

Rationale: This objective will test the following hypothesizes:

Ho: Kelt steelhead reconditioning rates are similar spatially and temporally; and, Ho: Kelt steelhead rematuration rates are similar spatially and temporally. Additionally this objective will provide the reproductive success experiment (objective 2) with reconditioned kelt steelhead for study.

\section{Management Scenario Evaluation}

An evaluation of the reconditioning is based on two fundamental hypotheses aimed at comparing the relative survival and rematuration rates of program fish.

$\mathrm{H}_{0}$ : Repeat spawner rates are similar among all treatments including: in-river release; transport and release; short-term recondition and transport; and longterm recondition and release.

$\mathrm{H}_{\mathrm{o}}$ : Rematuration rates are similar among all treatments including: in-river release; transport and release; short-term recondition and transport; and longterm recondition and release. 
Management scenarios include four types (in-river, no-term, short-term, longterm) described below with the long-term replicated geographically.

\section{Yakima In-River Release}

A systematically selected portion of the kelts that would have been suitable for reconditioning were PIT tagged and released immediately back to the Yakima River to act as a control group. These PIT-tagged kelts provide baseline data and an opportunity to compare Hockersmith et. al. (1995) reported repeat spawner rates inferred from steelhead scale pattern analysis from the Yakima River.

\section{No-term Treatment}

In this treatment we directly transport steelhead kelts around the hydro-system and evaluate success by measuring survival to the ocean and survival to return. In addition we observe Lower Columbia River seaward and return spawning migration. Given the high mortality rates of seaward migrating kelts observed during radio telemetry experiments in the Snake and Columbia Rivers (Evans et al. 2001; Evans 2002; Hatch et al 2003a) iteroparity may be augmented by simply transporting kelts around the hydro system, thereby improving access to the marine environment.

The purpose of this objective is to evaluate the lowest cost alternative aimed at increasing steelhead iteroparity. Prior to implementation of a large-scale kelt steelhead transportation program it is important to consider potential effects on non-target fish. If kelts maintain residence in the estuary rather than migrating to the ocean, they may have a predatory effect on migrating salmonid smolts. It is also important to assess whether transportation impacts the homing ability of these fish. To address these concerns, all steelhead kelts were PIT-tagged with a portion also receiving hydro-acoustic tags. This technology will provide us with the necessary information regarding fish survival, movement, distribution, travel time, velocity, residence time in the estuary, and return rates.

\section{Short-Term Reconditioning Treatment}

Successful expression of iteroparity in steelhead may be limited by postspawning starvation and downstream passage through the mainstem corridor. Thus, short-term reconditioning may augment iteroparity rates by initiating the feeding response while still allowing kelts to naturally undergo gonadal recrudescence in the estuary and marine environments. Short-term reconditioning is defined as the period of time needed (approx. 3-12 weeks) for kelts to initiate post-spawn feeding, followed by the transportation of kelts around mainstem hydroelectric facilities for release, and rematuration in the Pacific

Ocean. Since short-term reconditioned fish were also transported and released 
below Bonneville Dam, PIT-tag and hydro-acoustic tags were used to assess fish survival, movement, distribution, travel time, velocity, as well as residence time in the estuary.

\section{Long-term Reconditioning Treatment}

Currently we define long-term reconditioning as holding and feeding post-spawn steelhead until the upstream migrating runs appear, typically in mid to late October for the Yakima River. The fish are released to over-winter and return to the spawning sites on their own volition. During 2008, we continued with the most efficient and successful of the long-term steelhead reconditioning regimes by repeating the most successful diet and treatment identified during the 2001 and 2002 studies (krill and Moore-Clark pellets) (Hatch et al. 2001 and Hatch et al. 2002). Steelhead kelt reconditioning at the other sites utilized a modified version of the Prosser reconditioning with minor modification to feed types.

Two additional long-term reconditioned groups from Omak Creek and Shitike Creek were held at Cassimer Bar Hatchery and Warm Springs National Fish Hatchery, respectively. These groups of fish were treated similarly to the Yakima River origin kelt steelhead and provided a geographic replicates to the experiment.

\section{Study Area}

\section{Kelt Reconditioning}

Kelt reconditioning research was conducted at the Prosser Fish Hatchery in Prosser, Washington. Prosser Hatchery is located on the Yakima River at river kilometer (rkm) 75.6, downstream from Prosser Dam, and adjacent to the Chandler Juvenile Evaluation Facility (CJEF) where steelhead kelts are collected for the in-river, no-term, short-term, and long-term treatments (Figure 1). The Yakima River is approximately $344 \mathrm{~km}$ in length and enters the Columbia River at rkm 539. Summer steelhead populations primarily spawn upstream from Prosser Dam in Satus Creek, Toppenish Creek, Naches River, and other tributaries of the Yakima River (TRP 1995). The Prosser Hatchery is operated by the Yakama Nation (YN), with a primary function of rearing, acclimation, and release of fall chinook salmon $O$. tshawytscha, and is also used for coho salmon O. kisutch rearing prior to acclimation and release in the upper Yakima River Basin. 


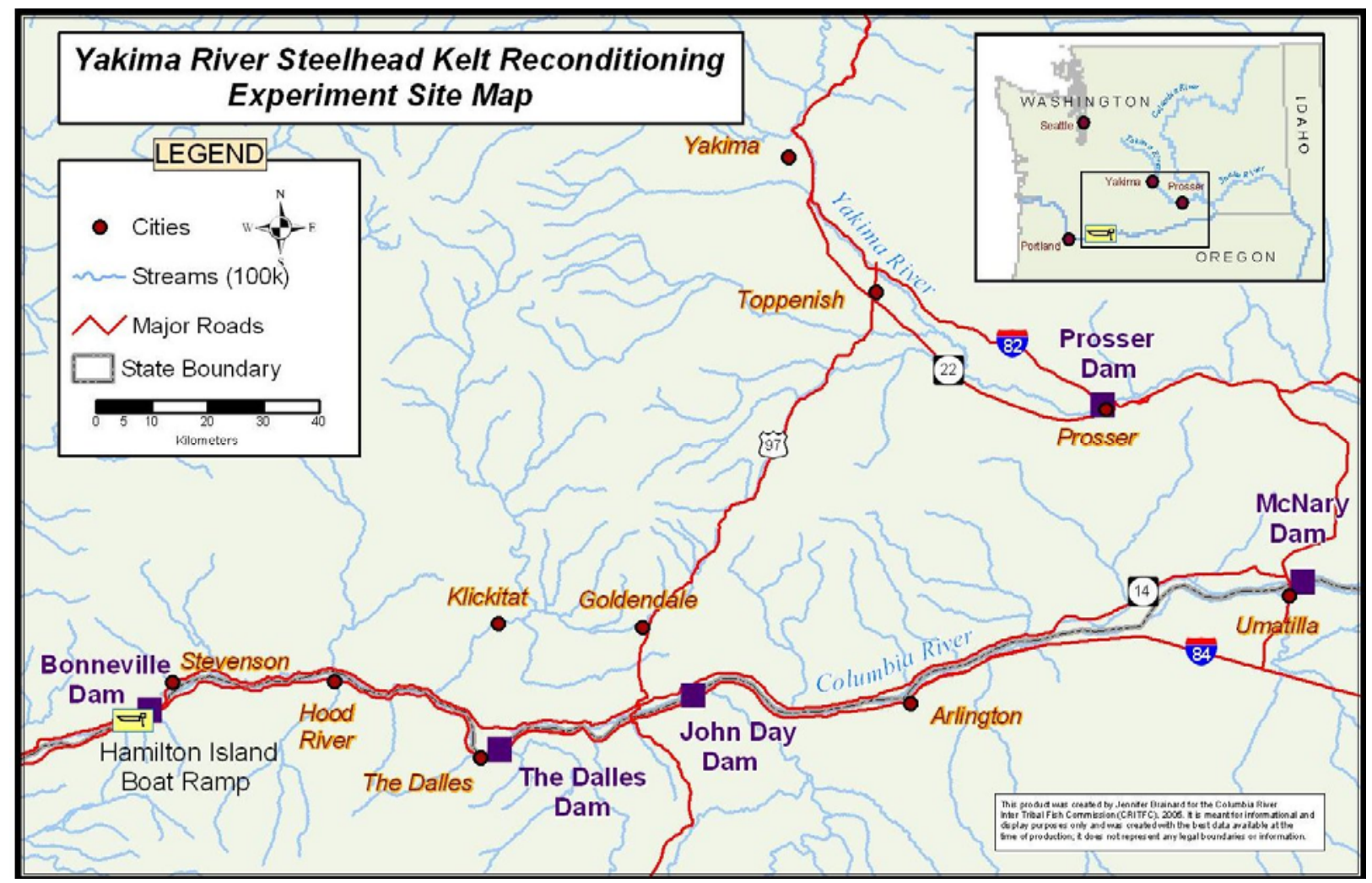

Figure 1. Reconditioning site (Prosser, WA) and release site (Hamilton Is. Boat Ramp) for No-term and Short-term reconditioning experiments.

Steelhead for the Short-term and No-term treatments were trucked and released at the Hamilton Island Boat Ramp (rkm 231) located downriver from Bonneville Dam on the Washington shore of the Columbia River. The lower Columbia River habitat from approximately rkm $75-0$ is typified as an estuarine environment, and is influenced by tidal oscillations from the Pacific Ocean. The migration of experimental groups was monitored in the lower Columbia River using acoustic telemetry technology (Figure 2) (rkm 138 to 0.) (Appendix B). Migration behavior, survival, and timing were evaluated for these treatments. 


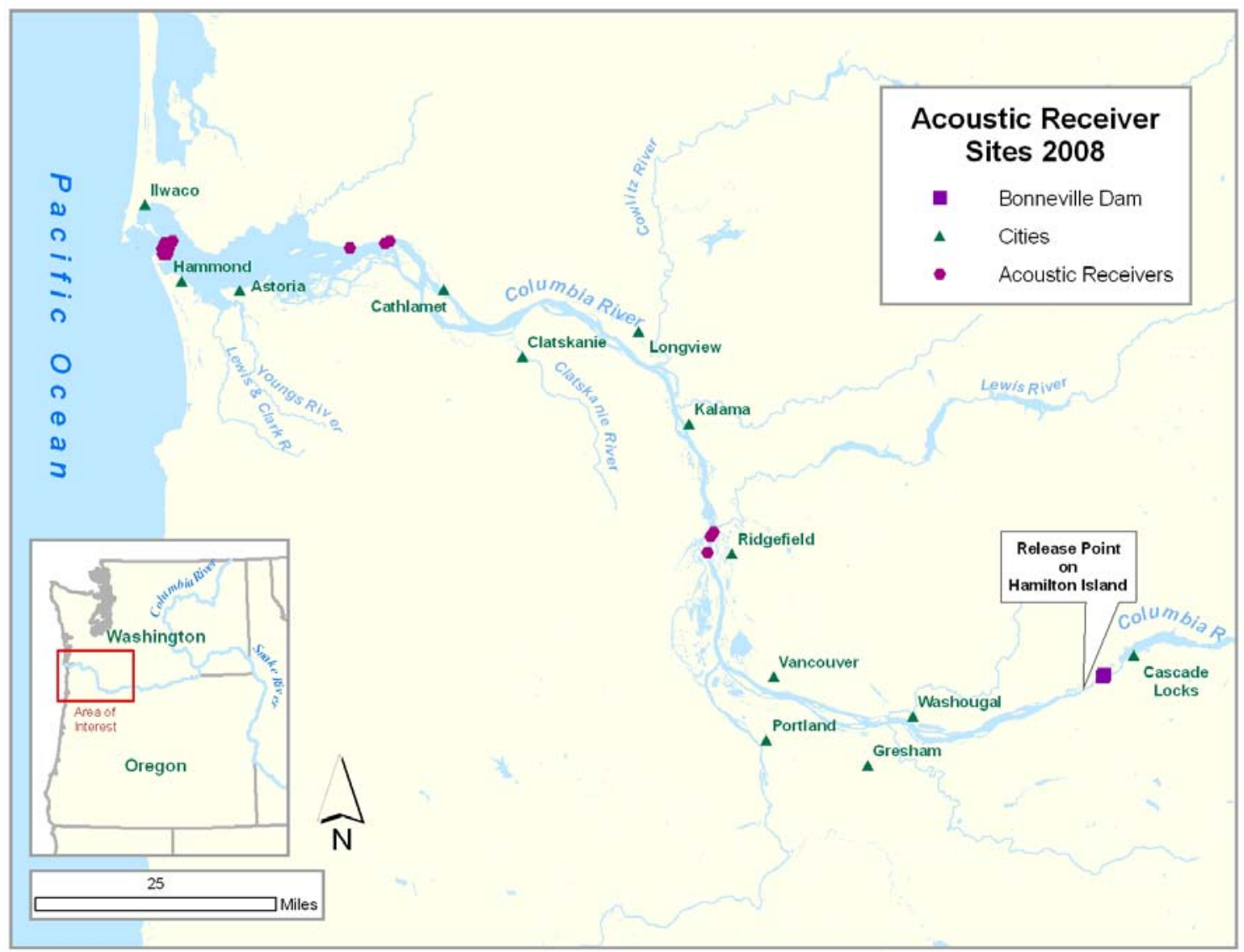

Figure 2. Lower Columbia River acoustic receiver deployment 2008.

The two additional groups of kelt steelhead collected for long-term reconditioning were from Omak Creek (tributary to the Okanagon River) and reared at Cassimer Bar Hatchery and Shitike Creek (tributary to the Deschutes River) and reared at Warm Springs National Fish Hatchery (WSNFH).

Omak Creek, a tributary to the Okanogan River, is located in Okanogan County in North Central Washington. It is approximately $35.4 \mathrm{~km}$ ending at its confluence with the Okanogan River (Figure 4). It runs entirely within the reservation of the Colville Confederated Tribes (CCT). Bonaparte Creek is a tributary to the Okanogan River, which closely parallels State Route 20 east of Tonasket. Omak Creek and Bonaparte kelt steelhead were reconditioned at the Cassimer Bar Hatchery located at the confluence of the Okanogan River and the Columbia River downriver of Chief Joseph Dam. Currently the CCT operate the Cassimer Bar Hatchery. The facility was originally constructed in 1994, as a sockeye salmon O. nerka production facility in an attempt to supplement Lake Osoyoos and is currently utilized for the development of locally-adapted stock to supplement natural production of steelhead in Omak Creek. 


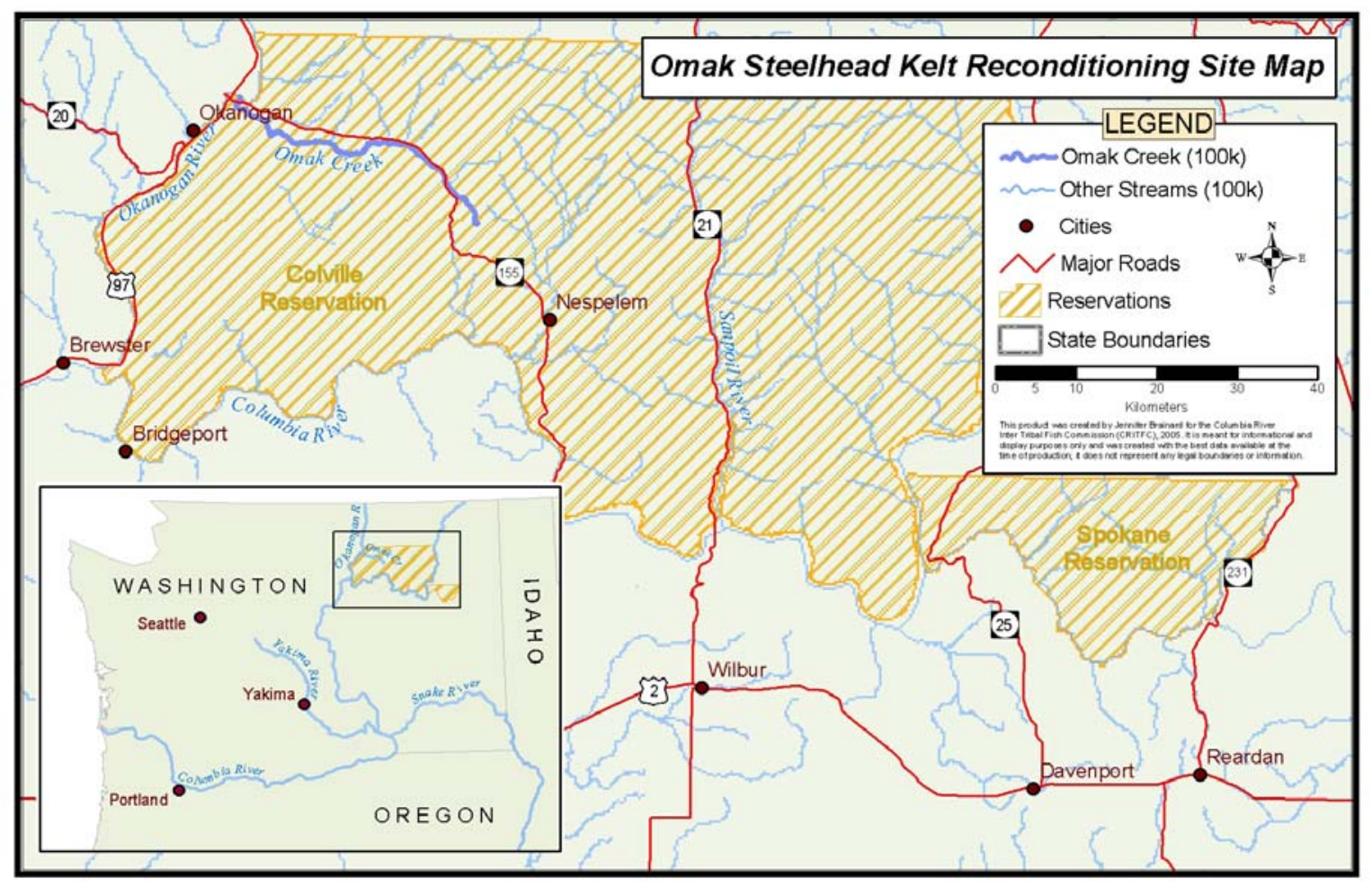

Figure 3. Map showing the locations of Omak Creek as well as the Confederated Tribes of the Colville Reservation.

Shitike Creek, located on the Warm Springs Reservation, flows into the Deschutes River at rkm 155, and is the reservation's second largest watershed. The Deschutes River is a tributary of the Columbia River located in north-central Oregon and is $406 \mathrm{rkm}$ long. Shitike Creek is a fourth order stream with a drainage area of 145.9 square kilometers (Figure 3). Shitike Creek kelt steelhead were reconditioned at Warm Springs National Hatchery, located at rkm 16 on the Warm Springs River, (downstream on the Deschutes River) of Shitike Creek. The hatchery is operated by the U.S. Fish and Wildlife Service on lands leased from the Confederated Tribes of Warm Springs (CTWS) to propagate and raise wild and hatchery spring Chinook salmon. 


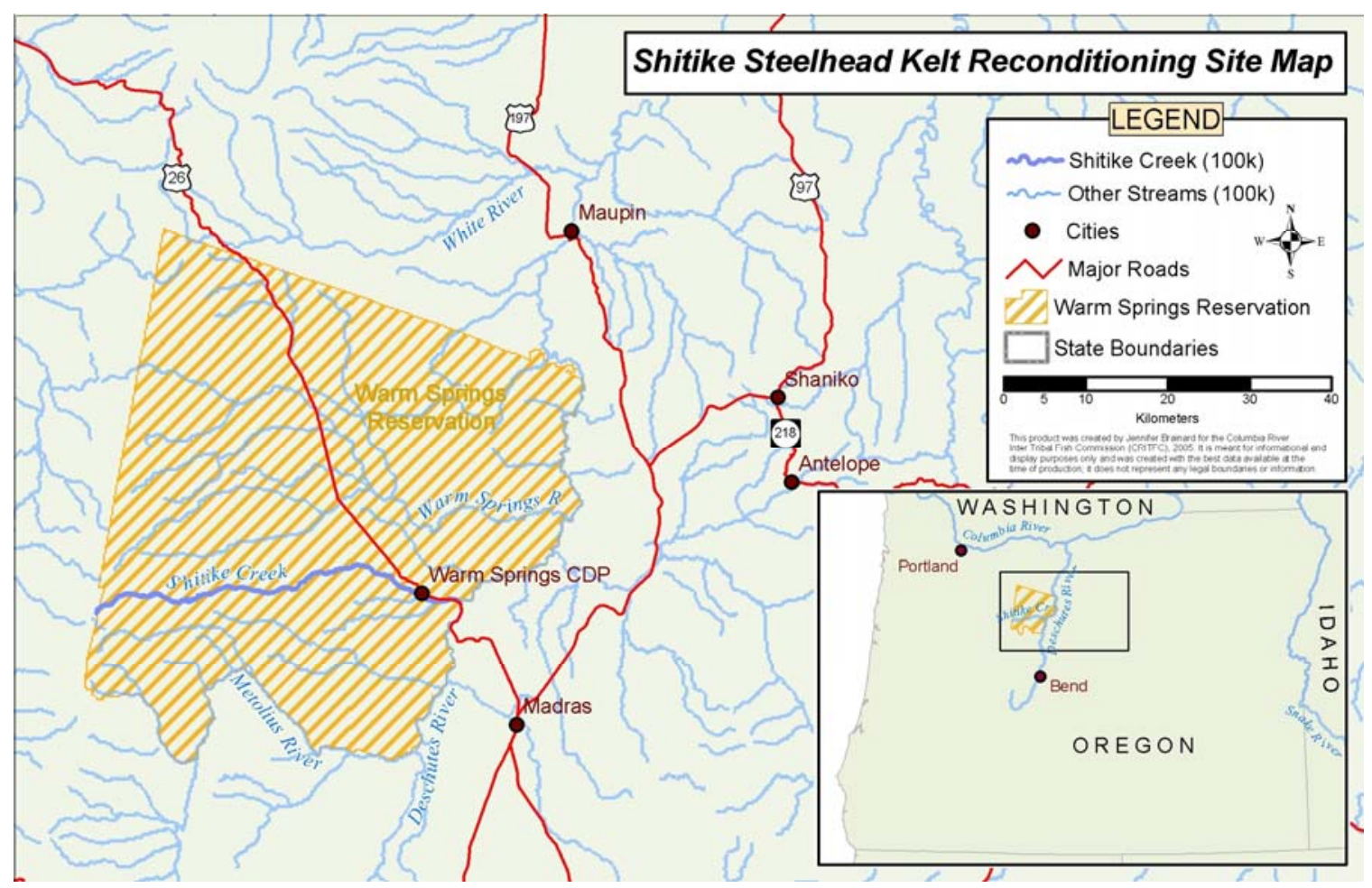

Figure 4. Map showing the location of Shitike Creek and the Confederated Tribes of the Warm Springs Reservation

\section{Methods}

\section{Kelt Collection and In-Processing}

\section{Yakima River}

After spawning naturally in tributaries of the Yakima River, a portion of the steelhead kelts that encounter Prosser Dam during emigration are unintentionally (meant to divert migrating juveniles) diverted into an irrigation channel that directly connects to the Chandler Juvenile Evaluation Facility (CJEF) (Figure 5. Fish screens divert migratory fishes away from the irrigation canal to reduce mortality associated with agriculture and into the CJEF. Once diverted into the CJEF, emigrating kelts can be manually collected from a fish separation device (a device which allows smaller juvenile salmonids to "fall through" for processing in the juvenile facility while larger fish can be dipnetted off the separator for processing or release back to the river). Yakama Nation (YN) staff monitored the Chandler bypass separator 24 hours a day from March 21 to June 23, 2008. 


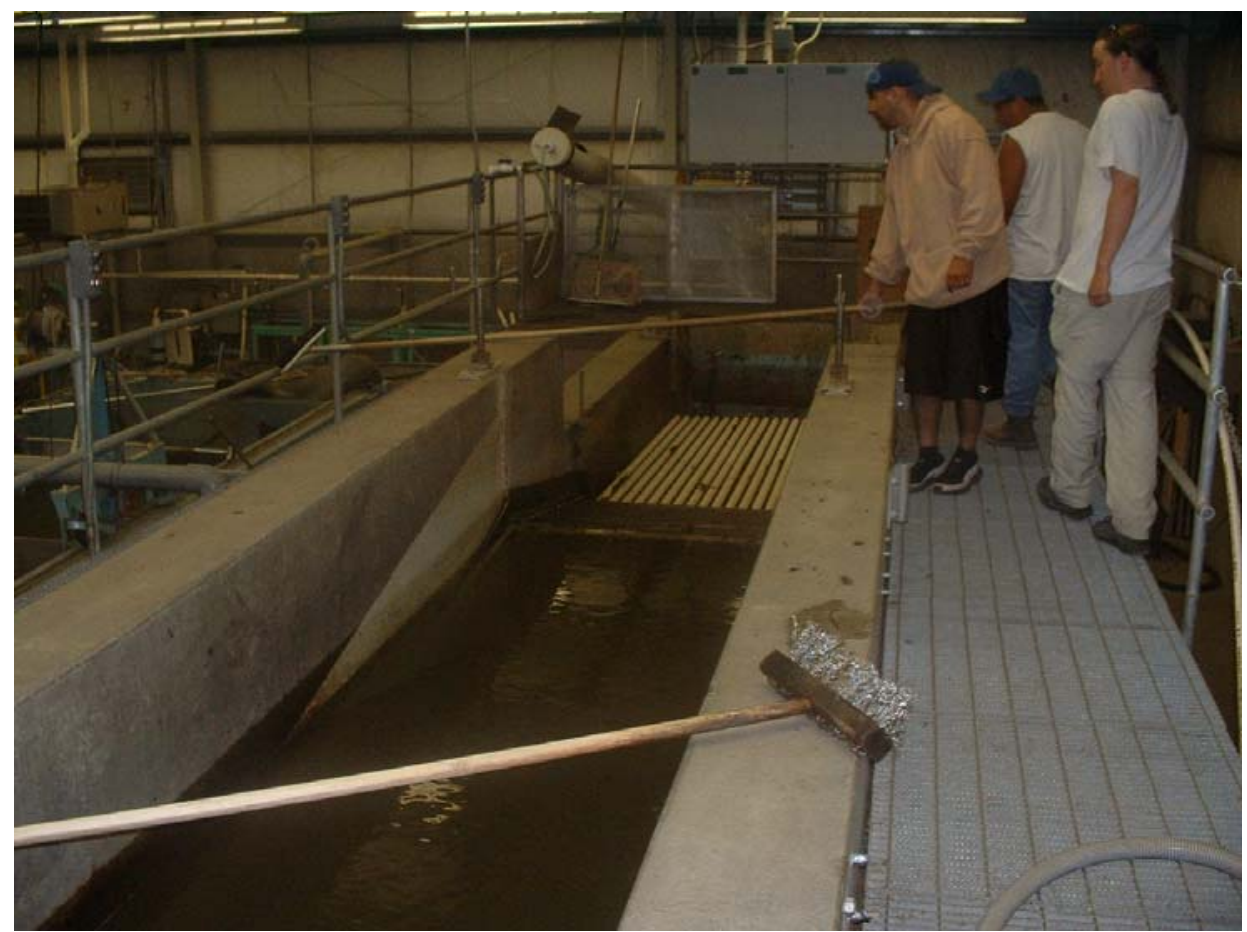

Figure 5. Chandler Juvenile Evaluation Facility adult separator.

All adult steelhead arriving at the CJEF separator were dipnetted off the separator (Figure 5 ) and placed into a water-lubricated PVC pipe slide that was directly connected to a temporary holding tank 20' (I) x 6' (w) x 4'(h) containing oxygenated well water $\left(57^{\circ} \mathrm{F}\right.$ or $\left.13.8^{\circ} \mathrm{C}\right)$. Post-spawned steelhead kelts were identified (Evans and Beaty 2001) then transferred with a dipnet from the temporary holding tank to a nearby $190-\mathrm{L}$ sampling tank containing fresh river water, and anesthetized in a buffered solution of tricaine methanesulfonate (MS222) at $60 \mathrm{ppm}$. All specimens visually determined to be prespawn individuals were immediately returned to the Yakima River.

Following kelt identification, we collected data on weight (collected in pounds but converted to kg for this report), condition (good- lack of any wounds or descaling, fair- lack of any major wounds and/or descaling, poor- major wounds and/or descaling), coloration (bright, medium, dark), and presence or absence of physical anomalies (e.g., head burn, eye damage). Passive Integrated Transponder (PIT) tags (if not already present) were then implanted in the fish's pelvic girdle for later individual identification The steelhead kelts deemed to be in "good" to "fair" condition were retained for reconditioning while steelhead kelts found to be in "poor" condition and dark in color were released back to the river. A portion of collected steelhead kelts that were found to be in good condition were released back to the river as a in-river treatment to establish baseline data on the natural repeat spawner rate in the Yakima River (In-river release group).

All kelts held for an extended period of time in reconditioning tanks, are susceptible to severe infestation of parasites which can be lethal to cultured 
fishes. Formalin is generally (varies to some degree at sites based on fungal growth) administered five times a week at 1:6,000 for 1 hour in all reconditioning tanks to prevent fungal outbreaks. Another concern with holding wild steelhead was susceptibility to Salmincola in such environments. Salmincola is a genus of parasitic copepod that can inhibit oxygen uptake and gas exchange at the gill lamellae/water surface interface by attachment to the lamellae. Recent research by Johnson and Heindel (2000), suggested that Ivermectin ${ }^{\mathrm{TM}}-\mathrm{a}$ treatment often used to control parasites in swine and cattle - increases the survivorship of cultured fish by killing the adult morph of the parasite. Due to its successful use in treating Salminicola in this project's kelt reconditioning experiments during 2000 (Evans and Beaty 2000), Ivermectin ${ }^{\mathrm{TM}}$ was diluted with saline (1:30) and injected into the posterior end of the fish's esophagus using a small (1cc) plastic syringe. All kelts except for the in-river release were administered a one-time subcutaneous injection of Oxytetracycline.

\section{In-River Release}

A portion of the kelts that would have been suitable for reconditioning, were PITtagged, and then released immediately back to the Yakima River (Prosser, WA rkm 75.6) to monitor the rate of natural iteroparity. These data will be compared to iteroparity rates from other treatments and inferred from scale pattern analysis from the Yakima River (Hockersmith et. al. 1995). In-river release specimens were selected systematically from fish that were collected at the CJEF from 3/21$6 / 23 / 2008$.

\section{Adult Collection}

\section{Omak and Bonaparte Creeks}

Adult Steelhead kelts were also collected from both Omak and Bonaparte Creek weirs which are both tributaries of the Okanogan River. This stock is being used by the Cassimer Bar Hatchery to develop a naturalized steelhead broodstock for the Okanogan and Omak Rivers (including Omak Creek). Trapping began in Bonaparte Creek (rkm 0) on March 27, 2008. The first kelt was collected on April $29^{\text {th }}$ with the peak of kelt collection occurring between May 1 st and May $10^{\text {th }}$. Trapping ceased on May $16^{\text {th }}$ and the weir was pulled from the creek. The semipermanent weir was installed in Omak Creek ( $\mathrm{rkm} .8$ ) on March 22, 2008 and operated until July 25, 2008 (Figure 6).

Kelts are collected for reconditioning in either of two ways at Cassimer Bar: 1) males and females collected for broodstock that survive spawning are put into the kelt tank for reconditioning. 2) kelts exiting Omak Creek or Bonaparte Creek are collected at the trap site of the respective creek and transported to the Cassimer Bar hatchery. All anadromous O. mykiss, regardless of migration direction, broodstock or reconditioned were sampled for length, condition factor, 
DNA and tags (PIT or other), and were PIT tagged if needed and marked with a fin clip.

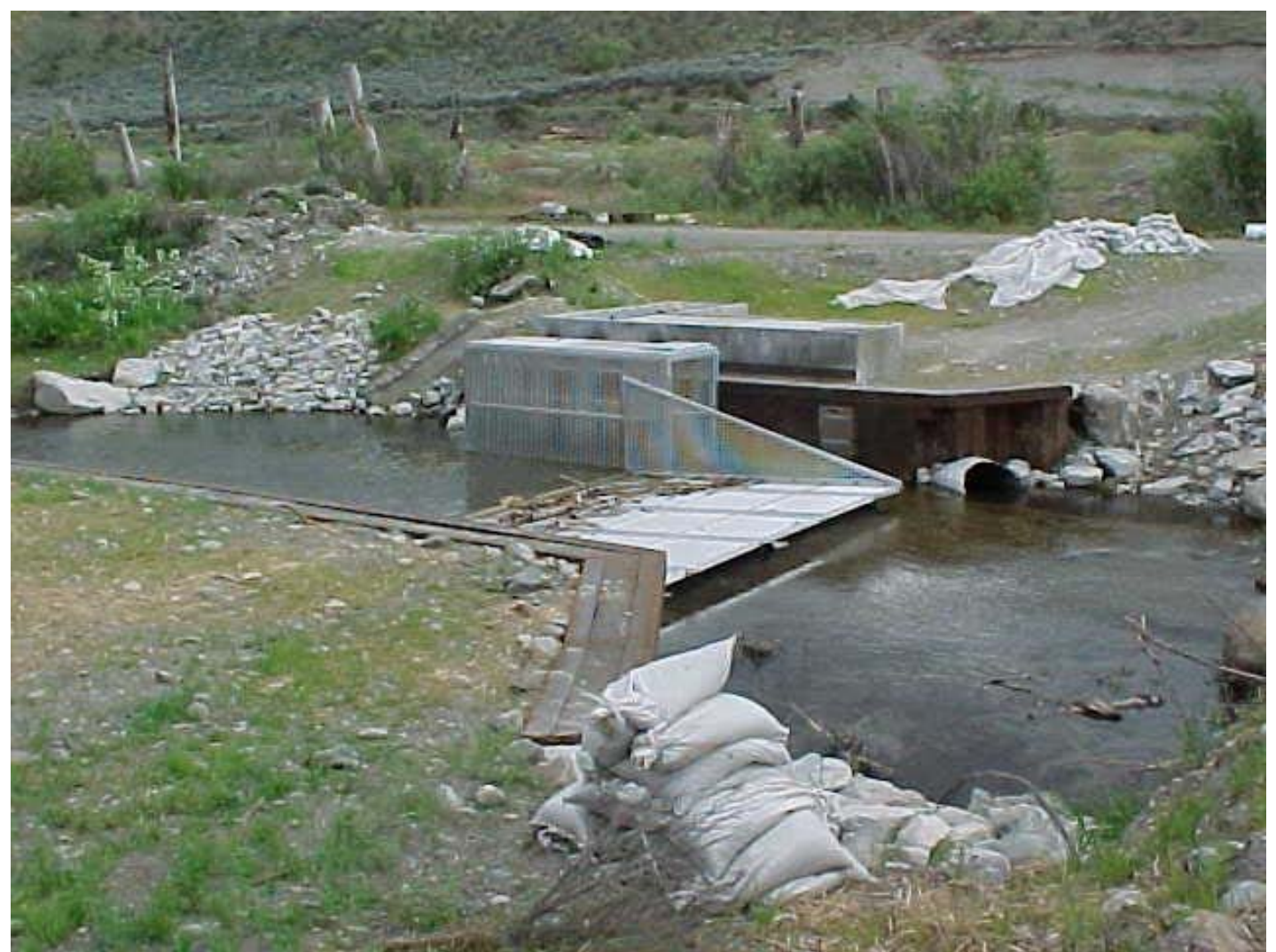

Figure 6. Photograph of the resistance board weir located on Omak Creek.

Shitike Creek

A picket weir was installed at rkm 0.7 on Shitike Creek (Figure 7). Security, accessibility, and channel morphology was used to determine weir location. The weir design incorporated two trap boxes; one for both upstream and downstream migration. The weir was oriented perpendicular to flow (Figure 7). The downstream trap (10'l $\times 4^{\prime} \mathrm{w} \times 3^{\prime} \mathrm{h}$ ) was situated away from the thalweg to minimize the amount of flow inside. It was also designed to reduce potential crowding. The weir was placed at an angle to funnel outmigrants into the downstream trap. Upstream box placement was in the deepest section of the river where fish were likely to migrate (Figure 8). To reduce potential impacts on fish due to high flows, a catch pen was constructed adjacent to the downstream box so that fish could access calmer water during high flow events. The catch pen allowed fish to access calm water, reducing their overall stress.

Weir operation began on March 11, 2008 and continued actively capturing fish until June 24, 2008. Post 24 June 2008 the trap was passively operating, using a video monitoring, to enumerate immigrant fish in Shitike Creek. The trap was checked twice daily every day of the week in the morning and afternoon. Fish 
$508 \mathrm{~mm}$ or greater in fork length (20 inch ODFW standard) were treated as anadromous adult steelhead based on the Oregon Department of Fish and Wildlife 20 in. standard. Information recorded for each fish captured at the weir included origin, sex, physical condition, coloration, fork length, and weight. Fish were also inspected for floy tags, PIT tags and other secondary marks. Physical condition was assessed by the amount of fungus present. Condition was as either good ( $<25 \%$ fungus), fair (25 - 50\% fungus), or poor (50-100\% fungus). All adipose clipped fish were released downstream.

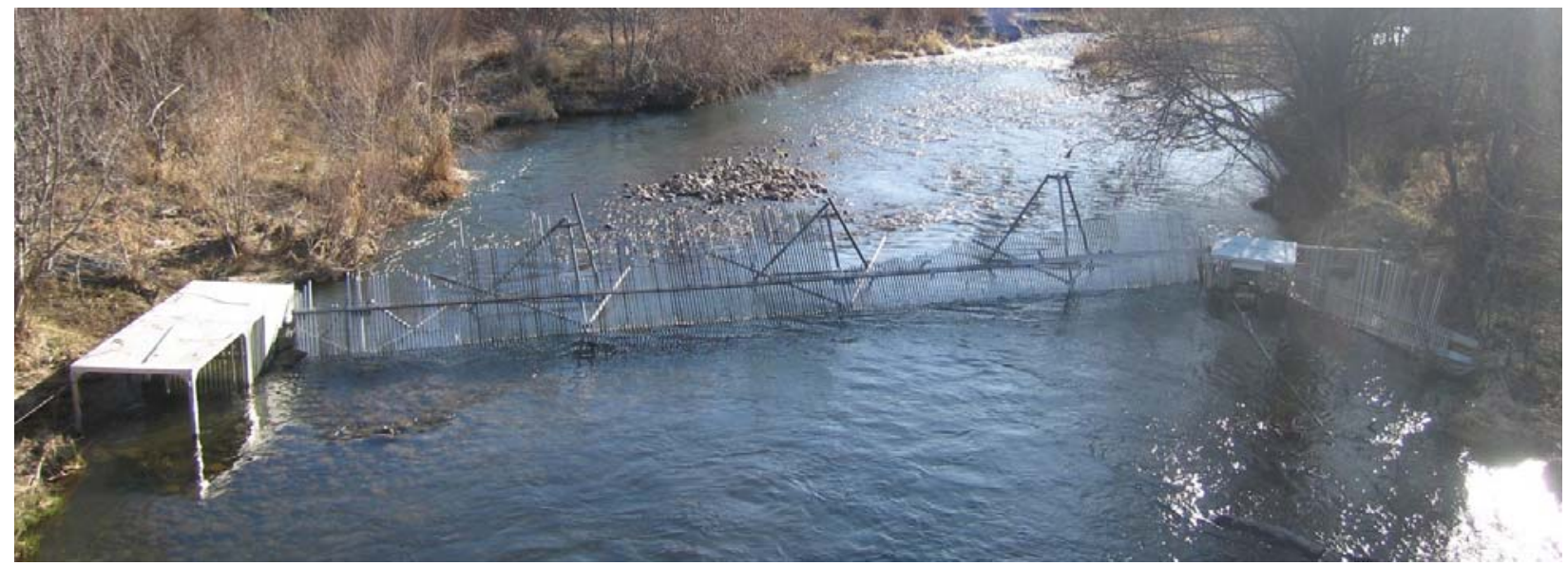

Figure 7. Shitike Creek weir March 2008.

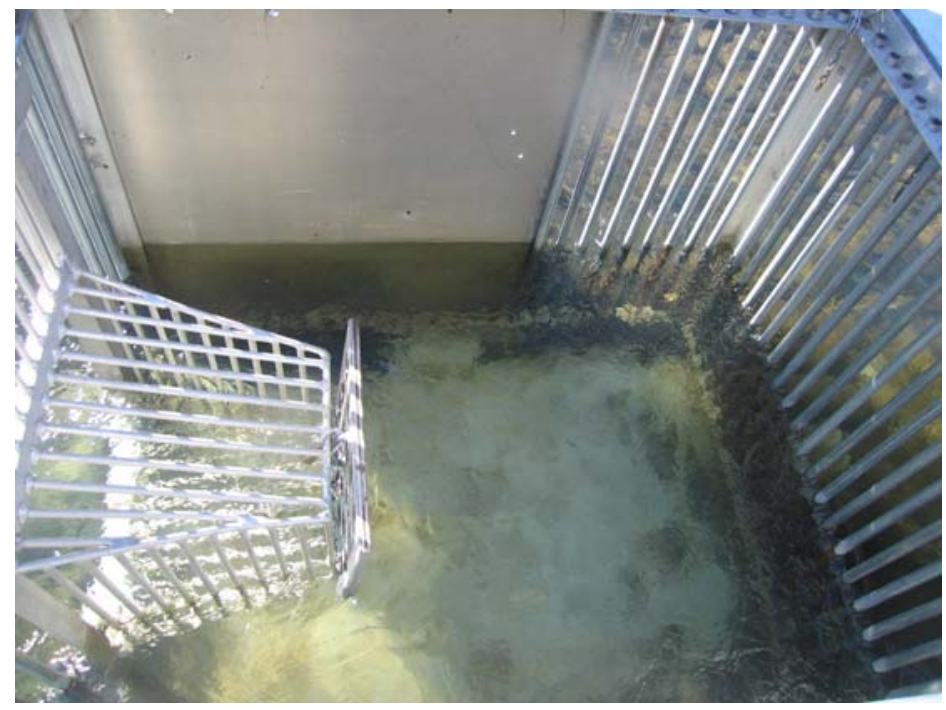

Figure 8. Shitike Creek weir upstream box. 


\section{Reconditioning}

Prosser

Steelhead kelts retained for the short-term and long-term reconditioning treatments at Prosser Hatchery were held in one of the four 20' (d) $\times 4^{\prime}(\mathrm{h})$ circular tanks (Figure 9). Loading densities were well below the 200 fish carrying capacities for these tanks. Tanks were fed oxygenated $13.8^{\circ} \mathrm{C}\left(57 .{ }^{\circ} \mathrm{F}\right)$ well water at 200 gallons/minute. Short-term reconditioned kelts were fed a diet of krill for the duration (3-5 weeks) of their captivity.

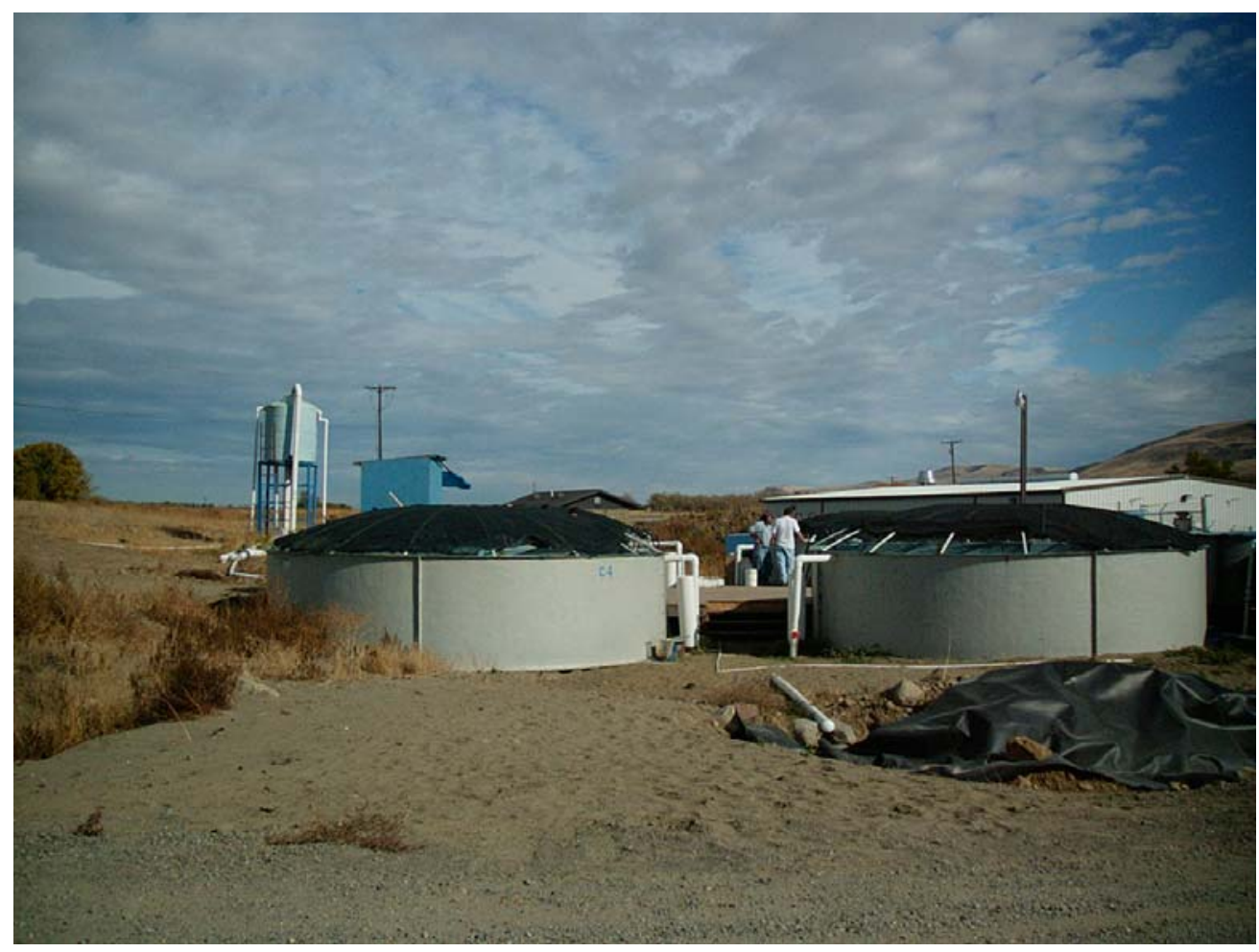

Figure 9. Steelhead kelt reconditioning tanks Prosser, WA.

The long-term reconditioned fish at Prosser Hatchery were initially fed frozen krill for 2.5 months then slowly switched over to Moore-Clarke Trout Broodstock pellets until release. Krill is utilized as a starter feed due to the readiness of kelts to consume this specific feed. Steelhead kelts are then slowly moved over to the Moore-Clark pellets to improve nutrition in the diet.

\section{Omak/Bonaparte}

One 22' circular tank was used to recondition Omak Creek steelhead kelts (Figure 10). Water was circulated at 120 gallons/minute at an average temperature of $13.3^{\circ} \mathrm{C}\left(56.0^{\circ} \mathrm{F}\right)$. Kelts are given an injection of bacterio-stat based on their weight. This will help minimize any bacterial related issues. Kelts 
are then separated by sex into circulars because CCT fisheries staff was concerned about territorial behavior when both sexes are kept in the same circular.

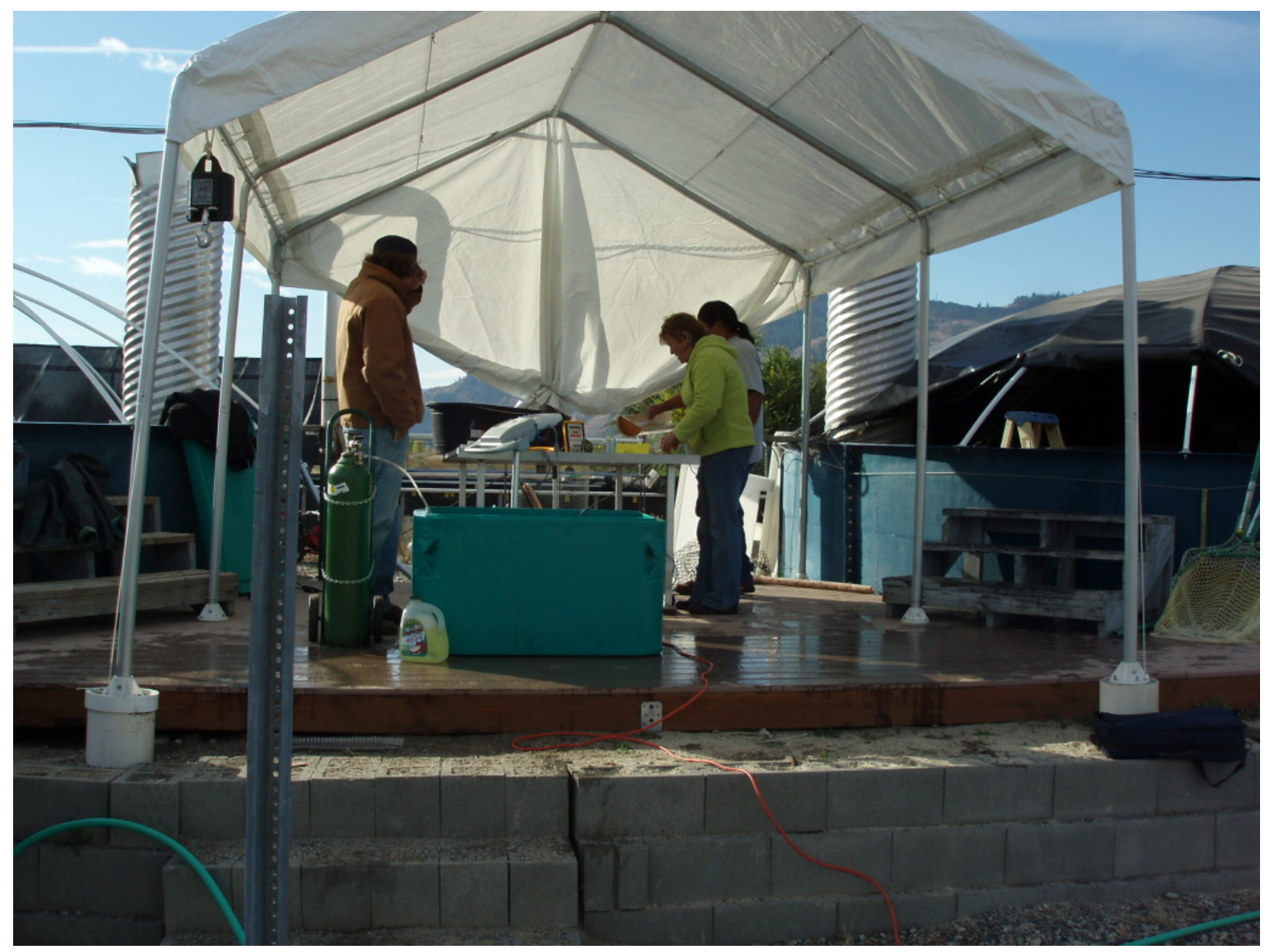

Figure 10. Steelhead kelt reconditioning facilities w/ sampling area at Cassimer Bar Hatchery.

\section{Shitike Creek}

Steelhead kelts captured from Shitike Creek are held in a circular kelt reconditioning tank, 16' (d) $\times 4^{\prime}(\mathrm{h})$, at Warm Springs National Fish Hatchery (WSNFH). The tank was installed exclusively for kelt reconditioning (Figure 11). The tank was fed with Warm Springs River water. Before induction into the tank water was filtered and treated with ultraviolet light to reduce pathogens. Water was circulated at 100 gallons/minute and fed on river water. Shitike Creek fish were administered a via formalin drip into the tank a slightly higher dosage of formalin 1:6000 three times a week for 45 minutes due to heavy infestations of fungus. 


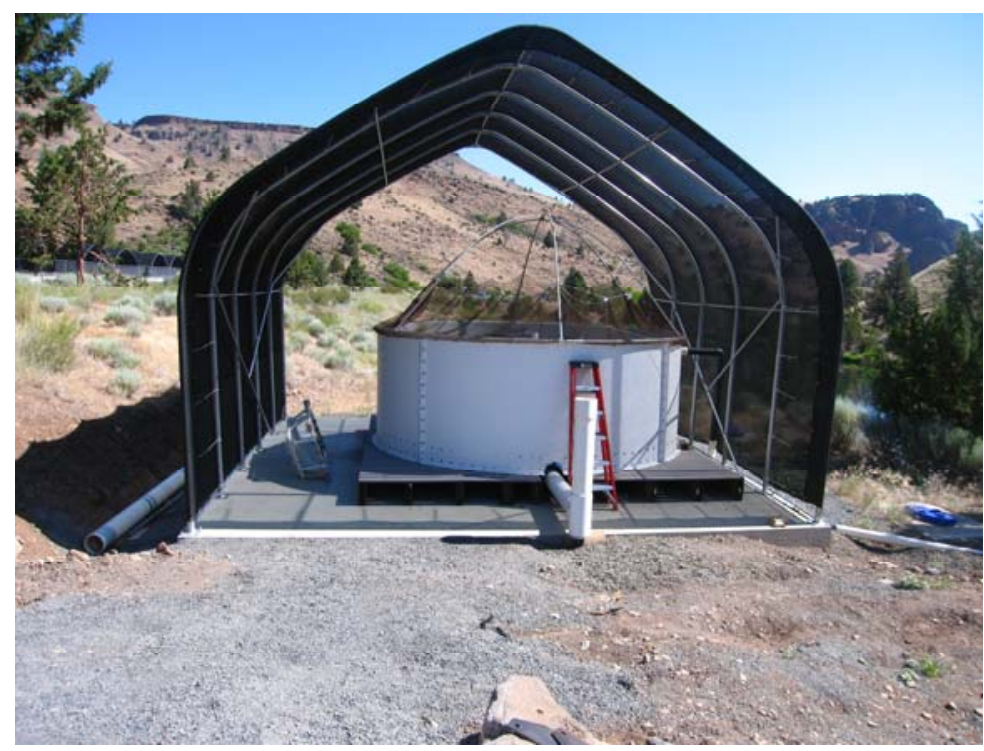

Figure 11. New placement of kelt reconditioning tank in 2008 at WSNFH.

\section{Feeding}

Modified versions of the feeding and holding protocols developed at Prosser Hatchery are utilized for long term reconditioning at Cassimer Bar Hatchery, Warm Springs National Fish Hatchery, and Parkdale Fish Facility (Hatch et al 2004). Generally fish are fed to satiation 2-3 times a day, and are monitored to prevent overfeeding which causes pollution in the holding tanks and is wasteful. Hatchery managers and project staff are allowed to modify protocols as needed to improve survival.

The staff at Cassimer Bar made the most modifications to the kelt diet. Food is introduced to the new kelts after an initial holding period of 24 hours. The holding period allows fish to become familiar with the circular tanks and the other fish in the tank. Initially, krill coated with cod liver oil are offered to the kelts. The cod liver oil has essential fatty acids needed by the kelts to help recover energy stores and skin issues (cuts, abrasions, fungus). Kelts are observed closely during feeding periods to assess feeding response. Typically, if a fish doesn't respond to feeding within the first week of being on station, the chance for mortality increases substantially. During the period of time between the first kelt arriving on station until the last kelt being processed, fish are fed natural foods. Given that ocean going steelhead diets are diverse with such prey as squid, euphausiids, amphipods and various fishes (LeBrasseur 1966) and (Manzer 1968) CCT fisheries staff attempted to provide similar diverse food such as krill coated with cod liver oil, and squid. In addition, the food is easier on the digestive system than pelletized food. After the last kelt arrives on station, kelts are fed natural food for an additional 2 weeks, to ensure that their digestive systems are functioning properly before introducing any hand made food. As hand made food is introduced, natural food is also offered. Eventually, fish are 
fed a rotating diet of natural and hand extruded food to ensure they are receiving the most complete array of nutrients available. Fish are fed multiple times throughout the day and are fed to satiation. Fish are also observed during feeding to check for any possible signs of pathogens or change in feeding response.

Shitike Creek fish did not accept pellet feed readily. Staff attempted to insert pellets into krill as well as mixing krill and pellets together creating a krill/pellet slurry, with little success. Fish continued to feed primarily on krill and were fed 3 times daily until satiation.

\section{Kelt Mortalities}

The following data were collected on all kelts that died during the reconditioning process at all facilities. On discovery of a mortality, fish were collected and examined externally by hatchery personnel to record the suspected time of death, general condition (good, fair, poor), fish color (bright, intermediate, dark), color of the gill arches (red, pink, white), size of the abdomen (fat, thin), presence of any scars or obvious lesions, and any other anomalies. Once the external exam was completed, an internal examination was conducted to record color of muscle tissue (red, pink, white), type of gonads (ovaries, testes), size of gametes (small, large), and presence of any internal anomalies. Internal acoustic and PIT tags were removed from mortalities and identification numbers recorded onto computer databases along with growth measurement data. We reused viable acoustic tags whenever possible.

\section{Steelhead Kelt Status and Release}

Prior to release, all steelhead kelts were scanned for PIT tags, weighed, and measured for fork-length. A majority of the no-term and short-term reconditioning releases were fitted with an acoustic receiver to compare releases strategies. All surviving specimens retained for reconditioning at the time of release were classified as either feeding or non-feeding based on weight change during captivity.

No-term and Short-term treatment groups were transported and released at the Hamilton Island Boat Ramp (rkm 231), below Bonneville Dam. Sequential returning fish were detected returning in the late summer of 2008, and we expect that fish may still return in 2009 and also possibly 2010 (skip spawning fish).

Fish in the long-term experiments were released in late October 2008 when river water temperatures match well water temperatures at the hatchery facilities and the spawning run is peaking in the river. They were released immediately downstream of Prosser Dam (Yakima River, $75.6 \mathrm{rkm}$ ) and into the Okanagon River ( $r k m$ 1). These long term reconditioned kelts over-winter within the 
systems they are released, and are able to volitionally return to the spawning grounds in late winter and spring.

Prior to release, all surviving steelhead in the long-term experiments were examined with ultrasound equipment (Evans et al. 2001) to assess maturation status. Growth measurement data and rematuration status were recorded on all released individuals. Overall success of the reconditioning process was based on the proportion of fish that survived the reconditioning process, the number of fish that successfully rematured (based on ultrasound examinations), and the number of fish that were detected actively migrating above Prosser Dam.

\section{Comparison of Treatments Using Biotelemetry}

\section{Acoustic Telemetry}

There were 49 kelts from the No-term and 50 kelts from the Short-term reconditioning experiments at Prosser Hatchery that had a coded Vemco@ V16$4 \mathrm{H}$ acoustic transmitter surgically implanted intraperitoneally (body cavity) using standard surgical procedures. The weight impact of the tag on adult fish was nominal with its length at $65 \mathrm{~mm}$ and weight in water at $10 \mathrm{~g}$, which constitutes on average $0.25 \%$ of the fishes total body weight. In an internal implantation, an incision just smaller than the transmitter is made into the body cavity, usually on the midline of the ventral surface halfway between the pectoral and pelvic fins (Langford et al. 1977). The incision is spread open utilizing a sterilized gloved finger as a dilator. The use of dilation splits the muscle which causes less damage and speeds healing than would cutting the muscle. The transmitter was properly disinfected before placement into the body cavity. Once the transmitter is securely inside the fish the original incision is closed. Closure of the incision is accomplished with several interrupted sutures. Sterile, non-reabsorbing suture was used due to concerns of seawater prematurely causing the suture to split. General anesthetics (MS-222) were used during surgery, and fish were returned to freshwater immediately following surgeries to recover. A biologist trained by a licensed veterinarian performed surgeries to minimize adverse effects associated with handling and surgery and to ensure a high tag retention rate.

After release, migration to the Pacific Ocean was tracked using acoustic telemetry arrays that spanned sections of the Columbia River and estuary below Bonneville Dam (Appendix B). Each acoustic tag has a unique bandwidth pulse that provides individual identification codes. The complete array was deployed in mid- April and was retrieved late December 2008. This year's array placement remained identical to previous year's (Branstetter et al 2008) (Appendix B) though there were slight modifications within each array regarding exact placement of a few individual receivers. This arrangement provided us data on survival and timing in-river, to the estuary, and to the ocean while attempting to reduce loss of receivers. Using acoustic telemetry data we compared No-term and Short-term reconditioning experiments to assess fish survival, movement, 
distribution, travel time, velocity, as well as residence time in the estuary (Appendix B).

\section{PIT Tags}

All fish in this study received a PIT tag in the pelvic girdle at the time of capture. Each tag is unique and identifies an individual fish to assess performance throughout the reconditioning process and to determine the fate of kelts after release by measuring movement, timing, and survival. Automatic adult PIT-tag detectors are present in all ladders at Bonneville Dam, McNary Dam, Prosser Dam, and weirs on smaller systems.

\section{Results}

\section{General Population Characteristics}

Yakima River

A total of 855 live kelts were captured between March 25 and June 23, 2008. Of these captures, 67 were culled due to poor condition, 88 were used in the Yakima River in-river release and 100 were used for the no-term release, leaving 108 for short-term and 472 for long-term reconditioning. Collection was continuous throughout the outward migration, with peak collection occurring on April 20 (Figure 12). The total number of kelts captured represented $25.8 \%$ (885 of 3,310 ) of the previous Yakima River spawning migration based on fish ladder counts obtained from Prosser Dam for the period July 1, 2007 through June 30, 2008.

The overwhelming majority of kelts captured were female which is consistent with previous findings. Based on visual observations, $756(88 \%)$ of the kelts were classified as female, whereas $97(11 \%)$ were identified as male in 2008 with $1 \%$ that could not be sexed. 


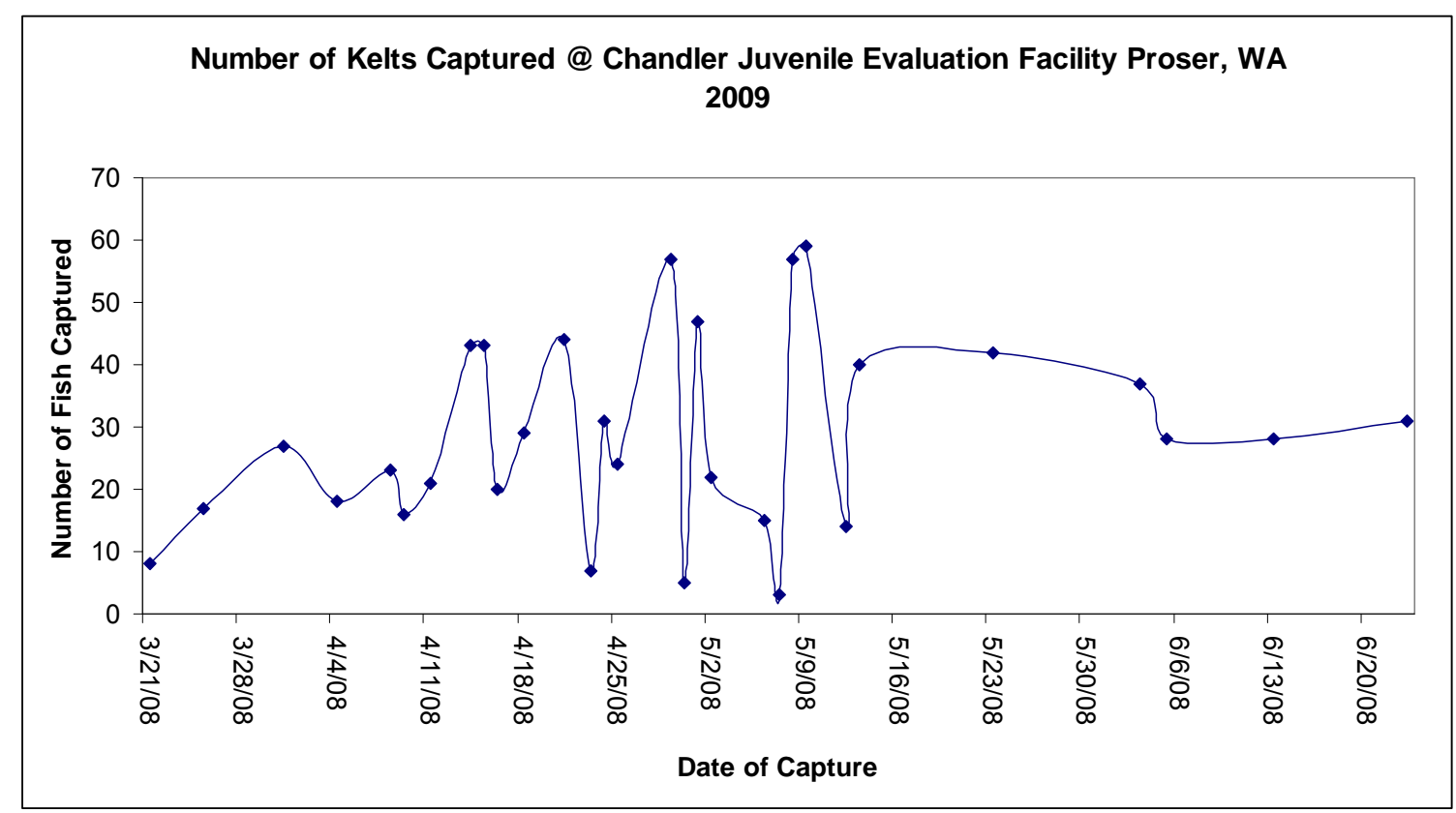

Figure 12. Steelhead kelt collection dates and numbers of fish removed from the CJEF in 2008.

Most Yakima River kelts collected during 2008 were classified as being in good $(41.6 \%)$ or fair $(50.5 \%)$ condition, with the remaining fish classified as poor $(7.9 \%)$. Coloration was predominately intermediate $(55.3 \%)$ or bright $(39.5 \%)$ with a small percentage that were dark $(5.2 \%)$ fish.

\section{Bonaparte and Omak Creek}

The first fish was enumerated on April 2, 2008 at Bonaparte Creek and the last fish released upstream was seen June 9, 2008. The first kelt was collected on April 16th with peak collection occurring between May 3rd and May $20^{\text {th }}$. Total there were 32 fish enumerated at Bonaparte Creek in 2008, compared to 168 fish enumerated in 2007. Of these fish, 3 had PIT tags and 29 scanned negative for a PIT tag. The ratio of males to females in Bonaparte Creek was approximately 2 males for every female. Unclipped fish accounted for $43.7 \%$ of the return to Bonaparte Creek (6 unclipped, untagged males, 1 unclipped, tagged male from the Wenatchee River and 7 unclipped, untagged females.

The first fish was enumerated at Omak Creek was on April 2, 2008 and the last fish put upstream was seen June 9, 2008. The first kelt was collected on April 16 th with peak collection occurring between May 3rd and May $20^{\text {th }}$.A total of 64 fish were processed at the adult trap in Omak Creek during 2008 compared to 94 fish in 2007. Samples of DNA were taken on 59 fish. Of the 64 fish sampled 11 had PIT tags, 53 did not. The ratio of males to females in Omak Creek was 2.54 males per female. There were 4 unclipped, untagged females and 12 unclipped untagged males, comprising $16.4 \%$ of the return to the creek. The numbers 
represented for the return do not include fish that spawned below the weir or in the lower portion of the creek.

\section{Shitike Creek}

A total of 41 upstream migrating summer steelhead (wild 35 and 6 adipose clipped) were trapped at the Shitike weir in 2008 (Table 1). All wild fish were passed above the weir. One adipose clipped steelhead was passed upstream of the weir.

Table 1. Summary of upstream migrating hatchery and wild summer steelhead captured at picket weir, Shitike Creek March- June 2008.

\begin{tabular}{ccc}
\hline Clip* & Male & \\
\hline NM & 19 & Sexale \\
AD & 3 & 15 \\
ADRM & 1 & 1 \\
D.DOR & 1 & 0 \\
UNK & 1 & 0 \\
Total & 25 & 0 \\
\hline
\end{tabular}

*note: clip marks are adipose (Ad), adipose left ventral (ADLV), adipose left maxillary (ADLM), adipose right maxillary (ADRM), wild (NM), deformed dorsal (D.DOR), and unknown (UNK).

The condition of upstream wild steelhead migrants was $55 \%$ good, $30 \%$ fair, and $15 \%$ in poor condition. The condition of upstream hatchery steelhead was $34 \%$ good, $38 \%$ fair, and $28 \%$ poor (Table 2 ).

Table 2. Condition of hatchery (AD) and wild (NM) steelhead caught in the upstream trap at the Shitike Creek weir (\%).

\begin{tabular}{lll}
\hline Condition & AD & NM \\
\hline Good & $34 \%$ & $55 \%$ \\
Fair & $38 \%$ & $30 \%$ \\
Poor & $28 \%$ & $15 \%$ \\
\hline
\end{tabular}

Twenty -three summer steelhead were processed in the downstream trap (20 wild and 3 adipose clipped). Eleven kelts in fair condition were transported to WSNFH for reconditioning, 4 were immediately returned to the river in poor condition, and 8 were mortalities at the trap.

\section{In-River, No-term, and Short term capture, treatment, and release}

A total of 88 kelts from the Yakima River were collected, processed, PIT tagged and released as part of the in-river treatment between March 21, 2008 and June 23, 2008 (Table 3). 
There were two No-term release groups. Both groups were collected, processed, PIT tagged and acoustic tagged. The first group was collected on April 24, 2008 and released one day later. The second group was collected and released on May 8, 2008 (Table 3).

Short-term reconditioned kelts were captured from March 25, 2008 through April 16,2008 , held for reconditioning, and then processed, PIT tagged, acoustic tagged, and released on May 25, 2008 (Table 3). Fish in the short-term release group lost an average of $.2 \%$ body weight in captivity.

Table 3. Release group results by treatment

\begin{tabular}{|l|c|c|c|c|}
\hline Treatment & In River & No-term 1 & No-Term 2 & Short-term \\
\hline Release Date & $\begin{array}{c}3 / 21 / 08- \\
6 / 23 / 2008\end{array}$ & $4 / 25 / 2008$ & $5 / 12 / 08$ & $4 / 25 / 2008$ \\
\hline No. Collected & 88 & 50 & 50 & 108 \\
\hline No. Released & 88 & 49 & 49 & 103 \\
\hline No. with acoustic tags & 0 & 24 & 25 & 50 \\
\hline Mean Capture Weight $\mathbf{( k g )}$ & 3.83 & 4.07 & 4.07 & 4.30 \\
\hline Mean Release Weight $\mathbf{( k g )}$ & 3.83 & 4.07 & 4.07 & 4.28 \\
\hline
\end{tabular}

Mortality

We assumed that we had high immediate survival for the In-River Release group as handling was minimal and fish were quickly released into the river. All known mortalities for the No-term experiment occurred shortly after capture, fish processing, and subsequent tagging surgery. We had 1 mortality at the time of the first release and additional mortality at the second release. We were unable to determine the source of mortality as all sampling and tagging procedures occurred within 48 hours after capture.

\section{Long-Term Reconditioning and Survival to Release}

\section{Yakima River}

Kelt steelhead were collected from March 25, 2008 to June 23, 2008. After induction into the Prosser Hatchery reconditioning facility, $35 \%$ of the mortalities occurred within the first week. The rest of the mortalities occurred steadily over time until fish were released. A total of $266(56.4 \%)$ of the fish collected for longterm reconditioning survived to release on October 23, 2008 into the Yakima River below the Prosser Dam (75.6 rkm) (Table 4). Based on ultrasound scans $99 \%$ of this year's release showed early to mid stages of maturity. 
Table 4. Long-term reconditioning results by tank 2008.

\begin{tabular}{|l|c|c|c|}
\hline Tank: & C1 & C3 & $\begin{array}{c}\text { Long-term } \\
\text { Total }\end{array}$ \\
\hline Held for Reconditioning & 231 & 242 & 473 \\
\hline Released & 132 & 134 & 266 \\
\hline Survival Rate & & & \\
\hline Detected Rematuration & $57.1 \%$ & $55.3 \%$ & $56.4 \%$ \\
\hline Pct with wt gain & $98.4 \%$ & $99.2 \%$ & $99 \%$ \\
\hline Avg. wt gain (kg) & & & $79.0 \%$ \\
\hline & & & .73 \\
\hline
\end{tabular}

To date, 82 (31\% of total release) fish from the long-term release were detected moving upriver by PIT tag observations at Prosser Dam. Most migratory movements occurred in October and November with only one fish detected in January of 2009.

\section{Omak}

Fish that did not feed within the first 48-72 hours deteriorated and died rapidly. External treatments for fungus (formalin) did not improve survival for fish that did not eat. Proper nutrition and initiating the feeding response are critical for improving survival of kelts. Out of the 32 fish transported to Cassimer, one fish died during transport, two fish died from jumping out of the tank, one fish had a systemic infection. The rest of the mortalities were determined to be caused by lack of feeding/secondary infections. One fish had a spinal deformity, three had old seal scrapes. Many of the fish had minor abrasions that developed into fungal infections. The fish that began feeding early recovered quicker and began gaining weight. Nine reconditioned steelhead were on station at Cassimer (5 females, 4 males) until early October. All fed well, had good skin tone, minor copepod development and gained a healthy amount of weight. The fish were being treated with formalin every other day to control fungus. Treatments continued until release, which occurred October 13, 2008.

\section{Shitike}

Eleven wild steelhead kelts were transported to WSNFH. Fifty-five percent of fish selected to recondition were female. Fish were in good (45\%), fair (18\%), and poor condition (36\%). Survival to reconditioning was zero in 2008 . Of the eleven kelts, fish that were in good condition survived longer than fish in fair or poor condition. Ninety percent of the steelhead kelts died within two weeks of being brought into the reconditioning facilities 


\section{Management Scenario Evaluation}

Acoustic Telemetry

Acoustic arrays were placed strategically throughout the lower Columbia River (Appendix B) to monitor and measure outmigration and return survival of the two release strategies (no-term release and short-term reconditioning). We had a "river array" located about half way to the ocean, an "estuary array" located in the upstream end of the estuary, and an "ocean array" located near the mouth of the river. We can use this data to determine if short-term reconditioning is beneficial to steelhead kelts or if simply bypassing the hydrosystem is more beneficial to kelt survival. Kelts in these release groups are released at the Hamilton Island Boat Ramp "Release" (rkm 233) (Appendix B).

No-term Release Survival Probability

Survival and detection probability for kelts in the No-term treatment is calculated by reach (Table 5) (Appendix $\mathrm{C}$ ). In the final reach (ocean array), we cannot separate survival from detection probability by derivation, therefore, for this reach we report a quantity termed lambda which is the product of survival and detection probability for this reach. If the detection probability is assumed to equal 1.0 for the detection array located at the mouth of the river, then reach survival would equal lambda. Therefore, the lambda value can be considered a minimum survival estimate. Survival this year was excellent for both no-term release groups. Survival from release to the estuary was up until the final reach which based on the lambda value is similar with other year's survival (Table 5)

Table 5. Survival rate and detection probability of No-term release 1 on 4/25/2008 and Noterm 2 on May 25, 2008. The lambda term is the product of survival and detection probability, this term cannot be decomposed in the reach 3 estimate.

\begin{tabular}{|c|c|c|c|c|c|}
\hline No-term Release 1 & \multicolumn{5}{|l|}{} \\
\hline Reach & Survival (S) & std. deviation & Detection (P) & std. deviation & Lambda \\
\hline $\begin{array}{c}\text { Reach 1 (Release to } \\
\text { River Array) }\end{array}$ & 0.8750 & 0.0675 & 1.0000 & 0.0001 & 0.8750 \\
\hline $\begin{array}{c}\text { Reach 2 (River Array to } \\
\text { Estuary Array) }\end{array}$ & 0.9004 & 0.0884 & 0.8462 & 0.1001 & 0.7619 \\
\hline $\begin{array}{c}\text { Reach 3 (Estuary Array to } \\
\text { Ocean Array) }\end{array}$ & - & - & - & - & 0.6875 \\
\hline No-term Release 2 & & & & & \\
\hline $\begin{array}{c}\text { Reach 1 (Release to } \\
\text { River Array) }\end{array}$ & 0.9270 & 0.0550 & 0.8630 & 0.0733 & 0.8000 \\
\hline $\begin{array}{c}\text { Reach 2 (River Array to } \\
\text { Estuary Array) }\end{array}$ & 1.0000 & 0.0005 & 0.8199 & 0.0814 & 0.8199 \\
\hline $\begin{array}{c}\text { Reach 3 (Estuary Array to } \\
\text { Ocean Array) }\end{array}$ & - & - & - & - & 0.6939 \\
\hline
\end{tabular}

No-term Treatment Release Detections and Run Timing

There were a total of 24 kelt steelhead in the first release and 25 kelts in the second release instrumented with acoustic tags. A total of $21(88 \%)$ from the first 
release and $20(80 \%)$ fish from the second release were detected at the river array. Of these, $14(58 \%)$ from the first release and $18(72 \%)$ fish from the second release were detected (Table $6 \& 7$ ) entering the upper estuary. Travel time from release to the ocean averaged 10.66 days for the first release and 6.25 days for the second release group. (Tables $6 \& 7$ ). Estuary residence averaged 44 hours for the first release and 49 hours for the second. We detected 13 kelts (54\% of total tagged) from the first release and 13 kelts (52\%) from the second release at arrays at the mouth of the Columbia River. We assumed that kelts that were not detected again were mortalities.

Table 6. Number detected, travel time and average travel speed to detection array from time of release of No-term release group 1, $\mathrm{N}=24$. Released 4/25/2008.

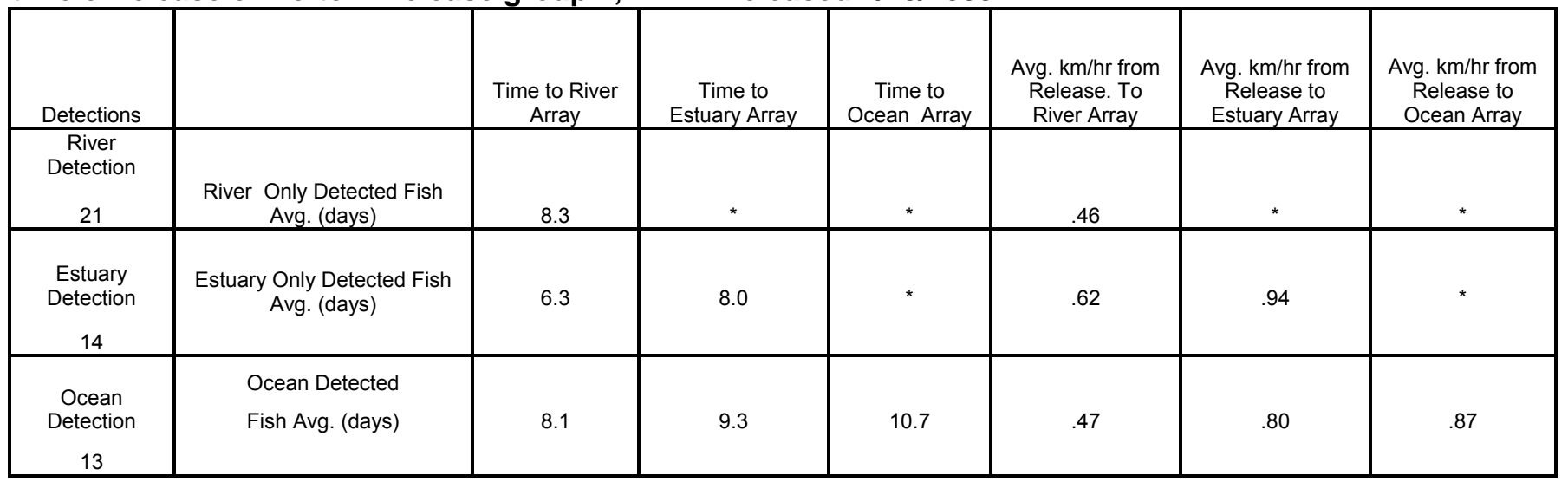

Table 7. Number detected, travel time and average travel speed to detection array from time of release of No-term kelt release group 2, N=25. Released May 12, 2008.

\begin{tabular}{|c|c|c|c|c|c|c|c|}
\hline Detections & & $\begin{array}{c}\text { Time to River } \\
\text { Array }\end{array}$ & $\begin{array}{c}\text { Time to } \\
\text { Estuary Array }\end{array}$ & $\begin{array}{c}\text { Time to } \\
\text { Ocean Array } \\
\end{array}$ & $\begin{array}{l}\text { Avg. } \mathrm{km} / \mathrm{hr} \text { from } \\
\text { Release to } \\
\text { River Array } \\
\end{array}$ & $\begin{array}{l}\text { Avg. } \mathrm{km} / \mathrm{hr} \text { from } \\
\text { Release to } \\
\text { Estuary Array }\end{array}$ & $\begin{array}{l}\text { Avg. } \mathrm{km} / \mathrm{hr} \text { from } \\
\text { Release to } \\
\text { Ocean Array } \\
\end{array}$ \\
\hline $\begin{array}{c}\begin{array}{c}\text { River } \\
\text { Detection }\end{array} \\
20 \\
\end{array}$ & $\begin{array}{c}\text { River Only Detected Fish } \\
\text { Avg. (days) }\end{array}$ & 1.5 & * & * & 2.65 & * & * \\
\hline $\begin{array}{c}\text { Estuary } \\
\text { Detection } \\
18 \\
\end{array}$ & $\begin{array}{l}\text { Estuary Only Detected Fish } \\
\text { Avg. (days) }\end{array}$ & 2.5 & 3.5 & * & 1.55 & 2.11 & * \\
\hline $\begin{array}{c}\text { Ocean } \\
\text { Detection } \\
13\end{array}$ & $\begin{array}{l}\text { Ocean Detected } \\
\text { Fish Avg. (days) }\end{array}$ & 2.4 & 4.7 & 6.3 & 1.60 & 1.59 & 1.55 \\
\hline
\end{tabular}

\section{Short-term Release Survival Probability}

Steelhead kelts assigned to the Short-term treatment performed well migrating through the lower Columbia River to the ocean with little mortality incurred during the outmigration (Table 8). The probability of detection at the various arrays was similar to other release groups and ranged from $89 \%$ to $100 \%$ (Table 8 ).

Utilizing the survival probability formula (Appendix B) to compute no-term survival probability, resulted in data suggesting that the short-term release group of steelhead kelts successfully navigated the lower Columbia River to the ocean 
with little mortality incurred (Table 8 ). This release had exceedingly high survival rates to Reach 1 and while Reach 2 survival was lowest (Table 8).

Table 8. Survival rate and detection probability of Short-term release on 4/25/2008. The lambda term is the product of survival and detection probability, this term cannot be decomposed in the reach 3 estimate.

\begin{tabular}{|c|c|c|c|c|c|}
\hline Short-term Release & \multicolumn{5}{|c|}{} \\
\hline Reach & $\begin{array}{c}\text { Survival } \\
\text { (S) }\end{array}$ & std. deviation & Detection (P) & std. deviation & Lambda \\
\hline $\begin{array}{c}\text { Reach 1 (Release to River } \\
\text { Array) }\end{array}$ & 0.9800 & 0.0198 & 1.0000 & 0.0000 & 0.9800 \\
\hline $\begin{array}{c}\text { Reach 2 (River Array to } \\
\text { Estuary Array) }\end{array}$ & 0.6857 & 0.0688 & 0.8929 & 0.0585 & 0.6122 \\
\hline $\begin{array}{c}\text { Reach 3 (Estuary Array to } \\
\text { Ocean Array) }\end{array}$ & - & - & - & - & 0.8333 \\
\hline
\end{tabular}

Short-term Release Detection and Run Timing

A total of 50 short-term reconditioned kelts were released with acoustic tags to assess their emigration behavior, survival, and timing after release from below Bonneville Dam to the Pacific Ocean. Fish were released on April 25, 2008 below Bonneville Dam (rkm 233) at Hamilton Island. Telemetry arrays were deployed at various locations in the lower Columbia River (described in detail in the previous No-term section). Forty-nine kelts from the Short-term treatment were heard at the St. Helens array and just over half $31(56 \%)$ were detected entering the ocean (Table 9). The kelt steelhead that reached the ocean traveled .87 $\mathrm{km} / \mathrm{hr}$ on average and took 11 days to complete the journey (Table 9). Short-term release kelts spent just over 3 days in the estuary. These times are greater in respect to the 2007 numbers for the short-term group (Branstetter et. al, 2008).

Table 9. Number detected, travel time and travel speed to detection array from time of release of Short-term kelt release $N=50$. Released on 4/25/2008.

\begin{tabular}{|c|c|c|c|c|c|c|c|}
\hline & & $\begin{array}{c}\text { Time to } \\
\text { River Array }\end{array}$ & $\begin{array}{c}\text { Time to } \\
\text { Estuary Array }\end{array}$ & $\begin{array}{c}\text { Time to } \\
\text { Ocean Array }\end{array}$ & $\begin{array}{c}\text { Avg. } \mathrm{km} / \mathrm{hr} \text { from } \\
\text { Release. To } \\
\text { River Array }\end{array}$ & $\begin{array}{c}\text { Avg. } \mathrm{km} / \mathrm{hr} \text { from } \\
\text { Release to } \\
\text { Estuary Array }\end{array}$ & $\begin{array}{c}\text { Arom } \\
\text { Bonneville to } \\
\text { Ocean }\end{array}$ \\
\hline $\begin{array}{c}\text { River } \\
\text { Detections } \\
49\end{array}$ & $\begin{array}{c}\text { River Only Detected } \\
\text { Fish Avg. (days) }\end{array}$ & 4.8 & $*$ & $* 81$ & $*$ \\
\hline $\begin{array}{c}\text { Estuary } \\
\text { Detection } \\
31\end{array}$ & $\begin{array}{c}\text { Estuary Only Detected } \\
\text { Fish Avg. (days) }\end{array}$ & 4.5 & 6.2 & $*$ & .86 & 1.2 \\
\hline $\begin{array}{c}\text { Ocean } \\
\text { Detection } \\
13\end{array}$ & $\begin{array}{c}\text { Ocean Detected } \\
\text { Fish Avg. (days) }\end{array}$ & 6.5 & 8.9 & 11.0 & .60 & .84 \\
\end{tabular}


Acoustic Telemetry Return Detections

In years with high survival to the ocean, it would be expected that a portion of the steelhead kelts from the no-term and short-term treatments would return with the following (within year) spawning migration. For the 2008 releases, there have been 5 returns detected by the acoustic arrays, with 2 no-term fish ( $4 \%$ of total release) detections and 3 short-term detections (6\% of total release) (Table 10). Most returns were detected in late July to early September in the lower Columbia River.

Table 10. Acoustic tag return migration detection in the lower Columbia River.

\begin{tabular}{|c|c|c|c|c|}
\hline Treatment & $\begin{array}{c}\text { Release } \\
\text { Year }\end{array}$ & Total Tagged & $\begin{array}{c}\text { Total Observed } \\
\text { Returning to } \\
\text { Columbia River }\end{array}$ & $\%$ of total Tagged \\
\hline No-Term & 2008 & 53 & 2 & $4 \%$ \\
\hline $\begin{array}{c}\text { Short-term } \\
\text { Release }\end{array}$ & 2008 & 50 & 3 & $6 \%$ \\
\hline $\begin{array}{c}\text { No-Term } \\
\text { Short-term } \\
\text { Release }\end{array}$ & 2007 & 33 & 0 & $0 \%$ \\
\hline No-Term & 2007 & 27 & 0 & $0 \%$ \\
\hline $\begin{array}{c}\text { Short-term } \\
\text { Release }\end{array}$ & 2006 & 49 & 3 & $6 \%$ \\
\hline No-Term & 2005 & 50 & 0 & $0 \%$ \\
\hline $\begin{array}{c}\text { Short-term } \\
\text { Release }\end{array}$ & 2005 & 57 & 1 & $2 \%$ \\
\hline No-Term & 2004 & 56 & 1 & $2 \%$ \\
\hline $\begin{array}{c}\text { Short-term } \\
\text { Release }\end{array}$ & 2004 & 24 & 1 & $4 \%$ \\
\hline
\end{tabular}

Long-term Reconditioning

To date the Long-term Reconditioning has shown the potential to contribute the largest number of potential spawners to the local populations within the Yakima system (Table 11). The worst year for reconditioning was in 2000 when we first began reconditioning; our methods then were much more intrusive to the fish likely resulting in high rates of mortality due from handling stress (Evans and Beaty 2001). We were also experimenting with a number of differing feeds in these years as well which also likely contributed to lower rates of success during these early years of the project. The long-term program decided on a single method of reconditioning in 2003 which coincidentally was the second most successful year of reconditioning at $53 \%$ (Table 11) (Hatch et al 2004). This year (2008) resulted in the best survival for the long-term reconditioning to date.

Short-term reconditioning has been the second best with an average of $7 \%$ of the release group attempting to return to the Yakima River Basin (Table 11) with its best year in 2002. The worst year for this release group was in 2006 which had no detections returning from the ocean. The No-term release group faired the worst of the four groups cumulatively, with its worst year in 2007 with no detected returns. The No-term release group had its best year in 2004 with $7 \%$ of the 
release detected attempting to return to spawn (Table 11). The In-River release group did consistently well since it was implemented in 2005 averaging a return rate of 4\% (Table 11) with its best year in 2007 and worst in 2006. 
Table 11. Prosser Management Strategy Results.

\begin{tabular}{|c|c|c|c|c|c|c|c|c|c|c|c|c|c|c|c|c|}
\hline \multicolumn{5}{|c|}{ Long term Reconditioning } & \multicolumn{4}{|c|}{ Short term reconditioning } & \multicolumn{4}{|c|}{ No-term } & \multicolumn{4}{|c|}{ In River } \\
\hline $\begin{array}{c}\text { Collection } \\
\text { Year }\end{array}$ & In & $\begin{array}{l}\text { Survived } \\
\text { to } \\
\text { Release }\end{array}$ & $\begin{array}{c}\text { Mature } \\
\text { @ } \\
\text { Release }\end{array}$ & $\begin{array}{l}\% \text { Mature } \\
\text { @ } \\
\text { Release }\end{array}$ & In & $\begin{array}{l}\text { Survived } \\
\text { to } \\
\text { Release }\end{array}$ & $\begin{array}{l}\text { Returned to } \\
\text { Bonneville }\end{array}$ & $\begin{array}{c}\% \text { Detected } \\
\text { Returning } \\
\text { to } \\
\text { Bonneville } \\
\end{array}$ & $\ln$ & $\begin{array}{l}\text { Survived } \\
\text { to } \\
\text { Release }\end{array}$ & $\begin{array}{l}\text { Returned to } \\
\text { Bonneville }\end{array}$ & $\begin{array}{c}\% \text { Detected } \\
\text { Returning } \\
\text { to } \\
\text { Bonneville } \\
\end{array}$ & In & $\begin{array}{c}\text { Survived } \\
\text { to } \\
\text { Release }\end{array}$ & $\begin{array}{l}\text { Returned to } \\
\text { Bonneville }\end{array}$ & $\begin{array}{c}\% \text { Detected } \\
\text { Returning } \\
\text { to } \\
\text { Bonneville } \\
\end{array}$ \\
\hline 2000 & 512 & 91 & 42 & $8 \%$ & -- & -- & -- & -- & -- & -- & -- & -- & -- & -- & -- & -- \\
\hline 2001 & 551 & 197 & 108 & $20 \%$ & -- & -- & -- & -- & -- & -- & -- & -- & -- & -- & -- & -- \\
\hline 2002 & 420 & 140 & 76 & $18 \%$ & 479 & 334 & 43 & $9 \%$ & -- & -- & -- & -- & -- & -- & -- & -- \\
\hline 2003 & 482 & 298 & 254 & $53 \%$ & 208 & 187 & 8 & $4 \%$ & -- & -- & -- & -- & -- & -- & -- & -- \\
\hline 2004 & 662 & 253 & 216 & $33 \%$ & 105 & 83 & 5 & $5 \%$ & 75 & 63 & 5 & $7 \%$ & -- & -- & -- & -- \\
\hline 2005 & 386 & 86 & 75 & $19 \%$ & 106 & 99 & 1 & $1 \%$ & 98 & 96 & 2 & $1 \%$ & 67 & 67 & 3 & $4 \%$ \\
\hline 2006 & 279 & 85 & 79 & $28 \%$ & 56 & 52 & 0 & $0 \%$ & 55 & 49 & 2 & $4 \%$ & 52 & 52 & 1 & $2 \%$ \\
\hline 2007 & 422 & 221 & 202 & $48 \%$ & 40 & 38 & 1 & $3 \%$ & 43 & 38 & 0 & $0 \%$ & 53 & 53 & 3 & $6 \%$ \\
\hline 2008 & 472 & 269 & 266 & $56 \%$ & 108 & 100 & 6 & $6 \%$ & 100 & 100 & 2 & $2 \%$ & 88 & 88 & 3 & $3 \%$ \\
\hline Total & 4186 & 1640 & 1318 & & 1102 & 893 & 64 & & 371 & 346 & 11 & & 260 & 260 & 10 & \\
\hline \multicolumn{5}{|c|}{ 2003-08 average } & & & & & \multirow{2}{*}{\multicolumn{4}{|c|}{ 2004-08 average }} & \multirow{2}{*}{\multicolumn{3}{|c|}{ 2005-08 average }} & \\
\hline $2000-08 \mathrm{av}$ & erage & & & $31 \%$ & $2002-08$ & verage & & $7 \%$ & & & & & & & & $4 \%$ \\
\hline
\end{tabular}




\section{Geographic Replication}

The best long-term reconditioning site overall has been at Prosser, WA with an average success rate of $40 \%$ since reconditioning techniques were developed at this site and established in 2003 (Table12) (Hatch et al 2004). Shitike fish have been difficult to recondition successfully with only two successful years that singular female kelts were released in 2005 and 2007 (Table 12). This is attributed to the small number of kelts that were collected and the generally poor condition of collected fish. Staff from Warm Springs remarked that the good quality fish collected at Shitike would have been designated as fair-poor quality fish at Prosser. Omak steelhead kelt reconditioning has been fairing better and is approaching levels of success seen at Prosser. The best year reconditioning at Omak was in 2008 with $28 \%$ of the fish being successfully reconditioned (Table 12). This site will likely continue to improve with time as staff continues to develop and optimize reconditioning techniques. 
Table 12. Long-term Reconditioning by Release Site

\begin{tabular}{|c|c|c|c|c|c|c|c|c|c|c|c|c|}
\hline \multicolumn{5}{|c|}{ Yakima River } & \multicolumn{4}{|c|}{ Shitike Creek } & \multicolumn{4}{|c|}{ Omak Creek } \\
\hline $\begin{array}{c}\text { Collection } \\
\text { Year }\end{array}$ & $\ln$ & $\begin{array}{c}\text { Survived } \\
\text { to } \\
\text { Release }\end{array}$ & $\begin{array}{r}\text { Mature at } \\
\text { Release } \\
\end{array}$ & $\begin{array}{c}\% \text { Mature @ } \\
\text { Release }\end{array}$ & In & $\begin{array}{l}\text { Survived to } \\
\text { Release }\end{array}$ & $\begin{array}{c}\text { Mature at } \\
\text { release }\end{array}$ & $\begin{array}{c}\% \text { Mature at } \\
\text { Release }\end{array}$ & In & $\begin{array}{c}\text { Survived } \\
\text { to } \\
\text { Release }\end{array}$ & $\begin{array}{l}\text { Mature at } \\
\text { release }\end{array}$ & $\begin{array}{c}\% \text { Mature at } \\
\text { Release }\end{array}$ \\
\hline 2000 & 512 & 91 & 42 & $8 \%$ & - & - & - & - & - & - & - & - \\
\hline 2001 & 551 & 197 & 108 & $20 \%$ & - & - & - & - & - & - & - & - \\
\hline 2002 & 420 & 140 & 76 & $18 \%$ & - & - & - & - & - & - & - & - \\
\hline 2003 & 482 & 298 & 254 & $53 \%$ & - & - & - & - & - & - & - & - \\
\hline 2004 & 662 & 253 & 216 & $33 \%$ & - & - & - & - & - & - & - & - \\
\hline 2005 & 386 & 86 & 75 & $19 \%$ & 9 & 1 & 1 & $11 \%$ & 51 & 3 & 3 & $6 \%$ \\
\hline 2006 & 279 & 85 & 79 & $28 \%$ & 4 & 0 & 0 & 0 & 27 & 2 & 2 & $7 \%$ \\
\hline 2007 & 422 & 221 & 202 & $48 \%$ & 14 & 1 & 1 & $7 \%$ & 43 & 8 & 8 & $19 \%$ \\
\hline 2008 & 472 & 269 & 266 & $56 \%$ & 11 & 0 & 0 & 0 & 32 & 9 & 9 & $28 \%$ \\
\hline $2000-08 \mathrm{av}$ & & & & $31 \%$ & 2005-2 & iverage & & $5 \%$ & \multicolumn{3}{|c|}{\begin{tabular}{|l|} 
2005-2008 average \\
\end{tabular}} & $14 \%$ \\
\hline
\end{tabular}




\section{Discussion}

The goal of this program is to evaluate management strategies that assist in the restoration of steelhead populations and promote iteroparity. In order to reach our goal we continued to investigate steelhead reconditioning strategies including; in-river release, no-term, short-term, and long-term treatments in 2008. Additionally, we researched gamete and progeny viability of kelts as well as investigate the reproductive success of long-term treatment fish. Future studies are currently in the planning phase to utilize the techniques that we have learned at the various research sites and apply these to determine effective treatments for the Snake River subbasin to conserve and enhance wild steelhead populations.

\section{Management Scenario Evaluation}

No-term had good survival to the ocean $(68.5 \%$, minimum estimate) while the short-term treatment group had an extremely high survival rate to the ocean (83\%, minimum estimate). We assume that the in-river release group survived at a much lower rate due to the difficulties of migrating through the hydrosystem but no monitoring system is in place to detect these fish prior to their return migration. Survival and rematuration of long-term reconditioned kelt steelhead held at Prosser Hatchery improved again from 2007 to 2008 . Survival to maturation for reconditioning continued to exceed the average across years by $25 \%$ (Table 12). Overall steelhead kelts entering the Prosser Hatchery were in extremely good condition likely resulting in the high survival of all treatment releases.

Lower Columbia River acoustic telemetry analysis continues to provide data that demonstrates that kelts are moving rapidly to the ocean with relatively short estuary residence time. Survival and travel time are plotted and measured from the time of release to the detection arrays for the no-term and short-term treatments releases over the last 5-years (Figure 13). Survival is negatively correlated with travel time, however the 2008 data weakens this relationship, because fish traveled at slower rates but still had relatively high survival rates. 


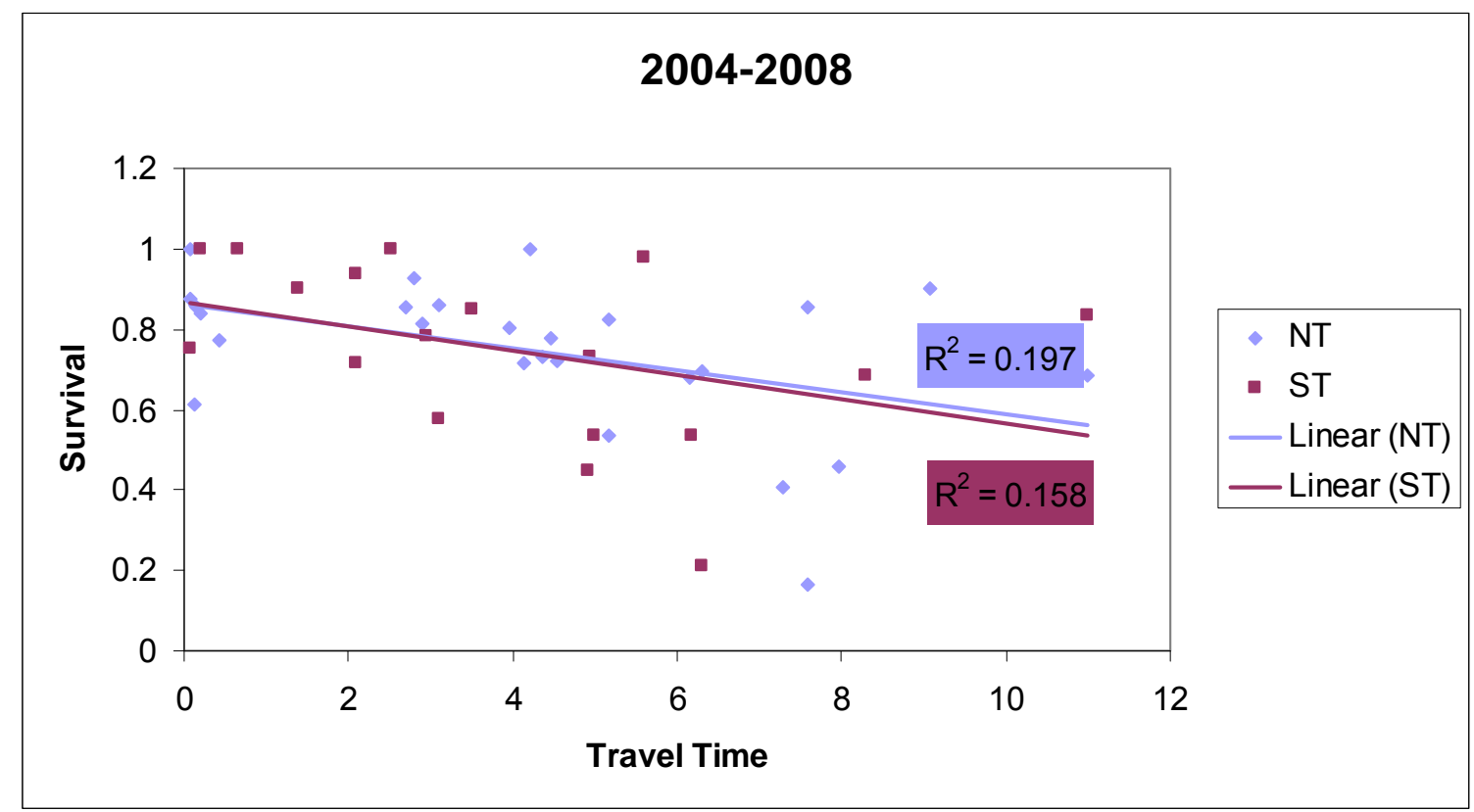

Figure 13. Steelhead kelt outmigration survival as a function of travel time (in days) for noterm (NT) and short-term (ST) treatment releases from 2004 through 2008.

River flows likely plays an important role in the survival of steelhead kelts migrating in the lower Columbia River. Prior to the 2007 release group, kelt steelhead migration survival to ocean was positively related to river flow $\left(R^{2}=0.525\right)$. However survival in release groups has been quite high ( $S$ range 60 to $100 \%$ ) at flows that previously were associated with lower survival (S range 0 to $54 \%$ excluding one release in 2006) (Figure 14). Adding the 2008 data to the survival as a function of flow slightly strengthens the correlation to $R^{2}=.250$. 


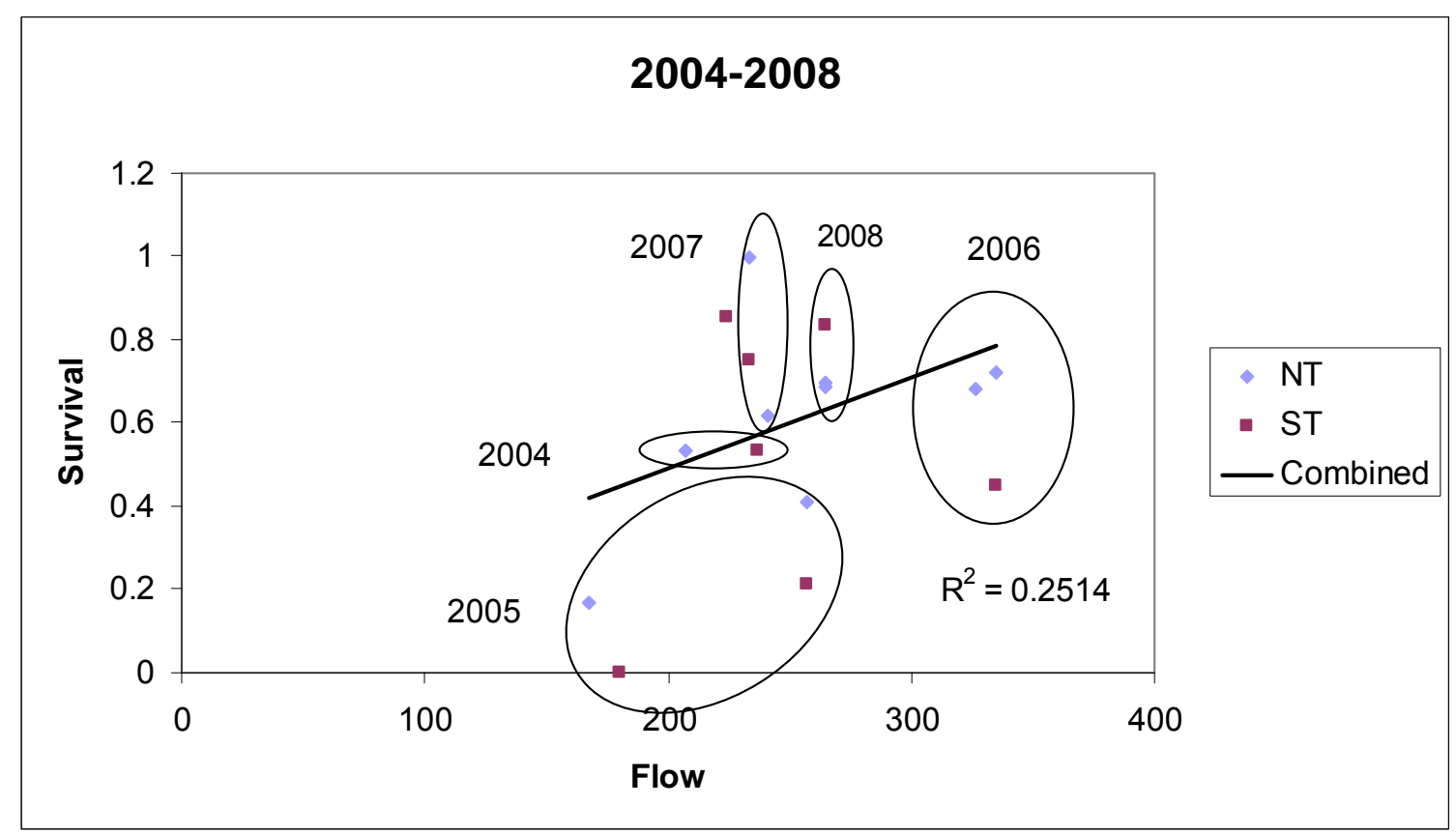

Figure 14. No-term (NT) and short-term (ST) release groups from 2004 through 2008 survival as a function of Columbia River flow (kcfs) measured at Bonneville Dam. The one point not included within an ellipse is from 2006.

There appears to be no relationship between migration survival and river water temperature until a critically high water temperature is reached (between 16 and $18 \mathrm{C})$. The lowest survival of any release group was a short-term group released in July of 2005, which also was the highest water temperature of all releases (Figure 15). 


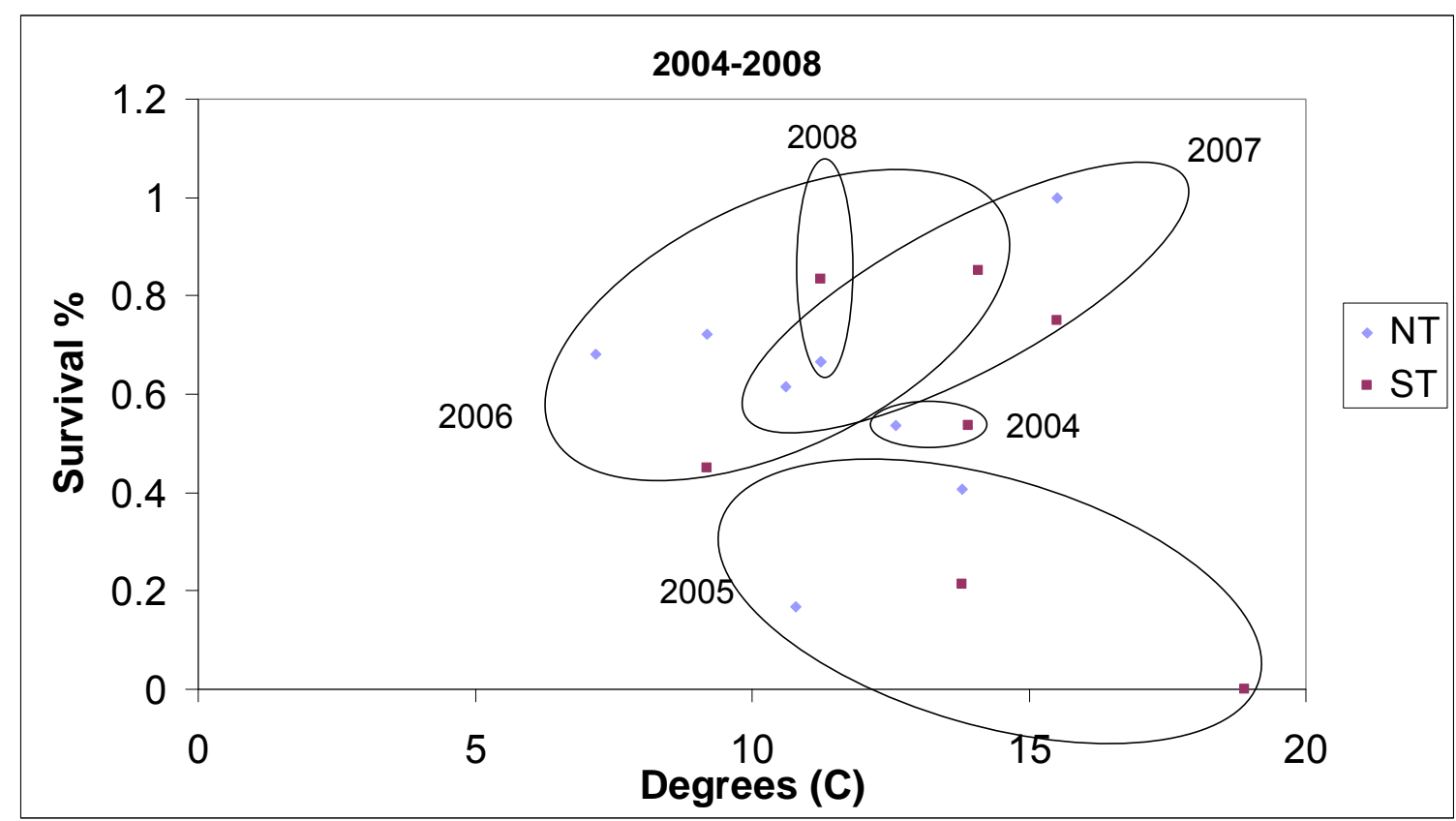

Figure 15. Survival of No-term (NT) and short-term (ST) release groups, in the lower Columbia River, from 2004 through 2008 as a function river temperature. One NT release from 2007 and one ST release from 2006 did not group in their respective ellipses.

Based on these data it appears that not all in-river environmental factors may be as integral in the survival of kelts migrating in the unimpounded sections of the Lower Columbia River and that the bioenergetics of the fish post-spawn may play a larger role in survival to the ocean. Measures of physiological status and possibly bioenergetics will be incorporated into future work.

\section{Steelhead Kelt Returns}

The ultimate measure of these scenarios is based on the number of kelts returning from the ocean to spawn a second time and contributing towards the next generation. The most successful of the transport strategies based on all years PIT tag returns to Bonneville Dam has been the short-term reconditioning. In the last two years, Short-term reconditioning has returned in the highest numbers to Bonneville, with drops in returns by the In-river releases (Appendix D). To date, 3 fish (3\%) from the In-river release, 2 fish (2\%) (1 acoustic tagged) from the No-term releases and 6 fish (6\%) (2 of them acoustic tagged fish) from the Short-term reconditioning release, were detected moving upriver at Bonneville Dam. Also, one of the 2007 short-term treatment fish was detected at Bonneville Dam.

The proportion of steelhead detected returning to the Yakima River at Prosser (Table 13) dam is usually lower than Bonneville (Table 13) and McNary Dam (Table 14) returns but the trend is consistent with no one treatment showing 
higher survival in multiple years (Table 13). It's possible that the kelts that were detected at McNary (Table 14) could still be on the move somewhere between McNary and Prosser or they could have perished after passing McNary. It also should be noted that only 2 of 3 ladders have had PIT- tag detectors at Prosser Dam from 2004 through early 2008 so some kelts could have passed via the ladder without detection in these years. The third ladder was outfitted with a PITtag detector in the spring of 2008.

Table 13. Total PIT- tag Detection By Release Year at Prosser 2004-2008 w/ Bonneville Comparison.

\begin{tabular}{|c|l|c|c|c|c|}
\hline Release Year & \multicolumn{1}{|c|}{ Treatment } & $\begin{array}{c}\text { Total } \\
\text { Released }\end{array}$ & $\begin{array}{c}\text { Total Observed } \\
\text { Returning to } \\
\text { Prosser }\end{array}$ & $\begin{array}{c}\% \text { of } \\
\text { total } \\
\text { Release }\end{array}$ & $\begin{array}{c}\text { Bonneville \% for } \\
\text { Comparison }\end{array}$ \\
\hline 2008 & In-River Release & 88 & 1 & $1 \%$ & $3 \%$ \\
\hline 2008 & No-Term & 100 & 0 & $0 \%$ & $2 \%$ \\
\hline 2008 & Short-term Release & 100 & 0 & $0 \%$ & $6 \%$ \\
\hline 2007 & In-River Release & 67 & 1 & $1 \%$ & $6 \%$ \\
\hline 2007 & No-Term & 43 & 0 & $0 \%$ & $0 \%$ \\
\hline 2007 & Short-term Release & 38 & 1 & $3 \%$ & $3 \%$ \\
\hline 2006 & In-River Release & 52 & 1 & $2 \%$ & $2 \%$ \\
\hline 2006 & No-Term & 49 & 1 & $2 \%$ & $4 \%$ \\
\hline 2006 & Short-term Release & 52 & 0 & $0 \%$ & $0 \%$ \\
\hline 2005 & In-River Release & 67 & 3 & $4 \%$ & $4 \%$ \\
\hline 2005 & No-Term & 96 & 0 & $0 \%$ & $1 \%$ \\
\hline 2005 & Short-term Release & 99 & 0 & $0 \%$ & $1 \%$ \\
\hline 2004 & No-Term & 63 & 0 & $0 \%$ & $7 \%$ \\
\hline 2004 & Short-term Release & 83 & 4 & $5 \%$ & $5 \%$ \\
\hline
\end{tabular}


Table 14. 2008 McNary Dam Detections

\begin{tabular}{|c|l|c|c|c|}
\hline $\begin{array}{c}\text { Release } \\
\text { Year }\end{array}$ & \multicolumn{1}{|c|}{ Treatment } & Total Released & $\begin{array}{c}\text { Total Observed } \\
\text { Returning to } \\
\text { McNary }\end{array}$ & $\begin{array}{c}\% \text { of total } \\
\text { Release }\end{array}$ \\
\hline 2008 & In-River Release & 88 & $4 *$ & $5 \%$ \\
\hline 2008 & No-Term & 100 & 2 & $2 \%$ \\
\hline 2008 & Short-term Release & 100 & 6 & $6 \%$ \\
\hline 2007 & In-River Release & 67 & 1 & $1 \%$ \\
\hline 2007 & No-Term & 43 & 0 & $0 \%$ \\
\hline 2007 & Short-term Release & 38 & 1 & $3 \%$ \\
\hline 2006 & In-River Release & 52 & 1 & $2 \%$ \\
\hline 2006 & No-Term & 55 & 2 & $4 \%$ \\
\hline 2006 & Short-term Release & 52 & 0 & $0 \%$ \\
\hline 2005 & In-River Release & 67 & 3 & $4 \%$ \\
\hline 2005 & No-Term & 98 & 0 & $0 \%$ \\
\hline 2005 & Short-term Release & 99 & 1 & $1 \%$ \\
\hline 2004 & No-Term & 75 & 2 & $3 \%$ \\
\hline 2004 & Short-term Release & 83 & 3 & $4 \%$ \\
\hline 2003 & Short-term Release & 187 & 5 & $3 \%$ \\
\hline 2002 & Short-term Release & 334 & 31 & $9 \%$ \\
\hline${ }^{*}$ One fish not detected at Bonneville & & & \\
\hline
\end{tabular}

It is likely that there are a multitude of external factors that have yet to be identified that ultimately determine the successful return of these fish. Ocean prey availability may play an important role in the success of kelts returning to the Columbia River.

In the event of a low water year or should budget considerations necessitate a lower cost option the No-term or Short-term reconditioning techniques would be useful to assist struggling populations. Evans et al. (2008) observed that In-River release groups faired poorly in 2002-2003 when compared against transport groups during those years. Our short-term reconditioning transport release group in 2002 faired extremely (9\%) well while it also appears that Evans et al (2008) transport group from Lower Granite Dam that same year was also successful $(5.7 \%)$. This suggests that conditions in the common environment (Columbia River from McNary Dam downstream including the ocean) for these two groups may be the most important factors for determining survival.

Parentage assignment data may ultimately prove that long-term reconditioning may be the best option for maximizing the usefulness of steelhead kelts as a restoration/conservation tool. Long-term reconditioning could possibly minimize the randomness of external variables that managers have little, to no control over, which may be negatively impacting the return of steelhead kelts from the 
ocean. Considering that $32 \%$ of the long-term reconditioning release at Prosser has actively migrated upriver to spawning grounds is promising if it is determined that these fish are contributing to production of the next generation.

\section{Geographic Replication}

Of the three long-term reconditioning sites (Yakima River, Omak Creek, and Shitike Creek) the Yakima site continues to perform the best while Shitike Creek performed very poorly. The disparity in the two sites can be explained with the abundant number of kelts that the Yakima River site has at its disposal while Shitike site has two factors that have put it at a disadvantage, small numbers of kelts available and of which a small number of them are in good condition. Other potential negative confounding influences such as river conditions or conspecific competition for spawning beds may be contributing to the poor reconditioning success at Shitike Creek. Warm Springs staff has continuously observed that steelhead are in much better shape heading to spawning grounds than they are returning from them. The CRITFC along with Warm Springs have decided that Shitike Creek collection of kelts is not an ideal collection site and we are currently planning to move the collection of kelts to the Warm Springs River in the hopes that this will give us adequate numbers of kelts that are in good condition to recondition. The Omak collection and reconditioning has steadily improved over the last few years and given more time should continue to improve as staff have become more proficient at steelhead kelt care. The biggest issue to date for Omak is that in extremely low water years collecting kelts at the fixed sites can be problematic, due to these systems (Omak/Bonaparte) becoming almost completely denuded of water.

Overall, long-term reconditioning success may be influenced, in part, to a number of environmental factors that have been in our favor for the last few years (low water temperatures, high river flows, colder Pacific Ocean). These environmental factors may partially explain the variable nature of the long-term reconditioning program. 


\section{Section 2: Gamete and Progeny Viability}

\section{Introduction}

Questions have arisen regarding the reproductive success that artificially reconditioned kelt steelhead may have. To evaluate those questions we first devised a study plan to evaluate reproductive success of long-term reconditioned kelt steelhead relative to first time spawners. That work continues and current progress is detailed in the next section of this report, however, many logistical challenges have arisen in the evaluation. Consequentially, we initiated a study to describe gamete and progeny viability in artificially reconditioned kelt steelhead. The premise is to collect hatchery-origin prespawn adults and place them in a hatchery. After the female fish are ripe they are air spawned, eggs are fertilized with cryopreseved milt, and the offspring are raised for several weeks while recording various measures of quality. Female steelhead, after air spawning, are placed in tanks and reconditioned in a manner similar to our other long-term reconditioning treatments (Prosser and Omak). This experiment utilizes a replicated, repeated measures experimental design, to assess and compare egg and progeny viability of reconditioned vs. first time spawners. Long-term reconditioning and subsequent captive spawning provides us with means to obtain valuable quantitative data on gonad processes, maturation rates and juvenile survival. Data resulting from this research will greatly contribute to the evaluation of reconditioning as a conservation tool. The hypothesis we are testing is:

$\mathrm{H}_{\mathrm{o}}$ : Measures of gamete and progeny viability and quality are similar between first spawning and second spawning following artificial reconditioning.

\section{Study Area}

Work was performed at the Parkdale Fish Facility located at rkm 5.6 on the Middle Fork of the Hood River (Figure 16). The Hood River is a tributary of the Columbia River in northwestern Oregon. Approximately $40 \mathrm{~km}$ long from its mouth to its farthest headwaters, the river descends from wilderness areas on Mount Hood and flows through the agricultural Hood River Valley to join the Columbia River in the Columbia River Gorge. Adult steelhead collection for the Parkdale Fish Facility is conducted at the Powerdale Dam located on at rkm 6.4 just north of the city of Hood River, Oregon and operated by Oregon Department of Fish and Wildlife (ODFW). 


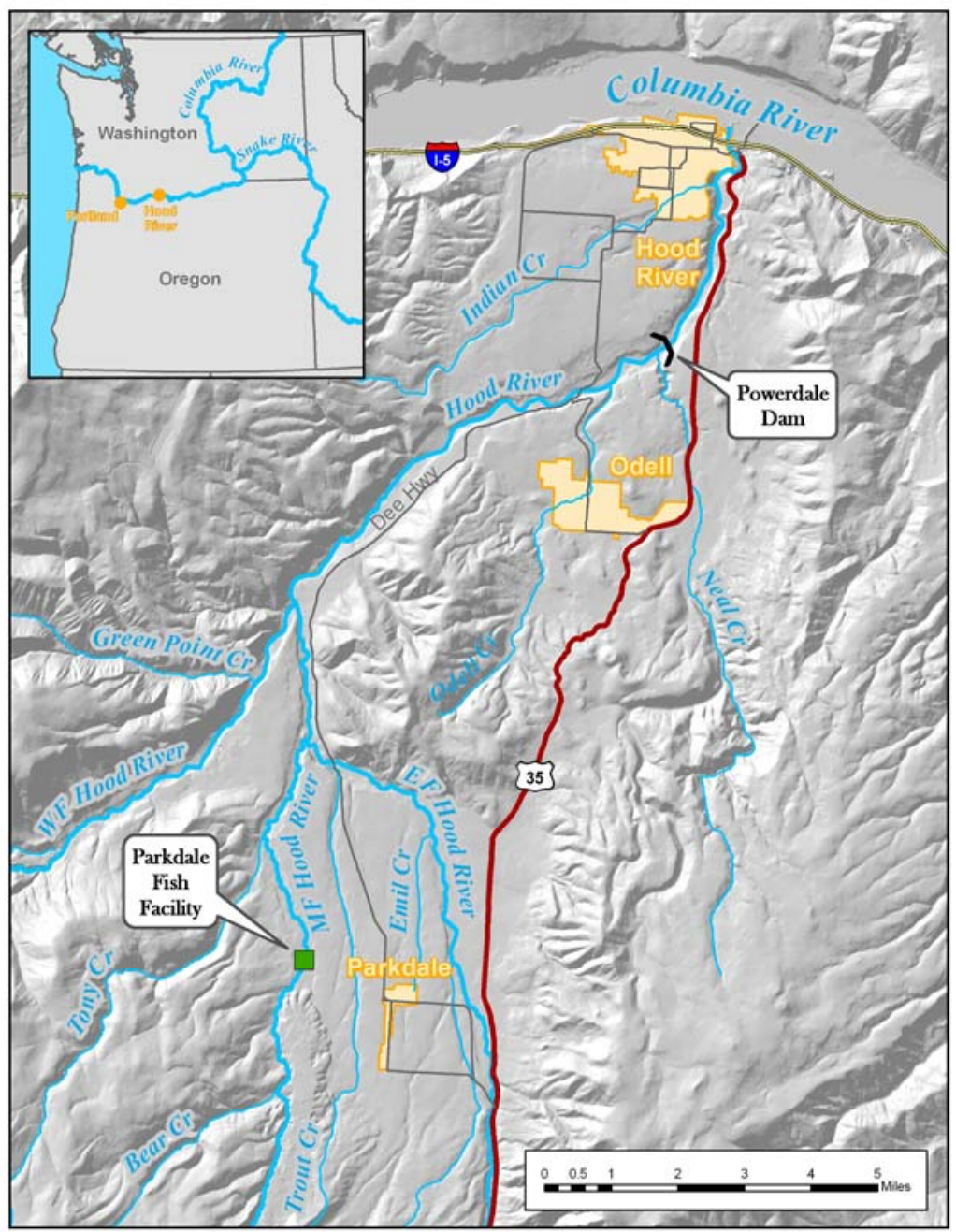

Figure 16. Location of Parkdale Fish Facility and Powerdale Dam/ Fish Trap.

\section{Methods}

Pre-spawn Skamania stock steelhead captured for this experiment, were trapped from July 27, 2007 to December 11, 2007 at the Powerdale Dam trap located on the Hood River. Fish were then transported to the Parkdale Fish Facility and held in a 40'l x 8'w x 4'd raceway at $400 \mathrm{gal} / \mathrm{min}$ until ripened and ready for spawning. All incoming fish were inspected for copepods and received a small dosage of diluted Ivermectin solution (1-2cc) as a parasitic preventative and florfenicol $(2 \mathrm{ml})$ as a preventative against cold water disease. Steelhead were also treated for fungus using formalin treatments at 1:6000, 3 times weekly, for one hour.

From February to June, staff sorted fish biweekly for ripeness based on previous experience with this stock. Male gametes were collected manually and 
cryogenically stored (Cloud \& Osborne 1997) prior to fertilization. Female gametes were collected using the air-spawning technique (Leitritz and Lewis 1980). Organ tissue and gamete samples were collected from post spawn males and a sample of ovarian fluid was obtained and then submitted to the ODFW pathology lab in Corvallis, OR to screen for infectious diseases (e.g. (Infectious Hematopoietic Necrosis virus (IHNV) and Bacterial Kidney Disease (BKD))). If disease screens were determined to be positive for any of the parents, the eggs were immediately disposed of and the female brood fish if still alive euthanized. After air spawning, the total number of eggs was estimated utilizing the Von Bayer method (Wedemeyer 2002) of egg estimation. A total of 1500 eggs from each female were spawned and subdivided into three groups. Each egg group was mixed with thawed cryopreserved milt (ODFW 2008) from two different males to avoid against any disease positive males from destroying an entire batch of eggs. The use of cryopreserved milt in all experimental matings allows us to spawn the same female with the same males in multiple years to evaluate any reconditioning effect on a female kelt's eggs. Each egg group was kept isolated using isolation baskets. Post water hardened eggs were treated with a diluted solution of iodaphor Povadine (Argentyne) to ensure disinfection of the eggs prior to placement into vertical stack incubators. Eggs were incubated at $5.5^{\circ} \mathrm{C}$ water and treated with formalin 3 times weekly at 1:600 for 15 minutes. A subsample of eggs $(\mathrm{N}=10)$ were collected on day 15 ( average of 120 Temperature Units) which put the eggs at the epiboly stage of development and fixed in Stockard's solution to estimate initial fertilization by counting the number of keels present. The proportion of eggs that were successfully fertilized post cold shock (Pennel and Barton 1996) and alevin that died post hatch was also recorded.

The fry subgroups were transferred to the picking troughs $\left(14^{\prime} \mathrm{l} \times 16.5\right.$ " $\mathrm{w} \times 4.5$ "d at $15 \mathrm{gal} / \mathrm{min}$ ) as single female groups (34" $\times 16.5$ " or 55.5 " x 16.5 depending on stocking density) for space saving purposes. They were fed Biovita starter feed \#0 every hour during daylight hours for the first 4 weeks to satiation then gradually moved to 4 times daily to satiation for the remaining 10 weeks. Water temperatures remained a constant $5.5^{\circ} \mathrm{C}$. Fry were sampled by collecting two 8 " quick net subsamples of juveniles every week for 10 weeks. From these subsamples wet weights were collected and a subsample of 10 individuals was collected for average length. All fish were anesthetized utilizing MS-222. At the end of the 10- week period all juvenile fry were euthanized administering a fatal dosage of MS-222 and then land filled.

Surviving females were reconditioned at the Parkdale Fish Facility and spawned a second time with cryopreserved milt from the same male combinations to assess the effect of reconditioning on viability and early juvenile survival. Females were administered another dosage of ivermectin after completion of air spawning and placed in 10' $\mathrm{d} \times 4.5$ 'I tanks at $50 \mathrm{gal} / \mathrm{min}$ for summer holding. Fish were checked again in late spring (May) for the presence of copepods and 
administered additional ivermectin treatment if copepods were present. Fish were started on krill but readily accepted pelleted feed and were fed 3-4 times daily until satiation. By mid-fall (October) the female kelts were moved back to the raceway and placed with incoming brood. Feeding was discontinued in mid December to prepare for spawning.

\section{Results}

\section{Adult Collection, Spawning and Reconditioning}

\section{Broodstock First-time Collection, Spawning}

There were a total of 23 female and 18 male fish captured for spawning at the Powerdale trap during the summer (June-July) of 2008. Five of the individuals died from what appears to be Ceratamyxa shasta infections. Currently we have 14 females and 13 males available. We anticipate that these fish will be ready to spawn through Febuary- April 2009. Juvenile data will be available in the 2009 Annual Report.

\section{Broodstock First-time Collection, Spawning, and Reconditioning}

We began with 14 male and 16 female first time spawners that were captured at the Powerdale Dam trap in (July-December) 2007. There were a total of 8 males that had milt available for cryopreservation and 14 first time females that survived to be spawned with cryopreserved milt in February- March 2008 for a total of 42 matings resulting in approximately 21,000 eggs that could have been fertilized. Based on keel presence/absence an average of $36 \%$ of the eggs were fertilized with a minimum of $0 \%$ and a maximum of $80 \%$ (Appendix E). Post cold shock eggs were compared against fertilization rates and these numbers were very close with the average survival rate at $37 \%$ and the maximum survival rate at $60 \%$ and the minimum at $5 \%$.

Most alevin mortality occurred directly after post hatch. Juvenile fish steadily increased in length and weight over the 10-week period gaining about .1gram per week on average. The juvenile growth was much slower at Parkdale Hatchery than what was previously observed at the University of Idaho due to the cool water conditions present at the facility $\left(5.5^{\circ} \mathrm{C}\right)$ (Appendix $\left.\mathrm{E}\right)$. A majority of the juvenile mortalities occurred immediately post-hatch with an average of 1 or 2 mortalities per group a week thereafter (Appendix E).

Currently there are still 6 female kelts that have survived reconditioning and we anticipate that over half will be available for spawning this year (2008) based on color, abdomen, and general condition. The first 2008 kelt spawner perished 
shortly after air spawning, likely due to compounding handling stress. The first female kelt (female kelt \# 2828) that was spawned this year was also the first spawner in 2008. She had an average of $33 \%$ of her eggs keel (table 1 ) and fry survival rate that averaged $45 \%$ in 2008 (Appendix D). Kelt juvenile data will be available in the 2009 Annual Report.

Table 15. Female kelt 2828: Successful keel development (\%) as an estimate of initial fertilization 2009

\begin{tabular}{|c|c|c|}
\hline Spawning year: 2009 & & \\
\hline Spawning Date & Male Group & Keel $\%$ \\
\hline $1 / 29 / 2009$ & A & $76 \%$ \\
\hline $1 / 29 / 2009$ & B & $57 \%$ \\
\hline $1 / 29 / 2009$ & C & $59 \%$ \\
\hline
\end{tabular}

\section{Broodstock Reconditioning}

Of the steelhead that were collected in 2006 and spawned in the spring of 2007 only one fish survived the reconditioning process after a large outbreak of copepods (Salmoncolla) in the spring of 2007 (Branstetter et al 2008). In 2008 she began to show characteristics of sexual maturation (filling of the abdomen and slight abdominal softening) but her color remained chrome. This remaining reconditioned female did not produce any eggs in early spring of 2008 we have observed this type of spawning behavior in the PIT-tag data and have termed them as "skip spawners". She was retained and reconditioned for an additional year and was placed with the incoming 2009 broodstock in the fall of 2008 . To date this fish has nearly doubled in size (2006 at $3.2 \mathrm{~kg}$ to 2009 at $5.2 \mathrm{~kg}$ ). She does appear to have some slight snout erosion from rubbing on the circular tank. The initial keel results for female 94 were within the range that has been exhibited from steelhead this current year. Actual egg counts post shock and juvenile results will be published in next year's annual report as work in ongoing currently

Table 16. Female Kelt 94: Successful keel development (\%) as an estimate of initial fertilization.

\begin{tabular}{|c|c|c|}
\hline spawn date & Male Group & $\%$ Keel \\
\hline $2 / 24 / 2009$ & A & $58 \%$ \\
\hline $2 / 24 / 2009$ & B & $69 \%$ \\
\hline $2 / 24 / 2009$ & C & $37 \%$ \\
\hline
\end{tabular}




\section{Discussion}

\section{Broodstock}

This year's broodstock has had a higher mortality rate (39\% female and $27 \%$ male) than previous years (average $21 \%$ female and $15 \%$ male). The higher mortality rate may be in part due to some of the fish having $C$. shasta infections (5 confirmed cases). The only known effective treatment for this myxozoan parasite is by introducing natural immunity to the stock (Bartholomew 1989). Half of the surviving males (5) that were collected for milt were successfully spawned and yielded 160 milt straws that were cryogenically preserved. Just under half of the females have already been spawned. Egg volumes have been in the 1670 to 3808 range which is a smaller egg estimate range than in previous year's egg estimates. There have been two immediate post spawn mortalities which were likely due from handling stress.

\section{Broodstock}

First year spawning was highly variable with percentages extremely low with rates around $5 \%$ to as high as $80 \%$. The average was much lower than what we initially saw in the 2007 broodstock. Gamete and progeny size was much smaller when comparing against the 2007 and 2006 brood spawning. This is due to the 2008 brood fish's rearing temperatures being much lower $\left(5.5^{\circ} \mathrm{C}\right)$ than University of Idaho's $\left(15^{\circ} \mathrm{C}\right)$ though progeny survival was much higher at Parkdale with less than $5 \%$ (min .2\%, max 4.5\%) of the population being lost by any group than University of Idaho with an average of $22 \%$ loss ( $\min 2 \%$, max $43 \%)$.

During reconditioning through 2008 and early 2009 we lost 7 females of the original 14 fish that we spawned in 2008. In late fall the 2009 brood were placed with the 2008 brood to mimic natural stream interactions and to assist in stimulating full gamete development.

One of the female steelhead kelts 2828 has been spawned this year (2009). Her egg quantity in the 2008 spawning was 3810 estimated eggs and her 2009 spawning had 2286 eggs estimated, which decreased by approximately $40 \%$ from her first-time spawning. The reduction in egg production may be a result of the reconditioning process but is likely the variable nature of steelhead reproductive capabilities (Maclean 2007). Based on the keel analysis her fertility rate has almost doubled in the second spawning compared to her first spawning (Table 17). 
Table 17. Spawner \#: 2828 keel comparison between first time spawning in 2008 and kelt spawning in 2009.

\begin{tabular}{|c|c|c|c|c|c|c|}
\hline Spawn date & Male Group & Keel $\%$ & Keel & Spawn date & Keel \% & Keel \\
\hline $2 / 14 / 2008$ & A & $20 \%$ & $2 / 10$ & $1 / 29 / 2009$ & $76 \%$ & $13 / 17$ \\
\hline $2 / 14 / 2008$ & B & $30 \%$ & $3 / 10$ & $1 / 29 / 2009$ & $57 \%$ & $11 / 19$ \\
\hline $2 / 14 / 2008$ & C & $70 \%$ & $7 / 10$ & $1 / 29 / 2009$ & $59 \%$ & $10 / 17$ \\
\hline
\end{tabular}

There should be 3 to 4 more females that will be available to spawn this year. Females that are not ready to spawn this year will be retained and spawned the next year.

\section{Broodstock}

Results from the first time spawning can be found in Branstetter (2008). This was the last year (2007) that we shipped eggs to the University of Idaho for analysis. Initial egg fertility (using keel measures) was fairly high in 2007 but juvenile mortality was fairly high averaging $22 \%$.

The solitary surviving fish from the 2007 brood was successfully spawned on $2 / 24 / 2009$. This female had a larger volume of eggs (4864 estimated eggs) initially than the rest of the females from that brood year. Her egg spawning count from the 2009 spawning event was an approximate $26 \%$ increase in egg production at 6604 estimated eggs. Initial egg fertility testing (using keels as an estimate) resulted in an average of $83 \%$ successfully fertilized in 2007 (Table 18). In 2009 keel samples resulted in $55 \%$ of egg fertilized based on keel samples. This is just under a $30 \%$ drop on average for egg fertilization with drops in fertilization for all 3 groups, with the minimum of $11 \%$ for group $B$ and maximum of $53 \%$ drop for group $C$.

Table 18. Steelhead (94) keel comparison between first time spawning in 2007 and kelt spawning in 2009.

\begin{tabular}{|c|c|c|c|c|c|c|}
\hline spawn date & Male Group & Keel & $\%$ Keel & spawn date & Keel & $\%$ Keel \\
\hline $3 / 23 / 2007$ & A & $8 / 10$ & 80 & $2 / 24 / 2009$ & $11 / 19$ & $58 \%$ \\
\hline $3 / 23 / 2007$ & B & $8 / 10$ & 80 & $2 / 24 / 2009$ & $13 / 19$ & $69 \%$ \\
\hline $3 / 23 / 2007$ & D & $9 / 10$ & 90 & $2 / 24 / 2009$ & $7 / 19$ & $37 \%$ \\
\hline
\end{tabular}

After spawning the 2007 broodstock, they were isolated from the incoming 2008 brood, based on observations from hatchery staff of the aggressive behavioral interactions between the 2006/2007 brood years. Their concern was that this aggressive behavior between brood years may potentially interfere with the ability for the female kelts to properly remature. In the absence of the remaining 2007 kelt's ability to remature in 2008 she was placed with the 2008 and 2009 brood fish in the fall of 2008. It was determined that placing these differing broods together should mimic the interaction that would be occurring within rivers. While there are a number of factors that prime sexual maturity in 
steelhead (e.g. temperature, diel patterns, nutritional, and genetic) placing steelhead kelts with incoming brood fish may contribute towards kelt sexual maturation via behavioral or hormonal cues (priming pheromones).

\section{Summary}

Data are very limited but suggest that artificial reconditioning does not negatively affect reproductive success in terms of egg quantity, quality, and progeny survival. Sample sizes should increase in the coming year and allow for statistical comparisons to be made to quantify comparisons between maiden spawning and artificially reconditioned spawning. 


\section{Section 3: Reproductive Success}

\section{Introduction}

The reproductive success of long-term reconditioned kelts needs to be explored to assess the net benefit of this program. Specific questions regarding the success of artificially reconditioning kelt steelhead include: do reconditioned kelts produce viable offspring that contribute to recruitment, how does kelt reproductive success compare with natural first time spawners, and how does kelt reproductive success compare with hatchery origin spawners? We will utilize microsatellite DNA markers and pedigree analysis to help us answer these questions. The answers to these questions will be important in determining if kelt reconditioning is a viable restoration tool that will aid in the recovery of ESA listed steelhead populations in the Columbia River Basin.

$\mathrm{H}_{\mathrm{o}}$ : Reproductive success among natural-origin, hatchery-origin, and reconditioned kelt steelhead is equal within and among streams.

\section{METHODS}

Anadromous adults were collected via an adult trap at a semi-permanent weir on Omak Creek. A PIT tag antennae array was also operated upstream of the confluence with the Okanogan River. Juveniles were collected with a screwtrap during the spring and with electrofishing techniques during the fall. Although residents were the target of electrofishing efforts, it was expected that progeny of the anadromous adults would also be sampled. Collection sites included both below and above Mission Falls, a partial barrier to migration. In 2008 samples above Mission Falls were collected at locations near Haley creek, and Lobe Road.

Three reconditioned kelts were released in October 2005, one male and two female. One of the females was detected at the PIT tag antennae on 23 March 2006 and again on 17 April 2006, but was not processed at the adult trap. The male was processed on 30 March 2006 at the adult trap, having passed the PIT tag antennae undetected. The second female was not detected after the October release. While two of the three kelts were not detected above the picket weir, their return and contribution to spawning in Omak Creek cannot be ruled out as weir operations in 2006 were subject to disturbances from high water flows. Additionally, spawning may have taken place below the picket weir and even below the screwtrap without an adult being sampled. Genetic sampling of juveniles in Omak Creek was preferentially targeted at age 1 fish in 2007 and 
Age 2 fish in 2008 to increase the chance of detecting the progeny of the reconditioned kelts that returned to spawn in 2006.

Eight reconditioned kelts were released into the Okanogan River in October 2007, four from Bonaparte Creek, and four from Omak Creek. The first was recaptured in Omak Creek on April $10^{\text {th }}$, passed upstream and captured again on May $3^{\text {rd }}$ after spawning. After the second capture, it was taken to the hatchery for reconditioning. The second was captured April $26^{\text {th }}$, having already spawned below the weir and was also taken to the hatchery for reconditioning. Prior to their capture, both fish were observed directly below the weir where up to 15 heavily superimposed redds were detected. Fry from these redds were sampled as they emerged after hatching. An additional male was detected by the PIT tag antennae, but was not observed at the adult trap.

None of the four reconditioned kelts from Bonaparte Creek were detected again. Both Bonaparte and Omak creeks had low water flows in March of 2008. In particular for Bonaparte Creek, fish that returned early were unable to migrate through the lower reaches of the stream and were thought to have subsequently spawned in the mainstem Okanogan River.

Samples were collected and stored in ethanol for preservation of DNA. Genetic analysis was conducted at the Hagerman Fish Culture Experiment Station in Hagerman, ID. DNA was extracted from tissue samples using standard manufacture's protocols from Qiagen ${ }^{\circledR}$ DNeasy ${ }^{\mathrm{TM}}$ extraction kit. The polymerase chain reaction (PCR) was used to amplify 16 microsatellite loci; Ogo 4 (Olsen et al. 1998), Oki 23 (GenBank Accession \#AF272822), Omm 1036 (GenBank Accession \#AF346686), Omm 1046 (GenBank Accession \#AF346693), Oke 4 (Buchholz et al. 1999), Omy 1001, Omy 1011 (P. Bentzen pers. comm.), Omy 7 (K.Gharbi, pers. comm.), One 102 (Olsen et al. 2000), One u14 (Scribner et al. 1996), Ots 100 (Nelson and Beacham 1999), Ots 3M (Greig and Banks 1999), Ots 4 (Banks et al. 1999), Ssa 289 (McConnell et al. 1995), Ssa 407 and Ssa 408 (Cairney et al. 2000). Genotypes from thirteen of the microsatellites are standardized over multiple labs (Stephenson et al. in press). PCR products were genotyped using manufacture's protocols with an Applied Biosystems ${ }^{\circledR}$ model 3730 genetic analyzer and scored using Genemapper v3.7 Software.

Prior to statistical analysis, confirmed duplicate samples, samples with incomplete genotypes and non-target species samples were omitted, and are not included in the results. Expected and observed heterozygosity were calculated using Excel Microsatellite Toolkit (Park 2001). The number of alleles and allelic richness were calculated using HP-Rare (Kalinowski 2005). Although actual sample sizes of some populations were lower, gene number was set at 21 . Deviation from Hardy-Weinberg equilibrium and genotypic linkage disequilibrium between all pairs of loci was evaluated using exact tests (Haldane 1954, Weir 1990, Guo and Thompson 1992) implemented in GENEPOP v3.4 (Raymond and Rousset 1995). Corrections to the significant value were made using the 
Bonferroni method (Rice, 1989). Parentage analysis was performed using CERVUS v 3.0 (Marshall et al. 1998, Kalinowski et al. 2007) without incorporation of fish gender.

To help infer population structure in Omak Creek, the program STRUCTURE v.2.0 (Pritchard et al. 2000, Falush et al. 2003) was used. Aside from the known adult anadromous steelhead, samples in Omak Creek were expected to be mixed collections of the anadromous steelhead juveniles and resident populations. Potential population numbers $(\mathrm{K})$ from one to ten were tested. Lacking strong support for $\mathrm{K}$ greater than two, assignment results are reported for two putative populations. The group containing the majority of anadromous adult steelhead was labeled the anadromous population, and the alternative group the resident population. Results are reported for assignment probabilities of both 0.70 and 0.90 or greater.

Parentage data, when successful, was used to assign ages to juveniles. Length of known age juveniles captured at the screwtrap was then plotted in length histograms. To eliminate variation between years, separate histograms were created for 2007 and 2008 sampling years. To discriminate between first time and reconditioned kelt spawning events, juveniles assigning to reconditioned kelts were compared to the length histogram of the known age fish.

\section{RESULTS}

Statistical analysis was performed on 1,693 samples collected in Omak and Bonaparte creeks between 2004 and 2008. Sample numbers and population statistics are reported for each sample collection in Table 19. Departures from Hardy-Weinberg equilibrium (critical level $=0.05 / 16$ loci $=0.00313$ ) and or linkage disequilibrium (critical level $=0.05 / 120$ pairwise comparisons $=0.00042$ ) were seen in most population collections, commonly as a heterozygote deficit. Additional statistical analysis proceeded as normal as population admixture is not unexpected, and Hardy-Weinberg equilibrium is not needed for the additional analyses completed. 
Table 19. Population Statistics. Each collection is reported in terms of sample size (n), expected heterozygosity $\left(H_{E}\right)$, observed heterozygosity $\left(H_{O}\right)$, average number of alleles per locus (A), allelic richness (AR), number of loci out of Hardy-Weinberg equilibrium (HW), and number of pairwise loci comparisons showing linkage disequilibrium (LD).

\begin{tabular}{lrrrrrrrr}
\hline Collection & Year & $\mathrm{n}$ & $\mathrm{E}$ & $\mathrm{HO}$ & $\mathrm{A}$ & $\mathrm{AR}$ & $\mathrm{H}-\mathrm{W}$ & $\mathrm{LD}$ \\
\hline Omak Anadromous & 2004 & 89 & 0.8117 & 0.8110 & 12.1 & 5.4 & 11 & 82 \\
Omak Anadromous & 2005 & 104 & 0.8149 & 0.7932 & 13.5 & 5.5 & 1 & 19 \\
Omak Anadromous & 2006 & 89 & 0.8166 & 0.8118 & 13.6 & 5.6 & 0 & 3 \\
Omak Anadromous & 2007 & 70 & 0.8273 & 0.8153 & 13.6 & 5.7 & 0 & 7 \\
Omak Anadromous & 2008 & 50 & 0.8147 & 0.8075 & 13.4 & 5.6 & 0 & 1 \\
Bonaparte Anadromous & 2006 & 11 & 0.8135 & 0.8443 & 7.9 & 5.5 & 0 & 0 \\
Bonaparte Anadromous & 2007 & 59 & 0.8233 & 0.8167 & 12.8 & 5.7 & 1 & 3 \\
Bonaparte Anadromous & 2008 & 28 & 0.8181 & 0.8000 & 10.9 & 5.6 & 0 & 3 \\
Omak above falls & 2005 & 21 & 0.8328 & 0.7796 & 10.0 & 5.6 & 0 & 0 \\
Omak above falls & 2006 & 45 & 0.7676 & 0.7904 & 9.7 & 4.8 & 2 & 13 \\
Omak above falls-Haley & 2008 & 25 & 0.8079 & 0.7660 & 9.7 & 5.3 & 0 & 0 \\
Omak above falls-Lobe & 2008 & 67 & 0.7260 & 0.7148 & 10.1 & 4.5 & 2 & 11 \\
Omak below falls & 2005 & 78 & 0.8270 & 0.7999 & 12.3 & 5.5 & 8 & 63 \\
Omak below falls & 2006 & 93 & 0.8443 & 0.8098 & 13.8 & 5.9 & 3 & 18 \\
Omak below falls & 2007 & 93 & 0.8437 & 0.8322 & 14.4 & 5.9 & 1 & 8 \\
Omak below falls & 2008 & 43 & 0.8300 & 0.8196 & 12.1 & 5.6 & 1 & 17 \\
Omak Screwtrap & 2006 & 96 & 0.8386 & 0.7968 & 13.9 & 5.7 & 7 & 26 \\
Omak Screwtrap & 2007 & 278 & 0.8263 & 0.8115 & 15.7 & 5.7 & 10 & 45 \\
Omak Screwtrap & 2008 & 326 & 0.8285 & 0.8202 & 15.8 & 5.7 & 9 & 35 \\
Omak Fry & 2008 & 28 & 0.7476 & 0.7716 & 8.1 & 4.8 & 1 & 22 \\
\hline
\end{tabular}

Structure results supported multiple populations with the largest change in LN probability of data between $\mathrm{K}$ values of 1 and 2 (Figure 17). While the LN probability continued to increase with $\mathrm{K}$ values greater than 2 , the relative increases were minor and do not provide compelling evidence of further population substructure 


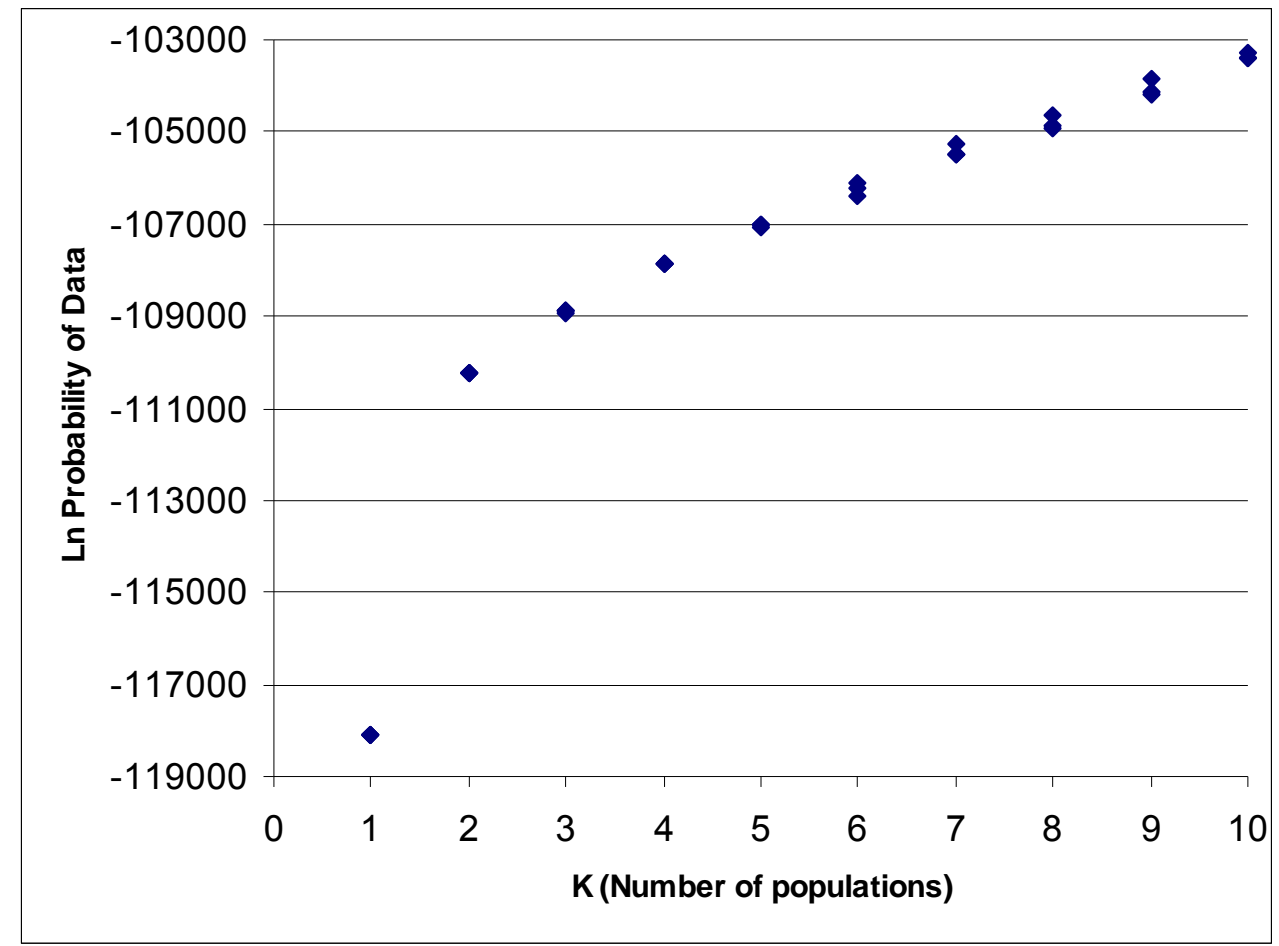

Figure 17. Ln Probability of Data. For each value of $K=1-10$, three In Probability values are graphed. The large increase between $K=1$ and $K=2$ is considered to be the only one of significant interests.

Structure results for two populations $(\mathrm{K}=2)$ are shown in Figure 18. To further quantify the relationships between collections, the percentage assigning to each group are listed in Table 20. Results are reported for both a cutoff value of 0.70 and 0.90 . Using the 0.90 cutoff, self assignment values varied from 0.94 to 0.99 for known anadromous collections. 


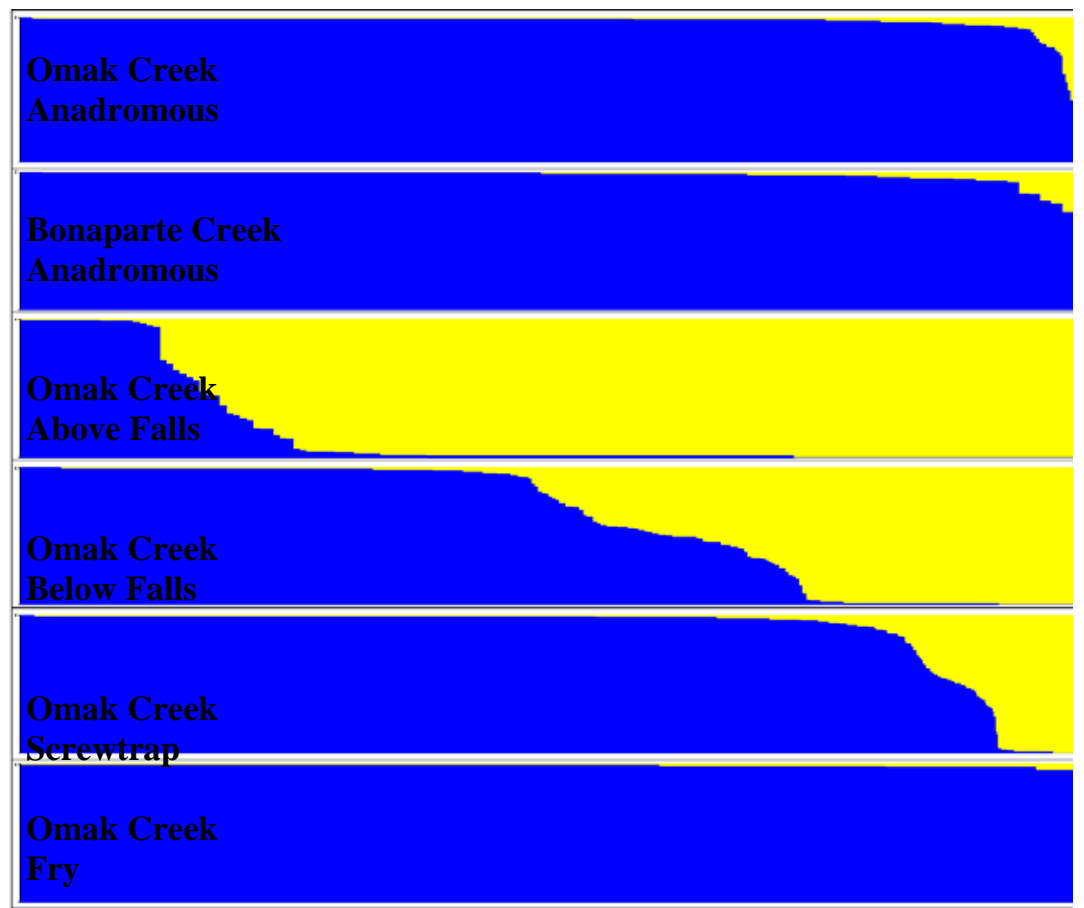

Figure 18 Graphical representations of structure results with $\mathrm{K}=2$. The inferred ancestry of each individual is shown as blue (Anadromous), yellow (Resident), or as a portion of both. Results for each site are condensed across all years 
Table 20. Population assignments by structure. Percentage of each collection assigning to the group labeled as anadromous (Anad), Resident (Res), or Mixed. Mixed is defined as having intermediate values of less than 0.90 or 0.70 for both the anadromous and resident groups.

\begin{tabular}{lcrrrrrrr} 
& \multicolumn{4}{c}{0.90 cutoff } & \multicolumn{4}{c}{0.70 cutoff } \\
Collection & Year & Anad & Res & Mixed & Anad & Res & Mixed \\
\hline Omak Anadromous & 2004 & 0.98 & 0.00 & 0.02 & 0.99 & 0.00 & 0.01 \\
Omak Anadromous & 2005 & 0.98 & 0.00 & 0.02 & 1.00 & 0.00 & 0.00 \\
Omak Anadromous & 2006 & 0.99 & 0.00 & 0.01 & 1.00 & 0.00 & 0.00 \\
Omak Anadromous & 2007 & 0.94 & 0.00 & 0.06 & 0.99 & 0.00 & 0.01 \\
Omak Anadromous & 2008 & 0.88 & 0.00 & 0.12 & 0.96 & 0.00 & 0.04 \\
Bonaparte Anadromous & 2006 & 0.91 & 0.00 & 0.09 & 1.00 & 0.00 & 0.00 \\
Bonaparte Anadromous & 2007 & 0.95 & 0.00 & 0.05 & 1.00 & 0.00 & 0.00 \\
Bonaparte Anadromous & 2008 & 0.96 & 0.00 & 0.04 & 1.00 & 0.00 & 0.00 \\
Omak above falls & 2005 & 0.52 & 0.33 & 0.14 & 0.57 & 0.38 & 0.05 \\
Omak above falls & 2006 & 0.00 & 0.87 & 0.13 & 0.00 & 0.87 & 0.13 \\
Omak above falls-Haley & 2008 & 0.24 & 0.64 & 0.12 & 0.24 & 0.72 & 0.04 \\
Omak above falls-Lobe & 2008 & 0.06 & 0.82 & 0.12 & 0.06 & 0.90 & 0.04 \\
Omak below falls & 2005 & 0.53 & 0.28 & 0.19 & 0.56 & 0.31 & 0.13 \\
Omak below falls & 2006 & 0.47 & 0.31 & 0.22 & 0.55 & 0.32 & 0.13 \\
Omak below falls & 2007 & 0.60 & 0.14 & 0.26 & 0.62 & 0.18 & 0.19 \\
Omak below falls & 2008 & 0.19 & 0.35 & 0.47 & 0.23 & 0.37 & 0.40 \\
Omak Screwtrap & 2006 & 0.63 & 0.19 & 0.18 & 0.68 & 0.20 & 0.12 \\
Omak Screwtrap & 2007 & 0.83 & 0.09 & 0.08 & 0.86 & 0.09 & 0.05 \\
Omak Screwtrap & 2008 & 0.85 & 0.02 & 0.13 & 0.90 & 0.03 & 0.07 \\
Omak Fry & 2008 & 1.00 & 0.00 & 0.00 & 1.00 & 0.00 & 0.00 \\
\hline
\end{tabular}

Figure 19 shows histograms for age one and age two fish collected at the screwtrap in spring of 2007 and 2008. While there was length overlap between age classes, it occurred at a low frequency. Three juveniles collected at the screwtrap in 2007 were progeny of the male first spawning in 2005 and again as a reconditioned kelt in 2006. At sizes of 97,103 and $135 \mathrm{~mm}$, these juveniles were consistent with the age one size class, therefore the result of the second spawning event. In 2008 two additional juveniles were assigned to the reconditioned male. At sizes of 152, 182 and 193mm, they now represent age 2 progeny of the second spawning event. 

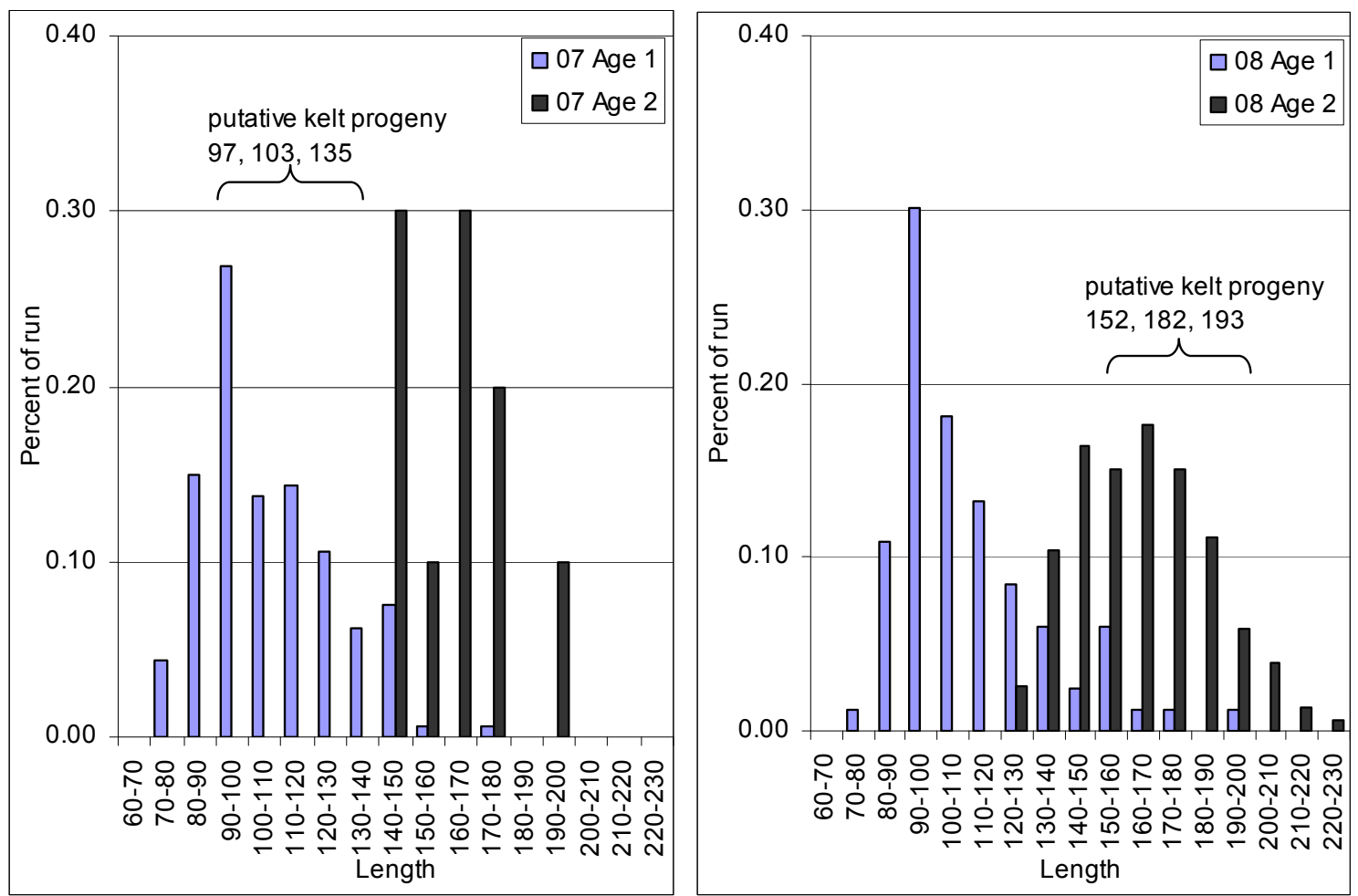

Figure 19. Length Frequency Histograms for fish sampled in 2007 and 2008. Percent of run for each length classes is reported for known age (via parentage) juveniles captured in the screwtrap. Range of putative kelt progeny is displayed to demonstrate relationship with known age fish.

An additional juvenile in 2008 matched both the female that was detected at the PIT tag antennae in 2006 and a second female listed as having been passed upstream of the weir. Either the second female was incorrectly sexed, or this is a mis-assignment from genetic data.

Of the 28 samples collected as emergent fry, at least one parent was assigned to 26. Of these, one was assigned to a female reconditioned kelt. After exhibiting spawning behavior below the weir, this fish was captured and released above the weir. It was captured again moving downstream and taken to the hatchery for reconditioning. No progeny were assigned to the second female that was captured after spawning below the weir. The remaining samples assigned to a first time female $(n=20)$ or to only the male parent $(n=5)$. Fourteen of the twenty fish assigned to a first time female were assigned to a stray female with Chewuch Hatchery PIT tag records. 


\section{DISCUSSION}

Departures from Hardy-Weinberg equilibrium and linkage disequilibrium were common in Omak Creek collections. In juvenile collections this is easily explained by the presence of both the anadromous and resident component of $O$. mykiss. While no reference collection of adult residents is available, results from population assignment tests support the presence of multiple populations, with the majority of samples upstream of Mission Falls being assigned to the putative resident collection

In adult collections, departures from Hardy-Weinberg equilibrium, and evidence of linkage disequilibrium is also seen. This can be partially explained by the recent re-introduction of steelhead into Omak Creek, and high rates of straying into Omak Creek as evidenced by PIT tag detections. Anadromous stocks in Omak Creek were almost non-existent since the early 1900's. Large scale habitat improvements and barrier removals now allow access to Omak Creek, with only a partial barrier at Mission Falls. Still, the majority of fish that have returned to Omak Creek are probably mixtures of hatchery origin adults. In 2003 it was estimated that two thirds of the fish were of hatchery origin (Fisher and Arterburn 2004), and in 2005 only five individuals (112 fish trapped) were observed to have an adipose fin (Arterburn et al. 2005). Additionally the system as a whole has seen major disturbances in the form of fish kills following fire retardant drops in both 2001 and 2003. These disturbances may have led to recent interbreeding between the anadromous and resident forms after disturbance to natural breeding systems. The pattern of intermediate assignment values commonly seen in samples collected below Mission Falls would be consistent with gene flow or interbreeding.

Population self assignment rates were high for anadromous adults with over $99 \%$ of samples assigning to the group subsequently labeled anadromous. Although resident samples were only collected as unknowns, the high consistency with which anadromous adults were assigned to as single group supports divergence of both anadromous and resident populations. As Mission Falls is a potential barrier to upstream migration of anadromous adults, fish collected above the falls are more likely to be derived from the resident component. Prior to 2005 when 12 redds were detected above the falls, Redds were recorded in only one year (Arterburn et al. 2005). While both parentage and population assignments show anadromous juveniles above the falls, this may be the result of hatchery stocking. Stocking in Stapaloop creek, a tributary to Omak Creek, was done as early as 1999 (Fisher and Arterburn 2004) and more recently in 2006 and 2008.

Reproduction by reconditioned kelts has now been confirmed for two individuals. The single male reconditioned kelt that passed above the Omak Creek picket weir in 2006 successfully spawned with progeny detected in both 2007 as age 1 and 2008 as age 2. One of the females observed below the weir was also shown to have reproduced by the single emergent fry assigned to it. 


\section{Section 4: Genetic Analysis of Yakima Subbasin Oncorhynchus mykiss}

\section{INTRODUCTION}

Genetic analysis of Yakima basin populations was performed to determine population structure as it relates to steelhead kelts. This effort expands on previous Oncorhynchus mykiss genetic work in the Yakima basin (Campton and Johnston 1985, Busack et al. 2006) in an attempt to identify the most favorable sites to perform kelt reproductive success. While kelt reconditioning is currently being done in the Yakima River, the reproductive success of post reconditioned kelts has not yet been shown. Tributaries to the Yakima River that produce a proportionally larger number of kelts will be targeted as sites for reproductive success studies.

\section{METHODS}

Anadromous adults migrating to spawning grounds were sampled at Prosser Dam and captured as kelts at the Chandler Juvenile Evaluation Facility. Adult collections were analyzed separately by year of collection and by collection type (putative first time spawners at Prosser or Kelts at Chandler trap. Juveniles were collected with a screw trap during the spring and electrofishing techniques during the fall. Juvenile samples were collected for five primary tributaries of the Yakima River: Ahtanum Creek, Teanaway Creek, Toppenish Creek, Satus Creek and Naches River. Within the Naches River, additional samples were collected at N.F. Little Naches River, Nile Creek, Pileup Creek, Little Rattlesnake Creek, and Quartz Creek. All collections were conducted for at least a two year time period.

Samples were collected and stored in ethanol for preservation of DNA. Genetic analysis was conducted at the Hagerman Fish Culture Experiment Station in Hagerman, ID. DNA was extracted from tissue samples using standard manufacturer's protocols from Qiagen ${ }^{\circledR}$ DNeasy ${ }^{\mathrm{TM}}$ extraction kit. The polymerase chain reaction (PCR) was used to amplify 16 microsatellite loci; Ogo 4 (Olsen et al. 1998), Oki 23 (GenBank Accession \#AF272822), Omm 1036 (GenBank Accession \#AF346686), Omm 1046 (GenBank Accession \#AF346693), Oke 4 (Buchholz et al. 1999), Omy 1001, Omy 1011 (P. Bentzen pers. comm.), Omy 7 (K.Gharbi, pers. comm.), One 102 (Olsen et al. 2000), One u14 (Scribner et al. 1996), Ots 100 (Nelson and Beacham 1999), Ots 3M (Greig and Banks 1999), Ots 4 (Banks et al. 1999), Ssa 289 (McConnell et al. 1995), Ssa 407 and Ssa 408 (Cairney et al. 2000). Genotypes from thirteen of the microsatellites are standardized over multiple labs. (Stephenson et al. in press). PCR products were 
genotyped using manufacturer's protocols with an Applied Biosystems ${ }^{\circledR}$ model 3730 genetic analyzer and scored using Genemapper v3.7 Software.

Ninety six SNPs (single nucleotide polymorphisms) loci were genotyped using a Fluidigm EP1 instrument in conjunction with Biomark Genotyping analysis software. The loci genotyped were recently developed by different labs and are not all published. SNPs developed by Columbia River Inter-Tribal Fish Commission include: Omy_aldB-165, Omy_aldB-414, Omy_arp-630, Omy_aspAT-123, Omy_aspAT-413, Omy_cox1-221, Omy_gdh-271, Omy_gh334, Omy_gh-475, Omy_myo1a-264, Omy_myo1b-111, Omy_myoD-178, Omy_NaKATPa3-50, Omy_nkef-241, Omy_nkef-308, Omy_nramp-146, Omy_Ogo4-212, Omy_Ots208-138, Omy_Ots249-227 (Campbell et al. 2009), and unpublished markērs Omy_hsc713-453, Omy_hsc715-80, Omy_hsf1b-241, Omy_hsf2-146, Omy_hsp47-86, Omy_hsp70aPro-329, Omy_hsp90BA-193, Omy_hsp90BA-229, Omy_mapK3-103, Omy_myclarp404-111, Omy_myclgh1043-156 and Omy_Omyclmk436-96. SNPs developed by Southwest Fisheries Science center include: Omy_113490-159, Omy_114315438, Omy_121006-131, Omy_121713-115, Omy_123044-128, Omy_123048119, Omy_126278-43, Omy_127236-583, Omy_128693-455, Omy_130295-98, Omy_130524-160, Omy_187760-385, Omy_95489-239, Omy_96222-125, Omy_97077-73, Omy_97660-230, Omy_97865-196, Omy_97954-618 (Aguilar and Garza 2008), and unpublished markers Omy_113490-159, Omy_114315438, Omy_121006-131, Omy_121713-115, Omy_123044-128, Omy_123048119, Omy_126278-43, Omy_127236-583, Omy_128693-455, Omy_130295-98, Omy_130524-160, Omy_187760-385, Omy_95489-239, Omy_96222-125, Omy_97077-73, Omy_97660-230, Omy_97865-196 and Omy_97954-618. SNPs developed by UC Davis include: Omy_b1-266, Omy_b9-164, Omy_crb-106, Omy_e1-147, Omy_g1-103, Omy_Idh-156, Omy_OmyP9-180, Omy_R0917-230, Omy_R1175-137, Omy_rapd-132 and Omy_rapd-167 (Sprowles et al. 2006). SNPs developed by Washington Department of Fish and wildlife include unpublished markers: Omy_BAC-B4-126, Omy_BAC-B4-324, Omy_u07-79-166. SNPs developed by Washington State University include: Omy_LDH-B2 and Omy_sSOD-1 (Brunelli et al. 2008), and unpublished markers Ōmy_aromat-280, Omy_cd28-130, Omy_cd59-206, Omy_cd59b-112, Omy_colla1-525, Omy_cox2335, Omy_cxcr-169, Ōmy_g12-82, Omy_gsdf-291, Omy_IL17-185, Omy_IL1b163, Omy_IL6-320, Omy_inos-97, Omy_mcsf-268, Omy_mcsf-371, Omy_nach200, Omy_oxct-85, Omy_star-206, Omy_stat3-273, Omy_tgfb-207, Omy_tlr3-377 and Omy_tlr5-205.

All 112 loci (16 microsatellites plus 96 SNPs) were initially examined using a subsample of 70-75 samples from each tributary. Departures from HardyWeinberg equilibrium and genotypic linkage disequilibrium between all pairs of loci was evaluated using exact tests (Haldane 1954, Weir 1990, Guo and Thompson 1992) implemented in GENEPOP v3.4 (Raymond and Rousset 1995). 
Of the total 112 loci genotyped in this study, 21 were removed from further statistical analyses due to either low polymorphism, deviation from HardyWeinberg equilibrium, linkage with another marker, or diagnostic for cutthroat species/hybrid identification. Specifically, three loci with heterozygote levels less than 0.05 for all five populations were dropped. Five loci showing significant departures from Hardy-Weinberg equilibrium at three or more of the five populations were dropped. For each of ten pairwise comparisons showing evidence of linkage disequilibrium at four or more of the five populations, the locus with lower heterozygosity was dropped. Finally, three loci used to indicate cutthroat hybridization were dropped prior to additional analysis. This left 91 remaining loci for further statistical analyses.

Of the 1377 total samples in the study, 167 were removed due to duplicate genotypes, missing data, or hybridization with cutthroat trout. Samples removed by category include the following: duplicate samples $(n=3)$, samples with greater than 4 incomplete genotypes for 16 of the microsatellites or 10 incomplete genotypes for 96 of the SNPs $(n=125)$, and samples with evidence of cutthroat hybridization $(n=39)$. Data for these fish are not included in the statistical analysis, although cutthroat hybridization is reported along with population statistics in Table 1. Six fish were sampled at both Prosser and again at Chandler and were included in the analysis for each collection. This left 1,210 samples remaining for further statistical analyses.

Expected and observed heterozygosity for the remaining 91 loci were calculated using Excel Microsatellite Toolkit (Park 2001). Number of alleles, allelic richness and private allelic richness for the 16 microsatellites were calculated using HPRare (Kalinowski 2005). For rarefaction estimates, gene number was set at 21 which was the lowest number of samples in any collection. Hardy-Weinberg equilibrium and genotypic linkage disequilibrium between all pairs of loci was reevaluated (after removing poor samples and problematic loci) using exact tests (Haldane 1954, Weir 1990, Guo and Thompson 1992) implemented in GENEPOP v3.4 (Raymond and Rousset 1995). The number of loci showing heterozygote excess or deficiency was also quantified (Rousset and Raymond 1995). Corrections to significant values were not made as the large number of comparisons makes corrections difficult to apply. Results are, however, reported as both the number and proportion of significant findings to help demonstrate true significance.

To help infer population structure, the program STRUCTURE v.2.0 (Pritchard et al. 2000, Falush et al. 2003) was used. Aside from the known adult anadromous steelhead, samples may include mixed collections of the anadromous steelhead juveniles and resident populations. Potential population numbers $(K)$ from one to ten were tested.

Genetic Mixture analysis and individual assignment tests were performed using methods reported in Anderson et al. (2008) as implemented in the software 
program ONCOR. In order to test the performance of the baseline samples for accurate stock assignment, known samples and collections were re-sampled from the baseline, treated as unknowns, and assigned to stocks. After estimates of baseline accuracy were determined, samples from mixed stock collections at Prosser and Chandler traps were then assigned to baseline stocks. Stock estimates were completed on both a proportional and individual basis.

\section{RESULTS}

Statistical analysis was performed on 1210 samples. Basic population statistics are reported in Table 21. The number of samples per population ranged from 21 to 160 , with a minimum of 76 samples for each of the five primary tributaries.

Average number of alleles across the microsatellite loci varied from a low of 8.63 in Pileup Creek to a high of 16.31 in Prosser 2007. Allelic richness was lowest in Toppenish Creek at 6.62 and highest in Prosser 2007 at 8.34. Cutthroat alleles were seen in nine of the collections. Teanaway had the highest incidence with 15 samples showing evidence of either introgression or sampling of a pure cutthroat trout.

Table 21. Population Statistics. Each collection is reported in terms of sample size (n), number of samples removed due to evidence of cutthroat sampling or introgression (cut), number of microsatellite alleles (A), microsatellite allelic richness (AR), microsatellite private allelic richness (PAR), expected heterozygosity $\left(H_{E}\right)$, and observed heterozygosity $\left(H_{O}\right)$, average number of alleles per locus $(A)$, allelic richness (AR), number of loci out of Hardy-Weinberg equilibrium (HW), and number of pairwise loci comparisons showing linkage disequilibrium (LD).

\begin{tabular}{lrcrclll}
\hline & \multicolumn{1}{c}{$\mathbf{n}$} & cut & \multicolumn{1}{c}{$\mathbf{A}$} & AR & PAR & $\mathbf{H}_{\mathrm{E}}$ & $\mathbf{H}_{\mathbf{O}}$ \\
\hline Ahtanum & 144 & 3 & 14.81 & 8.20 & 0.2160 & 0.3606 & 0.3515 \\
Teanaway & 76 & 15 & 12.13 & 7.70 & 0.2276 & 0.3408 & 0.3372 \\
Toppenish & 153 & 2 & 12.69 & 6.62 & 0.1317 & 0.2948 & 0.2896 \\
Satus & 76 & 0 & 12.25 & 7.30 & 0.1332 & 0.3155 & 0.3191 \\
Naches & 136 & 3 & 14.50 & 7.95 & 0.1710 & 0.3432 & 0.3395 \\
N.F. Little Naches & 21 & 1 & 9.25 & 7.48 & 0.0499 & 0.3162 & 0.3153 \\
Nile & 59 & 2 & 11.56 & 7.58 & 0.1544 & 0.3498 & 0.3503 \\
Pileup & 21 & 3 & 8.63 & 7.04 & 0.0478 & 0.3228 & 0.3301 \\
Little Rattlesnake & 46 & 1 & 11.25 & 7.66 & 0.1030 & 0.3384 & 0.3325 \\
Quartz & 26 & 0 & 9.50 & 7.41 & 0.0543 & 0.3432 & 0.3430 \\
Prosser 2000 & 71 & 0 & 13.88 & 7.80 & 0.1594 & 0.3284 & 0.3231 \\
Prosser 2007 & 160 & 3 & 16.31 & 8.34 & 0.2242 & 0.3583 & 0.3356 \\
Kelt 2006 & 90 & 0 & 14.25 & 7.87 & 0.1614 & 0.3306 & 0.3282 \\
Kelt 2008 & 131 & 0 & 15.56 & 8.14 & 0.1771 & 0.3486 & 0.3395 \\
\hline
\end{tabular}


Results for Hardy-Weinberg equilibrium are reported in Table 22. Results are reported for each collection as both the number and proportion of loci with $p \leq 0.05$. Loci out of equilibrium were common, in particular for Ahtanum Creek $(n=15)$ and Prosser $2007(n=16)$. Similar results are seen when testing for a heterozygote deficit, with the highest values at Ahtanum Creek $(n=11)$, Prosser $2007(n=21)$, and Kelt $2008(n=11)$. Minimal evidence is seen for heterozygote excess, with highs of four departures seen in both Toppenish and Satus. Results for linkage disequilibrium are reported in Table 23. The largest number of significant pairwise comparisons are seen in Ahtanum $(n=386)$, Teanaway $(n=377)$, Toppenish $(n=359)$ and Prosser 2007.

Table 22. Hardy-Weinberg equilibrium. Each collection is reported in terms of the number of comparison (comp), the number and proportion of loci showing departures from HardyWeinberg (Probability), and the number and proportion showing evidence of Heterozygote Deficit (Deficit) or Excess (Excess).

\begin{tabular}{lrrrrrrl}
\hline & comp & \multicolumn{2}{l}{ Probability } & \multicolumn{2}{l}{ Deficit } & \multicolumn{2}{l}{ Excess } \\
\hline Ahtanum & 91 & 15 & 0.1648 & 11 & 0.1209 & 3 & 0.0330 \\
Teanaway & 87 & 5 & 0.0575 & 5 & 0.0575 & 1 & 0.0115 \\
Toppenish & 89 & 8 & 0.0899 & 8 & 0.0899 & 4 & 0.0449 \\
Satus & 79 & 3 & 0.0380 & 4 & 0.0506 & 4 & 0.0506 \\
Naches & 89 & 3 & 0.0337 & 5 & 0.0562 & 1 & 0.0112 \\
NFL Naches & 66 & 3 & 0.0455 & 2 & 0.0303 & 2 & 0.0303 \\
Nile & 85 & 9 & 0.1059 & 3 & 0.0353 & 2 & 0.0235 \\
Pileup & 72 & 6 & 0.0833 & 2 & 0.0278 & 3 & 0.0417 \\
L. Rattlesnake & 85 & 5 & 0.0588 & 7 & 0.0824 & 1 & 0.0118 \\
Quartz & 76 & 6 & 0.0789 & 3 & 0.0395 & 0 & 0.0000 \\
Prosser 2000 & 91 & 2 & 0.0220 & 3 & 0.0330 & 0 & 0.0000 \\
Prosser 2007 & 91 & 16 & 0.1758 & 21 & 0.2308 & 1 & 0.0110 \\
Kelt 2006 & 88 & 3 & 0.0341 & 5 & 0.0568 & 0 & 0.0000 \\
Kelt 2008 & 91 & 8 & 0.0879 & 11 & 0.1209 & 1 & 0.0110 \\
\hline
\end{tabular}


Table 23. Linkage Disequilibrium. Each collection is reported in terms of the number of pairwise comparisons made (comp), and the number ( $\mathrm{n}$ ) and proportion (prop) of pairwise comparisons showing evidence of linkage disequilibrium (LD).

\begin{tabular}{lrrr} 
& Comp & n & comp \\
\hline Ahtanum & 4095 & 386 & 0.0943 \\
Teanaway & 4091 & 377 & 0.0922 \\
Toppenish & 4003 & 359 & 0.0897 \\
Satus & 3647 & 146 & 0.0400 \\
Naches & 4004 & 219 & 0.0547 \\
NFL Naches & 2992 & 108 & 0.0361 \\
Nile & 3914 & 220 & 0.0562 \\
Pileup & 2908 & 126 & 0.0433 \\
L. Rattlesnake & 3827 & 216 & 0.0564 \\
Quartz & 3235 & 126 & 0.0389 \\
Prosser 2000 & 4095 & 258 & 0.0630 \\
Prosser 2007 & 4095 & 426 & 0.1040 \\
Kelt 2006 & 4093 & 226 & 0.0552 \\
Kelt 2008 & 4095 & 307 & 0.0750 \\
\hline
\end{tabular}

Pairwise Fst values are shown in Table 24. Number of loci with $p \leq 0.05$ for each pairwise comparison are shown in Table 24. At $p=0.05$ it is expected that 4.55 of 91 loci will be counted as significant by chance alone $(0.05 * 91=4.55)$. The majority of pairwise comparisons have greater than 4.55 loci out of equilibrium demonstrating population differentiation. The average Fst and number of loci with $p \leq 0.05$ is 0.017 and 26.9 respectively. Between the five primary tributaries, Fst $=0.022$ with an average of 45.80 loci out of equilibrium. Within Naches these values are lower at 0.016 and 14.53 . The lowest values are seen when comparing all adult collections with average Fst of 0.003 and 11 loci out of equilibrium. 
Table 24. Pairwise Fst values and number of Loci with $P<0.05$. Fst values greater than 0.02 are highlighted. Number of Loci with $\mathrm{P}<0.05$. For each population pairwise comparison, the number of loci showing evidence of population differentiation is shown. Numbers greater than 25 are highlighted

\begin{tabular}{|c|c|c|c|c|c|c|c|c|c|c|c|c|c|c|}
\hline & $\begin{array}{l}\frac{c}{\infty} \\
\frac{.0}{2} \\
\frac{0}{0} \\
\text { ㅇ }\end{array}$ & 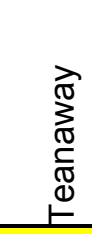 & $\begin{array}{l}\stackrel{\infty}{D} \\
\stackrel{\pi}{\mathbb{N}} \\
\mathscr{N}\end{array}$ & 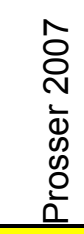 & 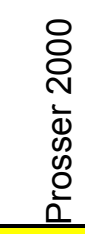 & 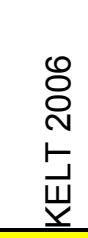 & 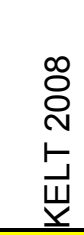 & 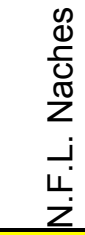 & $\begin{array}{l}\frac{N}{0} \\
\frac{\pi}{3} \\
0\end{array}$ & $\begin{array}{l}\frac{O}{\bar{D}} \\
\frac{0}{\bar{\alpha}}\end{array}$ & $\frac{0}{\bar{z}}$ & 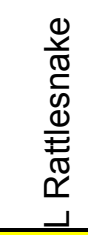 & $\begin{array}{l}0 \\
\frac{0}{0} \\
\tilde{D} \\
\mathcal{D}\end{array}$ & 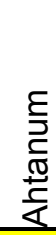 \\
\hline Topponish & & 53 & 44 & 56 & 37 & 39 & 52 & 28 & 40 & 33 & 46 & 45 & 53 & 55 \\
\hline Teanaway & 0.040 & & 46 & 36 & 31 & 41 & 37 & 27 & 30 & 28 & 40 & 35 & 42 & 39 \\
\hline Satus & 0.024 & 0.022 & & 43 & 13 & 8 & 30 & 24 & 28 & 29 & 40 & 36 & 42 & 44 \\
\hline Prosser 2007 & 0.020 & 0.013 & 0.011 & & 10 & 22 & 8 & 15 & 23 & 22 & 25 & 24 & 36 & 25 \\
\hline Prosser 2000 & 0.014 & 0.016 & 0.004 & 0.003 & & 3 & 8 & 16 & 21 & 22 & 23 & 24 & 26 & 20 \\
\hline KELT 2006 & 0.018 & 0.017 & 0.001 & 0.006 & 0.000 & & 15 & 15 & 22 & 24 & 34 & 24 & 31 & 28 \\
\hline KELT 2008 & 0.022 & 0.015 & 0.008 & 0.002 & 0.002 & 0.003 & & 14 & 17 & 21 & 25 & 20 & 33 & 13 \\
\hline NFL Naches & 0.039 & 0.021 & 0.017 & 0.015 & 0.014 & 0.016 & 0.012 & & 11 & 6 & 12 & 11 & 9 & 20 \\
\hline Quartz & 0.042 & 0.028 & 0.027 & 0.018 & 0.018 & 0.019 & 0.017 & 0.017 & & 12 & 17 & 18 & 15 & 22 \\
\hline Pileup & 0.053 & 0.038 & 0.034 & 0.024 & 0.025 & 0.032 & 0.024 & 0.016 & 0.025 & & 18 & 17 & 11 & 25 \\
\hline Nile & 0.035 & 0.023 & 0.020 & 0.009 & 0.015 & 0.015 & 0.008 & 0.016 & 0.015 & 0.027 & & 22 & 18 & 35 \\
\hline L Rattlesnake & 0.034 & 0.021 & 0.018 & 0.011 & 0.013 & 0.013 & 0.009 & 0.017 & 0.020 & 0.027 & 0.013 & & 21 & 30 \\
\hline Naches & 0.032 & 0.018 & 0.016 & 0.008 & 0.009 & 0.011 & 0.007 & 0.008 & 0.011 & 0.014 & 0.007 & 0.009 & & 40 \\
\hline Ahtanum & 0.028 & 0.014 & 0.011 & 0.004 & 0.006 & 0.007 & 0.003 & 0.022 & 0.020 & 0.031 & 0.013 & 0.014 & 0.011 & \\
\hline
\end{tabular}

The relationship of populations is shown in the neighbor joining dendrogram in Figure 20. All Naches tributaries were separated into a single group with a bootstrap value of $79 \%$. Further clustering in Naches is seen with Quartz Creek, Pileup Creek and North Fork Little Naches River. Ahtanum and Teanaway grouped together with a bootstrap of 86 . Satus and Toppenish Grouped together with a bootstrap value of 94 . 


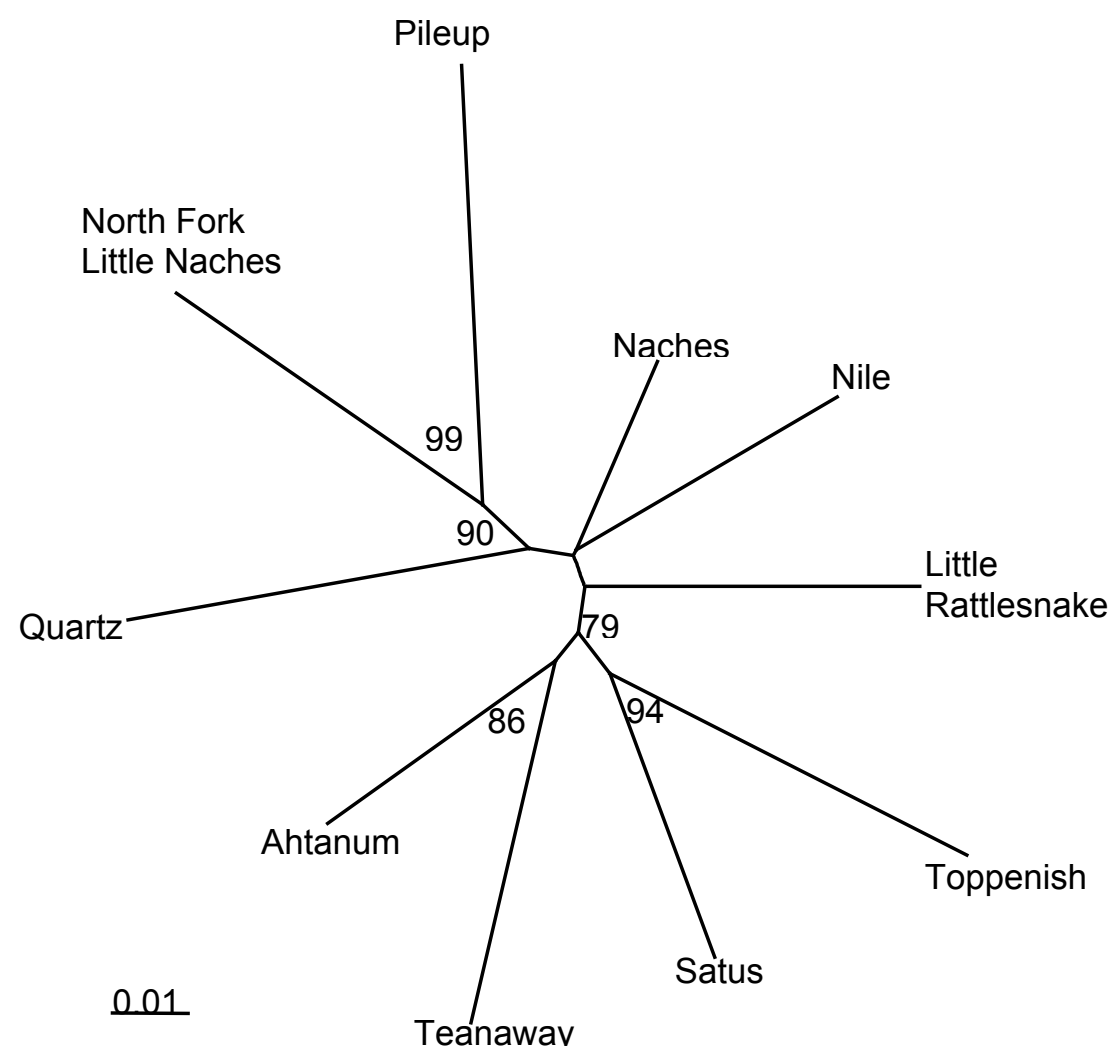

Figure 20. Neighbor joining dendrogram of Cavalli-Sforza Edwards genetic distance among studied populations. Numbers at nodes represent bootstrap percentage from 1000 replicates (only those greater than 50 percent shown).

The estimated number of populations as computed using the program STRUCTURE is shown in Figure 21. The results show a peak when all adults are included, indicative of 3-4 primary populations. There is no clear peak when analyzing all the tributary samples, although the graph appears to plateau around $k=5$, roughly indicating the presence of at least $4-5$ populations. The different results may indicate that not all samples collected as juveniles are represented in the adult collections, as would be expected if resident populations were captured in the tributary sampling efforts. 

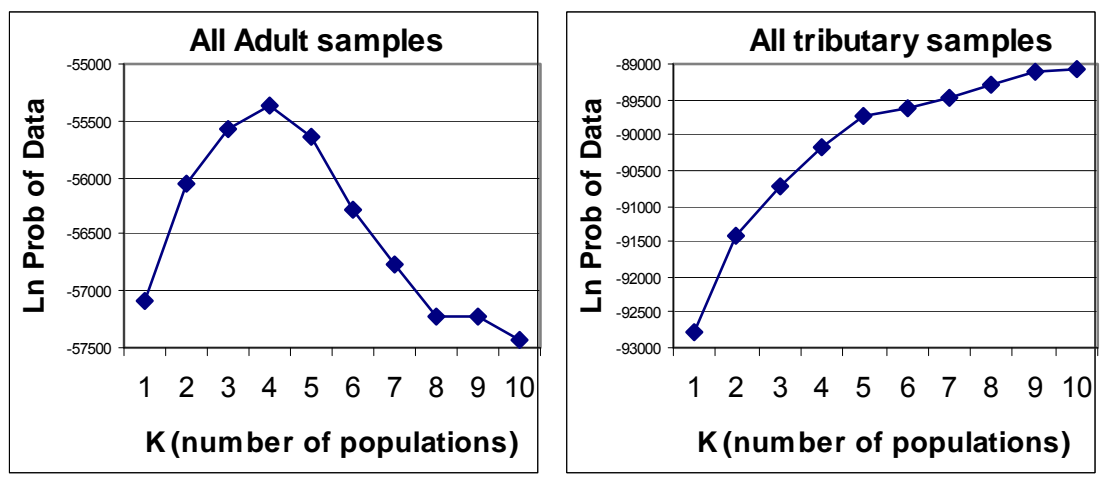

Figure 21. Ln Probability of Data. For each value of $K=1-10$, the average of three In Probability values is graphed.

Individual assignments to reference populations are shown in Table 25.

Assignments are reported back to both collection site and primary tributary with all Naches samples condensed into a single reporting group. After condensing all Naches collections, irregularities are still seen, particularly the 23 samples collected in Ahtanum Creek that mis-assigned to Satus Creek.

Table 25. Individual assignments to reference populations. The number of fish assigning to baseline collections is listed. Each row lists where samples are from. Columns list where individuals were assigned to. Assignments are given for both collection level, and reporting group with all Naches tributaries treated as a single reporting group. Bold numbers are assigned to their population of collection.

\begin{tabular}{|c|c|c|c|c|c|c|c|c|c|c|c|c|c|c|c|c|}
\hline & 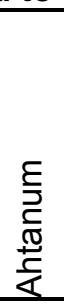 & 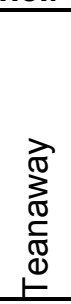 & 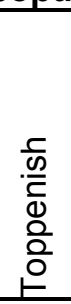 & $\begin{array}{l}\stackrel{\infty}{P} \\
\underset{N}{\mathbb{N}} \\
\stackrel{\infty}{n}\end{array}$ & $\begin{array}{l}0 \\
\frac{0}{U} \\
\frac{0}{0} \\
\mathcal{D}\end{array}$ & 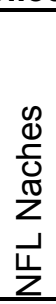 & $\frac{\oplus}{\bar{z}}$ & $\frac{0}{\underline{a}}$ & 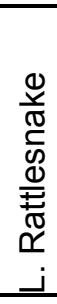 & $\begin{array}{l}\frac{N}{t} \\
\frac{\pi}{3} \\
0\end{array}$ & 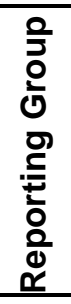 & $\begin{array}{l}\frac{E}{J} \\
\frac{1}{\pi} \\
\stackrel{T}{ \pm} \\
\frac{1}{2}\end{array}$ & 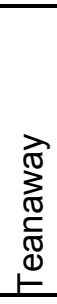 & $\begin{array}{l}\frac{c}{.0} \\
\frac{.0}{\Phi} \\
\frac{0}{0} \\
\stackrel{0}{0} \\
\end{array}$ & $\begin{array}{l}\stackrel{\infty}{P} \\
\stackrel{\pi}{\mathbb{N}} \\
\infty\end{array}$ & $\begin{array}{l}0 \\
\mathbb{d} \\
\\
0 \\
\tilde{\pi} \\
Z\end{array}$ \\
\hline Ahtanum & 57 & 4 & 4 & 23 & 6 & 0 & 1 & 0 & 0 & 0 & & 57 & 4 & 4 & 23 & 7 \\
\hline Teanaway & 5 & 43 & 0 & 0 & 3 & 0 & 0 & 0 & 0 & 0 & & 5 & 43 & 0 & 0 & 3 \\
\hline Toppenish & 4 & 2 & 81 & 2 & 0 & 0 & 0 & 0 & 0 & 0 & & 4 & 2 & 81 & 2 & 0 \\
\hline Satus & 2 & 0 & 1 & 35 & 3 & 0 & 1 & 0 & 0 & 0 & & 2 & 0 & 1 & 35 & 4 \\
\hline Naches & 2 & 0 & 0 & 1 & 55 & 2 & 3 & 3 & 6 & 3 & & 2 & 0 & 0 & 1 & 72 \\
\hline NFL Naches & 0 & 0 & 0 & 2 & 7 & 5 & 1 & 0 & 0 & 0 & & 0 & 0 & 0 & 2 & 13 \\
\hline Nile & 2 & 0 & 0 & 0 & 12 & 0 & 18 & 0 & 0 & 1 & & 2 & 0 & 0 & 0 & 31 \\
\hline Pile & 0 & 0 & 0 & 0 & 2 & 2 & 1 & 2 & 0 & 0 & & 0 & 0 & 0 & 0 & 7 \\
\hline L. Rattlesnake & 1 & 1 & 0 & 3 & 9 & 0 & 1 & 0 & 15 & 1 & & 1 & 1 & 0 & 3 & 26 \\
\hline Quartz & 0 & 0 & 0 & 0 & 8 & 0 & 0 & 0 & 0 & 3 & & 0 & 0 & 0 & 0 & 11 \\
\hline
\end{tabular}

Proportional mixed stock assignment of unknown fish to each of the five primary tributaries is shown in Figure 22. Differences in relative assignment proportions were statistically significant at $p \leq 0.05$ for all pairwise comparisons except Prosser 2000 and Kelt 2008 (Table 26). 

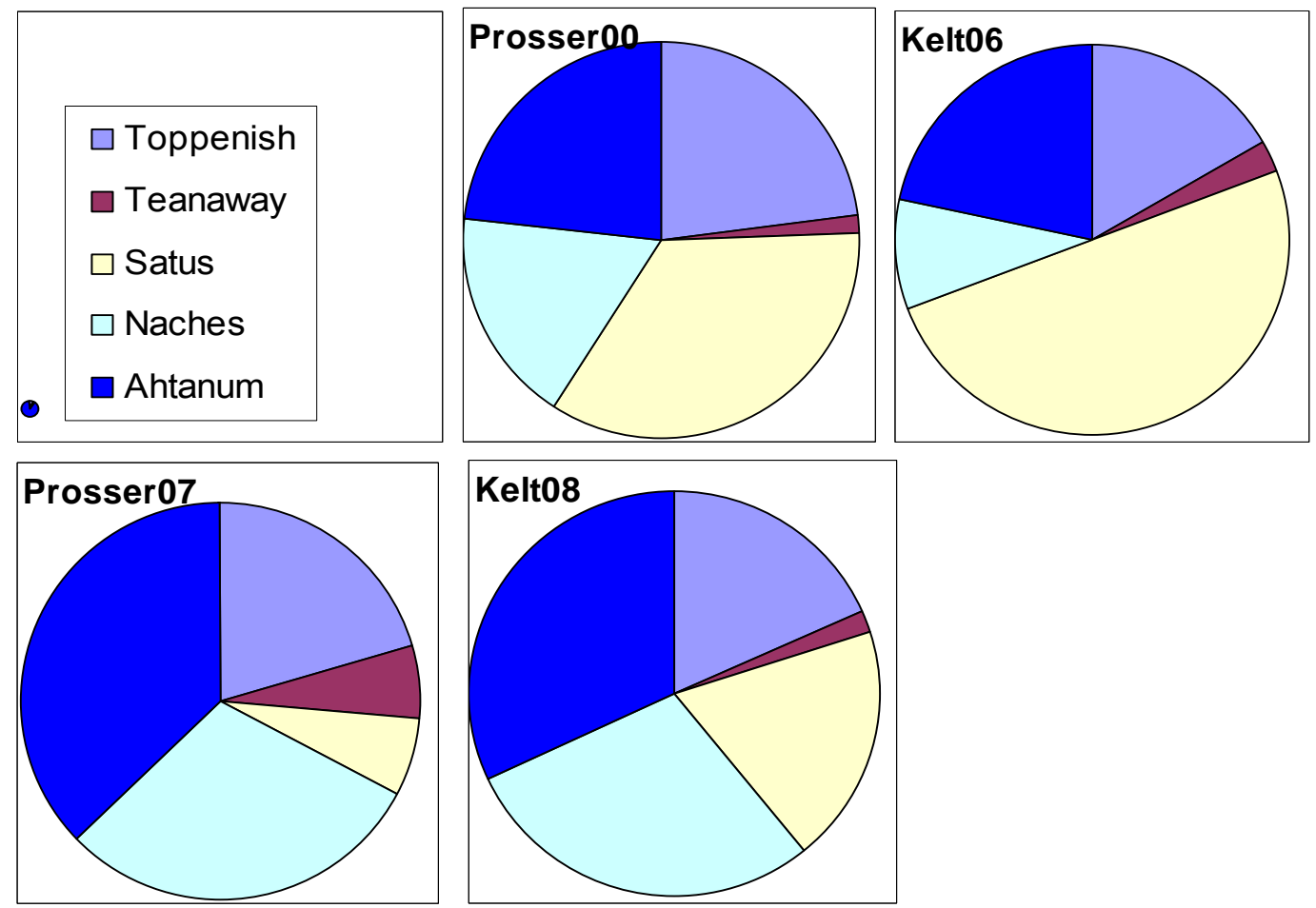

Figure 22. Proportional mixed stock assignments. The percentage of each collection of unknown fish assigned to the reference populations. Unknown fish consist of adults collected at either Prosser Dam during first spawning migration, or as outmigrating kelts at the Chandler fish trap. Reference populations consist of the five tributary collections of juveniles.

Table 26. Chi-squared tests for comparisons between each unknown collection of adult steelhead. P-values for each pairwise comparison are given.

\begin{tabular}{lrrr}
\hline & Prosser07 & Prosser00 & Kelt06 \\
\hline Prosser01 & 0.0000 & & \\
Kelt06 & 0.0000 & 0.0345 & \\
Kelt08 & 0.0000 & 0.0661 & 0.0000 \\
\hline
\end{tabular}

\section{DISCUSSION}

Analysis clearly shows that there are multiple populations of $O$. mykiss in the Yakima basin and that some if not all of the collections contain multiple breeding groups. The differential results when analyzing either all adults are all tributaries with the program STRUCTURE shows all populations present in the tributaries may not be represented in the adult anadromous collections. While there was evidence for only 3-4 populations in the adult samples, there are 4-5 likely populations in the tributaries. This is further supported by the levels of linkage disequilibrium and departures from Hardy-Weinberg equilibrium. While this may be partially explained by the loci used which include previously untested SNP markers, other studies have shown that resident $O$. mykiss are present and that 
introgression may have occurred (Campton and Johnston 1985, Busack et al. 2006).

Most of the collections (especially Ahtanum $\mathrm{Cr}$. and the adult collections) are likely demonstrating the Wahlund effect of a heterozygote deficit, with multiple populations present in a single collection. The most obvious cases of this are in the adult collections that are expected to be mixed collections. Indeed, the highest number of departures from Hardy-Weinberg equilibrium and pairwise comparisons showing patterns of linkage disequilibrium are seen in adults collected at Prosser Dam in 2007.

Self assignment rates using GSI were correct 89.1 percent of the time, supporting divergence between the tributary populations. Pairwise Fst comparisons between the tributaries were also significant. While the program STRUCTURE failed to show evidence of multiple populations within Naches River, other parameters suggest that there may be further sub-structure. However, sample numbers within each tributary of Naches River are small, and results are not conclusive.

As mentioned previously, individual self assignment rates were high. The exception being samples collected in Ahtanum Creek assigned back to Ahtanum Creek only $60 \%$ of the time. Assignment to the other tributaries consisted of 23 samples to Satus Creek, 7 samples to Teanaway Creek, 4 samples to Toppenish Creek and 4 samples to Teanaway Creek. Of the five tributaries, Ahtanum Creek also had the highest number of departures from Hardy-Weinberg equilibrium, and the highest amount of linkage disequilibrium. The cause of these apparent discrepancies is not fully understood, although it is apparent that samples collected within Ahtanum Creek are not from a single population.

Proportional mixed stock assignments of unknown collections at Prosser Dam and Kelts from Chandler trap were done to determine relative proportions for each of the five baseline tributaries. While two years were analyzed for each collection type (first time spawners at Prosser Dam and kelts at Chandler) little is known about the samples collected at Prosser in 2001. Compared to samples collected in 2007, they had lower allelic richness, less evidence of departures from Hardy-Weinberg equilibrium, and less incidences of linkage disequilibrium. These results suggest that not all the tributary populations were represented in the adult samples collected. Additionally, the samples collected in 2007 are not a random selection at Prosser. These samples were a subset of samples for which previous microsatellite analysis was unable to assign a population of origin.

Genetic analysis in the Yakima Basin should be continued in 2009 to confirm and improve upon results of the 2008 study. Several changes will allow for a more complete analysis. It is recommended that additional baseline samples for Satus Creek and Teanaway Creek be included. Alternatively, some samples analyzed in 2008 may have tissue remaining that can be re-extracted for additional 
genotyping. Although the number of samples from Ahtanum Creek is relatively high (144), additional samples, and analysis by collection year should be beneficial. It is also recommended that an additional sampling year for both first time spawners collected at Prosser and kelts collected at Chandler be added, to more closely examine temporal effects. Samples chosen to represent first time spawners should be a random collection to allow stock composition comparison with kelt steelhead.

A more thorough review of the loci used will be completed in 2009. While the microsatellites were well known, the suite of SNP markers is relatively new and has not been broadly genotyped in populations throughout the Columbia River. This study was the first to make use of this combination of SNPs, and issues such as null alleles may not be completely resolved in the current dataset. Additional markers may need to be removed, and some that were omitted from this analysis may be included after additional testing is completed. In particular the markers that were removed due to linkage disequilibrium will be included after the relationship between marker pairs is more clearly understood. To maximize the efficiency of marker selection, the relative power of each marker and marker type will be examined. Many of the samples excluded from analysis in 2008 were due to failures primarily at the microsatellite loci. Whether SNP markers will suffice for GSI purposes will be tested.

Although data is not included in this report, samples from Roza dam were also genotyped as part of a cooperative agreement between CRITFC and WDFW. This collaboration was intended to maximize the use of baseline data, which both agencies would otherwise have to create causing a duplication of effort. Genetic sampling in 2009 will continue this collaboration to maximize the efficiency of both labs. 


\section{References}

Aguilar, A., and C. J. Garza. 2008. Isolation of 15 single nucleotide polymorphisms from coastal steelhead, Oncorhynchus mykiss (Salmonidae). Molecular Ecology Resources 8 659-662.

Anderson, E.C., R.S. Waples, S.T. Kalinowski. 2008 An improved method for estimating the accuracy of genetic stock identification. Canadian Journal of Fisheries and Aquatic Sciences 65:1475-1486.

Arterburn, J., K. Kistler and R. Dasher. 2005. Okanogan Basin Steelhead Spawning Ground Surveys. Colville Confederated Tribes Fish and Wildlife, Anadromous Fish Division, Omak WA.

Bartholomew, J.L., J.S. Rohovec, and J.L. Fryer. 1989. Ceratomyxa shasta, a Myxosporean Parasite of Salmonids. U.S. Fish \& Wildlife Service, National Fisheries Research Center.

Banks, M.A., M.S. Blouin, B.A. Baldwin, and V.K. Rashbrook. 1999. Isolation and inheritance of novel microsatellites in chinook salmon (Oncorhynchus tshawytscha). Journal of Heredity 90:281-288. See erratum May/June 1999 for primer sequence corrections.

Behnke, R.J. 1992. Native trout of western North America. American Fisheries Society Monograph 6.

Bell, G. 1980. The costs of reproduction and their consequences. The American Naturalist 116(1):45-76.

Branstetter R., J. Stephenson, D. Hatch, J. Whiteaker S.Y. Hyun, B. Bosch, D. Fast, J. Blodgett, and T. Newsome, L. Hewlett-Dubisar, J. Graham, J. Lovetang, R. Dasher,C. Fisher, 2008. Steelhead Kelt Reconditioning and Reproductive Success. 2007 Annual Report to U.S. Dept. of Energy, Bonneville Power Administration, Project No. 2007-401-00. Prepared by the Columbia River InterTribal Fish Commission, Portland, OR.

Brunelli, J.P., G.H. Thordaard, R.F. Leary, and J.L. Dunnigan. 2008. Single Nucleotide Polymorphisms Associated with Allozyme Difference between inland and coastal rainbow trout. Transactions of the American Fisheries Society 137:1292-1298.

Buchholz, W., S.J. Miller, and W.J. Spearman. 1999. Summary of PCR primers for salmonid genetic studies. U.S. Fish and Wildlife Service, Alaska Fisheries Progress Report 99-1. 
Busack, C., A. Fritts, T. Kassler, J. Loxterman, T. Pearsons, S. Schroder, M. Small, S.I Young, C. Knudsen, G. Hart, P. Huffman, "Yakima/Klickitat Fisheries Project Genetic Studies; Yakima/Klickitat Fisheries Project Monitoring and Evaluation", 2005-2006 Annual Report, Project No. 199506325, 205 electronic pages, (BPA Report DOE/BP-00022370-5).

Cairney, M., J.B. Taggart, and B. Hoyheim. 2000. Characterization of microsatellite and minisatellite loci in Atlantic salmon (Salmo salar L.) and cross-species amplification in other salmonids. Molecular Ecology 9:2175-2178.

Campbell N., and S. Narum. 2009. Characterization of 22 novel single nucleotide polymorphism markers in steelhead and rainbow trout. Molecular Ecology Resources 9:318-322.

Campton, D.E., and J.M. Johnston. 1985. Electrophoretic evidence for a genetic admixture of native and non-native rainbow trout in the Yakima River, Washington. Trans. Amer. Fish. Soc. 114:782-793.

Cloud, J.G. and C. Osborne. 1997. Cryopreservation of Salmonid Sperm. Department of Biological Sciences, University of Idaho.

Evans, A.F. 2002. Steelhead (Oncorhynchus mykiss) kelt outmigration from Lower Granite Dam to Bonneville Dam: Abundance, downstream conversion rates, routes of passage, and travel times. Annual Report to U.S. Army Corps of Engineers, Walla Walla District, for Contract No. DACW68-01-0016. Prepared by the Columbia River Inter-Tribal Fish Commission, Portland, OR.

Evans, A.F., and R.E. Beaty. 2001. Identification and enumeration of steelhead (Oncorhynchus mykiss) kelts in the juvenile collection systems of Lower Granite and Little Goose dams, 2000. Annual Report to U.S. Army Corps of Engineers, Walla Walla District, for Contract No. DACW-00-R-0016. Prepared by the Columbia River Inter-Tribal Fish Commission, Portland, OR. 
Evans, A.F., R.E. Beaty, D.R. Hatch, J. Blodgett, and D. Fast. 2001. Kelt reconditioning: A research project to enhance iteroparity in Columbia Basin steelhead (Oncorhynchus mykiss). 2000 Annual Report to U.S. Dept. of Energy, Bonneville Power Administration, Project No. 2000-017. Prepared by the Columbia River Inter-Tribal Fish Commission, Portland, OR.

Evans, A.F., R.H. Wertheimer, M.L. Keefer, C.T. Boggs, C.A. Peery, and K. Collis. 2008. Transportation of Steelhead Kelts to Increase Iteroparity in the Columbia and Snake Rivers. North American Journal of Fisheries Management 28:1818-1827, 2008

Falush, D.,M. Stephens and J.K. Pritchard. 2003. Inference of population structure using multilocus genotype data: Linked loci and correlated allele frequencies. Genetics 164:1567-1587.

Fisher, C., and J. Arterburn. 2004. Improvements of anadromous fish habitat and passage in Omak Creek; Includes 2003 steelhead surveys in Omak Creek. 20022003 Annual Report, Project No. 200000100, 23 electronic pages, (BPA Report DOE/BP-00005103-1).

Fleming, I.A. 1998. Pattern and variability in the breeding systems of Atlantic salmon (Salmo salar), with comparisons to other salmonids. Canadian Journal of Fisheries and Aquatic Sciences 55:59-76.

Greig, C. and M.A. Banks. 1999. Five multiplexed microsatellite loci for rapid response run identification of California's endangered winter chinook salmon. Animal Genetics 30:316-324.

Gunsolus, R.T. and G.J. Eicher. 1970. Evaluation of fish-passage facilities at the North Fork project on the Clackamas River in Oregon. Research report to the Fish Commission of Oregon, Oregon Game Commission, United States Bureau of Commercial Fisheries, United States Bureau of Sport Fisheries and Wildlife, and Portland General Electric.

Guo, S.W. and Thompson EA, 1992. Performing the exact test of HardyWeinberg proportions for multiple alleles. Biometrics 48:361-372.

Haldane, J.B.S. 1954. An exact test for randomness of mating. Journal of Genetics 52:631-635.

Hatch, D.R., P.J. Anders, A.F. Evans, J. Blodgett, B. Bosch, D. Fast., and T. Newsome. 2002. Kelt reconditioning: A research project to enhance iteroparity in Columbia Basin steelhead (Oncorhynchus mykiss). 2001 Annual Report to U.S. Dept. of Energy, Bonneville Power Administration, Project No. 2000-017. Prepared by the Columbia River Inter-Tribal Fish Commission, Portland, OR. 
Hatch, D.R., R. Branstetter, and S. Narum. 2003a. Evaluate steelhead (Oncorhynchus mykiss) kelt outmigration from Lower Granite Dam to Bonneville Dam and test the use of transportation to increase returns of repeat spawners. Annual Report to US Army Corps of Engineers, Walla Walla District, for Contract No. DACW68-00-C-0027. Prepared by the Columbia River Inter-Tribal Fish Commission, Portland OR.

Hatch, D.R., R. Branstetter, J. Blodgett, B. Bosch, D. Fast, and T. Newsome. 2003b. Kelt reconditioning: A research project to enhance iteroparity in Columbia Basin steelhead (Oncorhynchus mykiss). Annual Report to the Bonneville Power Administration for Contract No. 00004185. Prepared by the Columbia River InterTribal Fish Commission, Portland OR.

Hatch, D.R., R.D. Branstetter, J. Whiteaker, J. Blodgett, B. Bosch, D. Fast, and T. Newsome. 2004. Kelt reconditioning: A research project to enhance iteroparity in Columbia Basin steelhead (Oncorhynchus mykiss). 2004 Annual Report to U.S. Dept. of Energy, Bonneville Power Administration, Project No. 2000-017. Prepared by the Columbia River Inter-Tribal Fish Commission, Portland, OR.

Hockersmith, E., J.Vella, L. Stuehrenberg, R.N. Iwamoto, and G. Swan. 1995. Yakima River radio-telemetry study: Steelhead, 1989-93. Report to U,S. Department of Energy, Bonneville Power Administration, for Project. No. 89-089, Contract No. DE-AI79-89BP00276, by Northwest Fisheries Science Center, National Marine Fisheries Service, Seattle, WA.

Howell, P., K. Jones, D. Scarnecchia, L. LaVoy, W. Kendra, and D. Ortmann. 1985. Stock assessment of Columbia River anadromous salmonids Volume II: steelhead stock summaries stock transfer guidelines - information needs. Final Report to U.S. Department of Energy, Bonneville Power Administration, Project No. 83-335.

ISRP (Independent Scientific Review Team) 1999. Scientific issues in the restoration of salmonid fishes in the Columbia River. Fisheries 24(3):10-19.

Johnson, K.A., and J.A. Heindel. 2000. Efficacy of manual removal and ivermectin lavage for control of Salmincola californiensis (Wilson) infestation of chinook salmon, Oncorhynchus tshawytscha (Walbaum), captive broodstocks. Eagle Fish Health Laboratory and Hatchery report, Idaho Department of Fish and Game, Boise. 
Kalinowski S.T. 2005. HP-Rare: A computer program for performing rarefactions on measures of allelic diversity. Molecular Ecology Notes 5:187-189.

Kalinowski S.T., M.L. Taper and T.C. Marshall. 2007. Revising how the computer program CERVUS accommodates genotyping error increases confidence in paternity. Molecular Ecology 16:1099-1106.

Langford, T.E., J.M. Fleming and N.P.James, 1977. The tracking of salmonids in the Afon Seiont River System, using ultrasonic tagging techniques. Central Electricity Research Laboratories, Lab. Note RD/L/N51/77, 16 p.

Leitritz, E. and R.C. Lewis. 1980. Trout and Salmon Culture. Division of Agricultural Sciences. University of California.

LeBrasseur, R.J. 1966. Stomach contents of salmon and steelhead trout in the northeastern Pacific Ocean. J. Fish. Res. Board Can. 23: 85-100.

Manzer, J.I. 1968. Food of Pacific salmon and steelhead trout in the northeast Pacific Ocean. J. Fish. Res. Board Can. 25: 1085-1089.

Marshall, T.C.J. Slate, L. Kruuk, and J.M. Pemberton. 1998. Statistical confidence for likelihood-based paternity inference in natural populations. Molecular Ecology 7:639-655.

McConnell, S., L. Hamilton, D. Morris, D. Cook, D. Paquet, P. Bentzen, and J. Wright. 1995. Isolation of salmonid microsatellite loci and their application to the population genetics of Canadian east coast stocks of Atlantic salmon. Aquaculture 137:19-30.

McLean, J.E., T. R. Seamons, M.B. Dauer, P. Bentzen and T.P. Quinn. 2007. Variation in reproductive success and effective number of breeders in a hatchery population of steelhead trout ( Oncorhynchus mykiss ): examination by microsatellite-based parentage analysis. Conservation Genetics DOI 10.1007/s10592-007-9340-0.

Narum S.R., D. Hatch, A.J. Talbot, P. Moran, and M.S. Powell. 2008. Iteroparity in complex mating systems of steelhead Oncorhynchus mykiss (Walbaum). Journal of Fish Biology 72:1-16.

Nehlsen, W., J.E. Williams, and J.A. Lichatowich. 1991. Pacific salmon at the crossroads: Stocks at risk from California, Oregon, Washington, and Idaho. Fisheries 16: 4-21. 
Nelson, R.J., and T.D. Beacham. 1999. Isolation and cross species amplification of microsatellite loci useful for study of Pacific salmon. Animal Genetics 30:228-229.

NMFS (National Marine Fisheries Service). 1996. Status review of west coast steelhead from Washington, Idaho, Oregon, and California. Seattle, WA.

NMFS (National Marine Fisheries Service). 1997. Endangered and threatened species: Listing of several evolutionary significant units (ESUs) of west coast steelhead. Final rule. Federal Register 62:43937.

NMFS (National Marine Fisheries Service). 1999. Endangered and Threatened Species: Threatened Status for Two ESUs of Chum Salmon in Washington and Oregon, for Two ESUs of Steelhead in Washington and Oregon, and for Ozette Lake Sockeye Salmon in Washington; Rules. Final rule. Federal Register $57: 14517$

NPPC (Northwest Power Planning Council). 1986. Compilation of information on salmon and steelhead losses in the Columbia River Basin. Portland, OR. 252 p.

NPPC (Northwest Power Planning Council). 1995. 1994 Columbia River Fish and Wildlife Program (revised 1995). Portland, Oregon.

NRC (National Research Council). 1996. Upstream: Salmon and society in the Pacific Northwest. National Academy Press, Washington D.C.

Oregon Department of Fish and Wildlife. 2008. Grande Ronde Basin Spring Chinook Salmon Captive Broodstock Program. 2008 Annual Operating Plan. Northeast Region Fish Research and Development, Oregon Department of Fish and Wildlife, La Grande.

Olsen, E.A., 2008. Hood River and Pelton Ladder Evaluation Studies. Annual Report 2007 to U.S. Dept. of Energy, Bonneville Power Administration, Project No.1988-053-04. Prepared by the Oregon Department of Fish and Wildlife, Portland, OR.

Olsen, J.B., P. Bentzen, and J.E. Seeb. 1998. Characterization of seven microsatellite loci derived from pink salmon. Molecular Ecology 7:1087-1089.

Olsen, J.B., P. Bentzen, M.A. Banks, J.B. Shaklee, and S.Young. 2000. Microsatellites reveal population identity of individual pink salmon to allow supportive breeding of a population at risk of extinction. Transactions of the American Fisheries Society 129:232-242.

Park, S.D.E., 2001. Trypanotolerance in West African Cattle and the Population Genetic Effects of Selection [ Ph.D. thesis ] University of Dublin. 
Pennel W. and Barton B.A., (Eds.) 1996. Principles of Salmonid Culture. Elsevier. Amsterdam, Netherlands.

Pritchard, J.K., M. Stephens, and P. Donnelly. 2000. Inference of population structure using multilocus genotype data. Genetics 155:945-959.

Raymond, M., and F. Rousset. 1995. GENEPOP (version 1.2): Population genetics software for exact tests and ecumenicism. Journal of Heredity 86:248249.

Rice, W.R. 1989. Analyzing tables of statistical tests. Evolution. 43: 223-225

Rousset, F., and Raymond, M. 1995. Testing heterozygote excess and deficiency. Genetics 140:1413-1419.

Savvaitova K.A., K.V. Kuzishchin, S.V. Maksimov, and S.D. Pavlov. 1996. Population Structure of Mikizha, Salmo mykiss in the Utkholok River (Western Kamchatka). Journal of Ichthyology 37(3):216-225.

Scribner, K.T., J.R. Gust, and R.L. Fields. 1996. Isolation and characterization of novel microsatellite loci: cross-species amplification and population genetic applications. Canadian Journal of Fisheries and Aquatic Sciences 53:685-693.

Seamons T.R., Guest Lecture. Individual lifetime reproductive success of repeat spawning vs. one-time spawning steelhead. Pacific Coast Steelhead Management Meeting. Pacific States Marine Forecast Comission. Port Townsend, WA. 7 March 2006.

Sprowles A.E., M.R. Stephens, N.W. Clipperton, and B.P May. 2006. Fishing for SNPs: A Targeted Locus Approach for Single Nucleotide Polymorphism Discovery in Rainbow Trout. Transactions of the American Fisheries Society 135:6 1698-1721.

Stephenson J.J., M.R. Campbell, J.E. Hess, C. Kozfkay, A.P. Matala, M.V. McPhee, P. Moran, S.R. Narum, M.M. Paquin, O. Schlei, M.P. Small, D.M. Van Doornik, J.K. Wenburg (In Press) A centralized model for creating shared, standardized, microsatellite data that simplifies inter-laboratory collaboration. Conservation Genetics. Published online: October 22, 2008. DOI 10.1007/s10592-008-9729-4.

Taborsky, M. 2001. The evolution of bourgeois, parasitic, and cooperative reproductive behaviors in fishes. Journal of Heredity 92:100-110. 
TRP (Tribal Restoration Plan). 1995. Wy-Kan-Ush-Mi Wa-Kish-Wit: The Columbia River anadromous fish restoration plan of the Nez Perce, Umatilla, Warm Springs, and Yakama tribes. Columbia River Inter-Tribal Fish

Commission, Portland, OR

U.S. v. Oregon. 1997. 1996 All Species Review, Columbia River Fish Management Plan. Technical Advisory Committee. Portland, OR.

Waples, R.S. 2002. Effective size of fluctuating salmon populations. Genetics 161:783-791.

Wedemeyer G.A., (Ed). 2002. Fish Hatchery Management Second Edition. North American Journal of Fisheries. Bethesda, Maryland.

Weir BS, 1990. Genetic data analysis. Sinauer Publ., Sunderland, MA.

Withler I.L. 1966. Variability in life history characteristics of steelhead trout (Salmo gairdneri) along the Pacific Coast of North America. Journal of the Fisheries Research Board of Canada 23:365-393. 


\title{
Appendices
}

\section{Appendix A. Snake River Study Plan}

\section{Developing Strategies to Improve Survival and Return Recruitment of Steelhead Kelts from Snake River Stocks}

\author{
Draft Work Plan
}

Christine M. Moffitt, Principal Investigator

Professor and Assistant Unit Leader

\author{
Scientific Staff \\ Shawn P. Young, Assistant Research Professor \\ Jessica Buelow, and Zachary Penney, Student Investigators \\ Idaho Cooperative Fish and Wildlife Research Unit \\ University of Idaho, Moscow, ID 83844-1141 \\ and \\ Andrew Pierce, Affiliate Assistant Professor \\ Columbia River Intertribal Fisheries Commission
}

2 March 2008

Prepared for Doug Hatch

and for Agency and Tribal Review 


\section{Background}

Few spent steelhead spawners of ESA-listed steelhead (Oncorhynchus mykiss) in the Snake River system are able to pass back to the ocean successfully. Instead, they are trapped within the hydrosystem because of lack of fish passage facilities for the large fish, and flow conditions in the reservoirs. Because of this increased post spawning mortality in the Snake River reservoir system, the potential of repeat spawning fish contributing to the population is lost. Rates of repeat spawning for pre-dammed Columbia River are not known, and the proportion of repeat spawning fish since development is reported to range from 1.6 to $17 \%$.

Research on post-spawn steelhead conducted at Lower Granite Dam in 2001-2003 indicates that the majority of kelt loss takes place during the downstream migration, with between 70\% and 95\% of tagged fish lost prior to reaching Bonneville Dam (Evans 2002, Hatch et al. 2003, Boggs and Peery 2004; Doug Hatch, personal communications). Kelt return data from adult PIT tag interrogation systems indicates less than $1 \%$ of in-river migrating kelts tagged at Lower Granite Dam have returned to spawn (Boggs and Peery 2004).

However, kelts tagged and released at John Day Dam, in the lower-Columbia River, have performed appreciably better with up to $10 \%$ of tagged fish returning to spawn again (Wertheimer et al. 2003 Doug Hatch, personal communications). Repeat spawning rates as high as $17 \%$ have been observed in the Kalama River located below Bonneville Dam (Leider et al. 1986). The Yakima Tribe has conducted research to identify options for kelt reconditioning in the Yakima River. This research has resulted in information on feeding preferences, and migration ability of reconditioned kelts and promising improvements in survival (Branstetter et al. 2007).

The Lower Granite Dam bypass collection facility currently has access to the largest number of kelts anywhere in the Columbia River Basin (Evans et al. 2004), making it an excellent location for both the research and management of threatened summer-run steelhead. Furthermore, the collection and reconditioning of kelts from Lower Granite Dam (or other bypass facilities in the Lower Snake River) has the potential to benefit all spawning aggregates upstream of the dam, and expands on the very promising pioneering work in the Yakima River.

Additional research focused on the physiology, health and reproductive potential of spawned out steelhead kelts is needed to establish viable management protocols that can be used to maximize the contribution of these animals to the population through increased iteroparity. 


\section{Goal of Project}

This project will study the physiology and endocrinology of steelhead kelts with a goal of evaluating the feasibility and success of several strategies for rehabilitating and handling of steelhead captured at Lower Granite Dam or at other sites during their downstream migration in the Snake River system. Our research will focus on the physiology, health and condition of both B and A stocks of steelhead trout. Through this research we will pose, develop and test protocols that can be used to collect and transport spent spawners, rehabilitate them for the most effective period of time to maximize their ability and contribution to the next spawning generation.

The focus of our first year of study is to develop the background science needed for evaluating different production plans for rehabilitation of kelts. The second and third years of the study will focus on more specific studies using metrics developed in the first year as evaluation tools. The second and third year of the study will test larger groups of fish and utilized some seawater testing systems. The details and infrastructure planning aspects of this project are recognized as goals during the first year of this project.

\section{Objectives- Year 1}

Objective 1. Obtain basic information describing the general physiology and endocrinology of kelts from the point of spawning through the early migration period using hatchery and nonhatchery origin stocks.

Objective 2. Describe and obtain physiological and endocrinological profiles from downstream migrating wild stocks captured at Lower Granite Dam, and compare and contrast these profiles with fish from upriver and downriver sites.

Objective 3. Evaluate the physiology of fish collected at Lower Granite Dam and transported via barge or truck to locations below Bonneville Dam.

Objective 4. Evaluate the physiology and endocrinology of small groups of kelts held for 2 months or more, and compare results with groups of fish from other sites, and with models from fish migrating through river corridors.

\section{Detailed Methods by Objective and Task}

Objective 1. Obtain basic information describing the general physiology and endocrinology of kelts from the point of spawning through the early emigration period using hatchery and non-hatchery origin stocks. 
Task 1.1. Construct a model of the physiology and endocrinology of B-run steelhead from the point of spawning up to three weeks post spawning, using kelts from Dworshak National Fish Hatchery (DNFH).

Activity 1.1.1. On weekly steelhead spawning dates starting with the early spawning cycle at DNFH (January), until the end of spawning in April, we will travel to DNFH and collect 8-15 female steelhead for sampling. Approximately 2 females will be selected at a time from the sorting table during each successive load of steelhead emptied from the brood stock baskets. Attempts will be made to only sample female steelhead in fair to excellent body condition, without adipose fins, and without prior treatment with any compounds such as $\underline{\mathrm{GnRH}}$. Selected females will be anesthetized using $100 \mathrm{mg} / \mathrm{L}$ buffered MS-222.

Air spawning or hand spawning techniques will be used to expel eggs from ripe female fish. The decision on air spawning or hand spawning will be based on the suitability and level of maturity of each fish. General characteristics and condition of each fish will be recorded.

All eggs obtained from successful air/hand spawns will be immediately sent to DNFH personnel for fertilization, rinsing, water hardening and incubation. Eye-up and hatch survival between air/hand spawned and knife-stripped eggs will be monitored by Dworshak and University of Idaho (U of I) personnel and compared.

Spawned fish will be sampled for blood from the caudal artery. Approximately, 1-1.5 $\mathrm{mL}$ of blood will be sampled from each steelhead with a heparanized syringe and 21-gage needle. The samples with be stored on ice until centrifuged (1 hr) and plasma will be aliquoted into samples for several assays in the dry laboratory of the fish health center.

After a blood sample is obtained, each fish will be tagged in the pelvic girdle with a 20 mm PIT tag for identification using an 8-gage needle. Following tagging all fish will be revived in a 400 gallon fish transport tank in freshwater with $0.5 \% \mathrm{NaCl}$. After all fish are sampled the tank will be driven to the $\mathrm{U}$ of I, and fish moved into the wet laboratory at the College of Natural Resources (CNR).

Activity 1.1.2. On arrival at the U of I CNR wet laboratory, kelts will be anesthetized in the tank and removed, weighed and placed into one of 8, 4-ft diameter circular tanks. Most tanks will be loaded with 2 fish per tank. Water flow to tanks will be held at approximately 2 gallons per minute, and water temperatures will be maintained through monitoring and adjusting the flow of chilled water to the tanks. Water supply to tanks is dechlorinated well water, and supplemental air will be provided with air stones in each tank. On the day following delivery, kelts will be provided $\sim 15-30$ grams of frozen krill/tank daily to induce feeding, except on sampling days. Tanks will be inspected daily for excess feed and cleaned if necessary.

Eight days following arrival in the U of I laboratory, kelts will be anesthetized (MS-222), identified, weighed $(\mathrm{kg})$, and sampled for blood from the caudal artery as before (1-1.5 
$\mathrm{mL}$ ). Blood samples will be held on ice and processed in the CNR analytical lab. Steelhead will then be returned to their respective tanks for revival.

Activity 1.1.3. Approximately two weeks to sixteen days following arrival at the U of I, all steelhead kelts with be lethally sampled. Fish will be placed in a lethal dose of MS222 (250 mg/L buffered). Fish will be identified via PIT tag and weighed. A final blood sample of approximately $3 \mathrm{~mL}$ will be sampled from kelts immediately following death. Blood samples will be transported to the U of I CNR analytical lab for preparation and analysis. Following the final blood sampling, all steelhead will be photographed for documentation of the final body condition.

A necropsy will be conducted. The total weight of eggs remaining in the body cavity will be measured (g). Then the wet weights of the spleen, liver + gall bladder, and Gastrointestinal (GI) tract will be weighed and documented. The remaining gonad tissue will be removed and weighted. Photographs of the tissues will be captured, and a section of the gonads will be removed and stored in $10 \%$ buffered formalin for later histological analysis. A small sample of the spleen will be removed and stored in buffered formalin for histological profile. The gall bladder will be inspected for bile content, and then samples of liver tissue will then be removed for histology and gene expression analysis. A large portion of the liver without the gall bladder will be weighed and saved for lipid analysis. The GI tract will be examined for condition and presence of food, feces, and bile. Four regions of the GI tract will be sampled (anterior and posterior stomach, pyloric, and posterior intestine) and stored in 10\% neutral buffered formalin for later analysis of histology. Additionally, the anterior, mid, and posterior kidneys will be inspected, and for some fish samples will be taken for profiling the bacterial content. Approximately 5-6 gill filaments with be sampled to describe sodium ATPase and stored in SEI buffer. A 200-400 g fillet of skin and muscle will be removed from the region below the dorsal fin and stored for later lipid analysis.

All carcasses will be stored in the Wet lab freezer and incinerated at intervals.

The physiological and endocrinological metrics that will be evaluated for model development consist of the following parameters.

Assessment of general external condition and survival

Wet weight and total length of each fish

Organosomatic indices for the liver, GI, gonads, and spleen at the time of necropsy

Histological profiles of tissues from the liver, spleen, intestinal tract and gonads sampled at necropsy.

Plasma metrics in a time series of three points, spawning, 1 and 2 weeks. Plasma constituents will include assessment of a number of metrics (Table 1).

Gill Na K ATPase

Gene expression analysis of liver and stomach tissue. Gene expression analysis will include the following RNA transcripts (Table 2)

Proximate content of muscle and liver

Table 1. List of analyses to be conducted on samples of plasma collected from steelhead kelts. Assays will be conducted using an autoanalyzer at Gritman Hospital Laboratory. Cortisol will be analyzed at Carl Schreck's laboratory at Oregon State University. Plasma growth hormone (GH), insulin-like growth factor-I (IGF-I), insulin-like growth 
factor binding protein-1 (IGFBP1), and ghrelin will be analyzed using facilities and collaborative arrangements yet to be determined.

\begin{tabular}{lll}
\hline Sodium & Alk Phos & Cortisol (OSU) \\
\hline Potassium & ALT & Total T4 \\
\hline Chloride & AST & \\
\hline Calcium & LDH & GH \\
\hline Glucose & Cholesterol & IGF-I \\
\hline Magnesium & CK & IGFBP-1 \\
\hline Phosphorous & Lipase & Ghrelin \\
\hline & Triglycerides & \\
\hline & Total Protein & \\
\hline
\end{tabular}

Table 2. List of analyses to be conducted on RNA samples collected from steelhead kelts. Assays will be conducted using quantitative real time reverse transcription polymerase chain reaction (qPCR) in the UI CNR analytical laboratory using existing instruments.

\begin{tabular}{ll}
\hline Liver & Stomach \\
\hline Insulin-like growth factor-I & Ghrelin \\
\hline Insulin-like growth factor-II & Reference gene \\
\hline Insulin -like growth factor binding protein-1 & \\
\hline Growth hormone receptor & \\
\hline Somatolactin receptor & \\
\hline Reference gene: acidic ribosomal phosphoprotein P0. & \\
\hline Additional possibilities: vitellogenins, estrogen receptors, & \\
\hline glucocorticoid receptors, IGFBP-3 & \\
\hline
\end{tabular}

Task 1.2. Construct a model of the physiology and endocrinology and migration success of kelts from stocks from at least two tributaries of the Clearwater River watershed, from the point of capture at local weirs within the tributary reaches.

We will obtain blood samples from naturally spawning steelhead kelts from two weirs in the Clearwater River tributaries: Fish Creek and Crooked River Weir. The Fish Creek Weir is located on Fish Creek, a tributary of the Lochsa River twenty miles east of Lowell, Idaho, is operated by the Idaho Fish and Game out of Nampa, Idaho. The Crooked River Weir is located on Crooked, a tributary of Red River near Elk City, Idaho, is operated from early April until mid June by Idaho Fish and Game out of Lewiston, Idaho.

A sampling schedule from mid April until mid June is proposed. Sampling will occur as the fish are collected at the weir sites migrating downstream. We anticipate that from 6 to 50 fish could be sampled over the season. The general condition of each fish will be observed, the length and sex will be measured and recorded, and we will note any evidence of previously applied tags. We will collect from 1.0 to $1.5 \mathrm{~mL}$ of blood from the caudal artery using our standard operating procedures and a heparanized, 3 cc syringe 
fitted with 1.5 inch 21 gage needle. Following blood collection, the kelts will be tagged in the pelvic girdle with a 20 -mm pit tag inserted with an 8-gauge needle. The blood collected will be stored on wet ice for up to an hour, and then centrifuged to separate the plasma fraction. Plasma will be stored on dry ice until it can be transferred to an ultracold freezer $\left(-80^{\circ} \mathrm{C}\right)$. Idaho Department of Fish and Game employees or $\mathrm{U}$ of I staff will conduct sampling of blood, using protocols established at the $U$ of Idaho. Training of all staff will be conducted prior to sampling.

Plasma constituents will be evaluated for the same parameters as in Task 1.1 (Table 1).

Objective 2. Describe and obtain physiological and endocrinological profiles from downstream migrating wild stocks captured at Lower Granite Dam, and compare and contrast these profiles with fish from upriver and downriver sites.

Task 2.1. Obtain baseline physiology of naturally spawning (wild) fish and marked hatchery origin steelhead kelts emigrating from Snake River tributaries collected at Lower Granite Dam.

Activity 2.1.1.We will collect data on the condition and origin of any tagged stocks, and sample blood from migrating fish at intervals during the migration period. We will use these data to compare with profiles of hatchery fish collected at Dworshak National Fish Hatchery (DNFH), and with data from naturally spawning wild fish sampled from Clearwater weirs. We will determine correlations of data with survival and potential ability to recondition and repeat spawn.

The proposed sampling will occur from March 26 - June 20, 2009. The following schedule is based upon the numbers of emigrating steelhead kelts captured during previous steelhead kelt studies (Evans 2008; Keefer et al. 2008) and numbers reported in 2008 fish passage data at Lower Granite Dam. Expected start of fish collection at LGD is March 26, and potential starting date of barging is April 5 (Mike Halter, LGD Project Fisheries Biologist, personal communication).

Beginning the week of March $22-28$ (week 1), we will sample twice weekly until end of week 6 (April 26 - May 2) while the number of emigrating kelts remains low. During May 3 - June 20 (weeks 7-13), we will sample three times per week during the peak in kelt abundance. Finally during June 14 - June 20 (weeks 13), we will conclude sampling as kelt numbers will likely begin to decline below numbers desirable for transport studies. The outmigration may be divided into two time periods, early (week $1-6$ ) and peak/late (week 7 -13). This is further based upon the findings of Keefer et al. (2008), in which percentage of kelts surviving to repeat spawn and probability a kelt returned in the fall of the same year or the fall of the next year differed by time of emigration.

Activity 2.1.2.We will collect a fin clip or tissue from all fish sampled in order to extract DNA for genetic studies to determine the origin of sampled kelts using genetic stock 
identification. We will pursue a collaborative effort with scientists that have previously conducted Snake River steelhead kelt genetic studies (Narum et al. 2008) to compare physiology of kelts from major Snake River tributaries to determine if differences exist that may translate into increased probability of survival or ability to recondition.

Activity 2.1.3. A minimum of 10 kelts will be collected on each occasion at LGD to collect blood samples. Each fish will be PIT tagged and released for volitional passage in concert with the transport study. In addition, a maximum of 10 kelts (5 wild females; 5 hatchery females) will be euthanized weekly at LGD to collect histological samples and tissue samples in order to expand on characterizing the baseline physiological profile of steelhead kelts. The sampling profile will be similar to that in Objective 1, Task 1.1.

Task 2.2. Compare the behavior, and response to captivity and transportation to the $U$ of Idaho lab of groups of fish collected at Lower Granite Dam with results obtained from Dworshak National Fish Hatchery in Objective 1.

Activity 2.2.1. Eight kelts (female, hatchery) will be transported weekly to the University of Idaho to compare the baseline physiology of LGD kelts to Dworshak hatchery-origin kelts and for short-term study of temperature effects and preliminary investigation of initiation of feeding. The treatment of these fish will be similar to those from the Dworshak groups, thus allowing a comparison of physiology between artificially spawned hatchery and naturally-spawning hatchery steelhead kelts. Blood samples will be collected on a weekly basis, and tissue weights, condition, genetic expression and histological samples will be collected at time of euthanasia.

\section{Objective 3. Evaluate the physiology of fish collected at Lower Granite Dam and placed into barges and transported via barge or truck to locations below Bonneville Dam.}

Task 3.1. Explore the effect of different modes of transport that may enhance survival and probability of repeat spawning by steelhead kelts emigrating down the Snake and Columbia Rivers by PIT-tagging and collecting physiology data from kelts being transported by truck and barge and possibly from those undertaking volitional passage.

Activity 3.1.1. We will PIT tag and transport groups of 25 kelts below Bonneville Dam by trucking and barging. The transport schedule may vary depending on number of kelts available throughout the downriver outmigration window. Based upon this schedule, each mode of transportation would be equally represented in terms of number of transport events $(\mathrm{N}=5)$ while incorporating emigration timing as a co-factor. Possibly, a run-ofthe-river (ROR) treatment consisting of fish released at LGD for volitional passage will be added. Low survival and low repeat spawning of kelts emigrating down the hydrosystem observed in a previous study (Evans et al. 2008, Keefer et al. 2008) suggests this option may not be beneficial unless we determine recapture of individuals at 
downriver facilities is feasible in order to collect physiological profiles of fish emigrating through the hydrosystem.

A minimum of 10 kelts will be sampled for blood at the initiation, during, and at the end of transport to determine effects of transport on kelt physiology. We will also investigate the possibility of recapturing a sufficient number of PIT-tagged run-of-the-river kelts at downriver dam collection facilities in order to obtain physiological data during emigration through the hydrosystem. This would allow for a comparison between the three modes of downriver passage and across time during the period of kelt emigration. Table 2. Schedule of sampling activities and number of fish to be sampled for each activity at LGD during March - June 2009.

Objective 4. Evaluate the physiology and endocrinology of small groups of kelts held for 2 months or more, and compare results with groups of fish from other sites, and with models from fish migrating through river corridors.

\section{Task 4.1. Determine the series of physiological changes that occur during long term reconditioning in DNFH captive steelhead kelts.}

Activity 4.1.1. Describe changes in appearance, body composition, digestive system function, plasma metabolic substrates, and gill and digestive enzyme activities in DNFH origin kelts. We will describe changes in endocrine factors associated with growth, stress, and anabolic/catabolic status of fish held over time. With this profile we will identify which factors are associated with survival, and when differences between surviving fish and mortalities develop.

Activity 4.1.2. Describe changes in reproductive endocrinology and gonadal development. We will determine when differences between sequential spawners and skip spawners develop, and evaluate indicators for classification of fish as sequential or skip spawners.

Female steelhead kelts will be hand or air-spawned at DNFH and stocked into one of four 15 foot diameter tanks currently on order, at 25 fish per tank. Water from DNFH will be supplied to the tanks, at a flow rate of $\sim 25-35$ gallons per minute per tank. Fish will be fed krill for the first month, and then transitioned to pelleted feed. Fish will be stocked into tanks during April. At the time of stocking all fish will be implanted with a PIT tag, weighed, measured, and a blood sample withdrawn. Beginning May $1^{\text {st }}$, fish will be sampled twice per month. Sampling will continue through Sept $15^{\text {th }}$. The sampling schedule may be adjusted based on fish numbers. In this study we will evaluated the physiology of fish during a short term, medium term, and long term reconditioning cycle. Sampling will occur in fish from two tanks, staggered across the month so that fish will be sampled only once per month. To obtain fish for samples, fish will be crowded and 5 fish removed from each of 2 tanks. All sampling will be terminal, and fish will be quickly anesthetized in a lethal concentration of MS222 $(250 \mathrm{mg} / \mathrm{L})$. Length, weight, condition, and fish health status will be noted, and blood drawn with standard procedures. 
The digestive tract, liver, spleen, and ovary tissue will be removed and weighed. Samples of liver and muscle will be taken for proximate analysis. Samples of stomach, liver, and gill will be taken for gene expression analysis. A gill sample will be taken for

$\mathrm{Na}^{+} / \mathrm{K}^{+}$ATPase activity. Digestive tract samples may be taken for enzyme activities, and samples from four regions of the GI tract, pyloric caeca, liver, and ovary will be removed and placed into $10 \%$ buffered formalin for histological analysis. Laboratory analyses will be similar to those described in Activity 1.1.3, with the addition of assays for plasma estradiol, testosterone, and vitellogenin, liver gene expression assays for vitellogenins and estrogen receptors, and gill gene expression assays for $\mathrm{Na}^{+} / \mathrm{K}^{+}$ATPase isoforms and osmotic stress transcription factor-1.

Activity 4.1.3. Compare the physiological profile of DNFH kelts during long term reconditioning with downriver fish. We will construct a physiological profile of kelts using nonlethal sampling for blood parameters at Parkdale hatchery on the Hood river, and at the Prosser kelt facility on the Yakima river.

Upriver migrant prespawning steelhead will be taken into the reconditioning facility at Parkdale after collection at Powerdale dam. Fish will be air spawned at Parkdale following standard hatchery procedures. Ideally, we would like to take a blood sample at collection, and a second blood sample at spawning. Fish will be reconditioned following standard hatchery procedures at Parkdale. Fish will be nonlethally sampled for blood twice during reconditioning, near the summer solstice (June 21) and autumn equinox (Sept 22). During sampling, fish will be anesthetized and $1.5 \mathrm{ml}$ blood withdrawn. Due to the low numbers of fish anticipated at Parkdale (14 male and 15 female steelhead in 2008, Branstetter et al., 2007), all fish will be sampled.

Downriver migrant steelhead kelts from the Yakima river will be taken into reconditioning facilities at Prosser, WA. Depending on run numbers, as many as 400 kelts may be held for long term reconditioning. Depending on staff availability and permission from the facility managers, we would like to sample at least 20 of these fish at the beginning of their holding period. Fish will be nonlethally sampled at least twice during reconditioning, near the summer solstice (June 21) and autumn equinox (Sept 22). We would like to add additional samplings, depending on staff availability and permission from the facility managers. During sampling, 10 fish will be withdrawn from each of the two reconditioning tanks and sampled for blood. Blood sampling will follow the same procedure as at Parkdale.

\section{References}

Boggs, C.T. and C.A. Peery. 2004. Steelhead (Oncorhynchus mykiss) kelt abundance, condition, passage, and survival in the lower Snake and Columbia rivers, 2003.Report to US Army Corps of Engineers, Walla Walla District. Contract No. DACW-02-D-0005.

Branstetter, R., J. S Stephenson, D. R. Hatch, J. Whiteaker, S-Y. Hyun, B. Bosch, D. Fast, J. Blodgett, T. Newsome, L. Hewlett, J. Lovetang, M. Gauvin, R. Dasher, and C. 
Fisher. 2007. Steelhead Kelt Reconditioning and Reproductive Success. Annual Report for 2007. Project Number: 2007-401-00, Contract Number: 0030769. Bonneville Power Administration. Portland.

Evans, A.F. 2002. Steelhead (Oncorhynchus mykiss) kelt outmigration from lower Granite Dam to Bonneville dam: Abundance, downstream conversion rates, routes of passage, and travel times, 2001. Submitted by CRITFC to U.S. Army Corps of Engineers Walla Walla District for Contract No. DACW68-01-0016.

Evans, A.F., M.S. Fitzpatrick, and L.K. Siddens. 2004. Use of ultrasound imaging and steroid concentrations to identify maturational status in adult steelhead North American Journal of Fisheries Management 24: 967-978.

Evans, A. F., et al. 2008. Transportation of steelhead kelts to increase iteroparity in the Columbia and Snake Rivers. North American Journal of Fisheries Management 28:18181827.

Hatch, D.R., R. Branstetter, and S. Narum. 2003. Evaluate steelhead (Oncorhynchus mykis) kelt Outmigration from Lower Granite Dam to Bonneville Dam and test the use of transportation to increase returns of repeat spawners. Submitted by CRITFC to U.S. Army Corps of Engineers Walla Walla District for Contract No. DACW68-00-C-0027.

Leider, S.A., M.W. Chilcote, and J.J. Loch. 1986. Comparative life history characteristics of hatchery and wild steelhead trout (Salmo gairdneri) of summer and winter races in the Kalama River, Washington. Canadian Journal of Fisheries and Aquatic Sciences 43:1398-1409

Wertheimer, R.H., P.L. Madson, and M.R. Jonas. 2003. Evaluation of Steelhead Kelt Project Abundance, Condition, Passage, and Conversion Rates through Lower Columbia River dams, in 2002. U.S. Army Corps of Engineers, Portland District Fish Field Unit, Bonneville Lock and Dam, Cascade Locks, OR.

Keefer, M. L., et al., 2008. Iteroparity in Columbia river summer-run steelhead (Oncorhynchus mykiss): implications for conservation. Can J Fish Aquat Sci. 65, 25922605.

Narum, S. R., et al. 2008. Iteroparity in complex mating systems of steelhead Oncorhyncus mykiss (Walbaum). Journal of Fish Biology 72:45-60.

\section{Key Project Staff Roles and Responsibilities:}

Christine Moffitt, Principal Investigator, Professor, and Assistant Unit Leader, cmoffitt@uidaho.eduFigure 1: Lower Columbia Acoustic Receiver Arrays 2008.

Shawn P. Young, Research Assistant Professor, Idaho Cooperative Fish and Wildlife

Research Unit, University of Idaho, Moscow, ID 83844-1141, syoung@uidaho.edu 
Andrew Pierce, Affiliate Assistant Professor, CRITFC, Department of Fish and Wildlife Resources, University of Idaho, Moscow, ID 83844-1136, apierce@uidaho.edu

Jessica Buelow, Masters Program Graduate Student, Department of Fish and Wildlife Resoruces \& Idaho Cooperative Fish and Wildlife Research Unit, University of Idaho, Moscow, ID 83844-1136, buel0184@vandals.uidaho.edu

Zachary L. Penney, Doctoral Program Graduate Student, College of Natural Resources \& Idaho Cooperative Fish and Wildlife Research Unit, University of Idaho, Moscow, ID 83844-1136, penn4282@vandals.uidaho.edu

Additional project members will include:

Dr. Ron Hardy, Hagerman Experiment Station, University of Idaho, expertise in nutrition and nutritional profiles.

Dr. Paul Hershberger, USGS Marrowstone Field Station, resource for seawater system testing.

Table 3. Integrated Field Schedule of Events.

\begin{tabular}{|c|c|c|c|c|c|c|c|c|c|c|c|c|}
\hline ACTIVITY & JAN & FEB & MAR & APR & MAY & JUN & JULY & AUG & SEP & OCT & NOV & DEC \\
\hline 1.1 .1 & $\mathrm{X}$ & $\mathrm{X}$ & $\mathrm{X}$ & $\mathrm{X}$ & & & & & & & & \\
\hline 1.1.2 & $\mathrm{X}$ & $\mathrm{X}$ & $X$ & $\mathrm{X}$ & $X$ & & & & & & & \\
\hline 1.1 .3 & & $X$ & $X$ & $X$ & $\mathrm{X}$ & & & & & & & \\
\hline 1.2 .1 & & & & $X$ & $X$ & $X$ & & & & & & \\
\hline 2.1.1 & & & $X$ & $X$ & $\mathrm{X}$ & $X$ & & & & & & \\
\hline 2.1.2 & & & $X$ & $X$ & $X$ & $X$ & & & & & & \\
\hline 2.1.3 & & & $\mathrm{X}$ & $\mathrm{X}$ & $\mathrm{X}$ & $\mathrm{X}$ & & & & & & \\
\hline 2.2.1 & & & & $\mathrm{X}$ & $X$ & $\mathrm{X}$ & & & & & & \\
\hline 3.1.1 & & & & $\mathrm{X}$ & $\mathrm{X}$ & $\mathrm{X}$ & & & & & & \\
\hline 4.1.1 & & & & $\mathrm{X}$ & $\mathrm{X}$ & $X$ & $X$ & $X$ & $X$ & & & \\
\hline 4.1.2 & & & & $X$ & $X$ & $\mathrm{X}$ & $X$ & $\mathrm{X}$ & $\mathrm{X}$ & & & \\
\hline 4.1.3 & & & & & $X$ & $\mathrm{X}$ & & & $X$ & & & \\
\hline
\end{tabular}




\section{Appendix B. Lower Columbia River Array Locations}

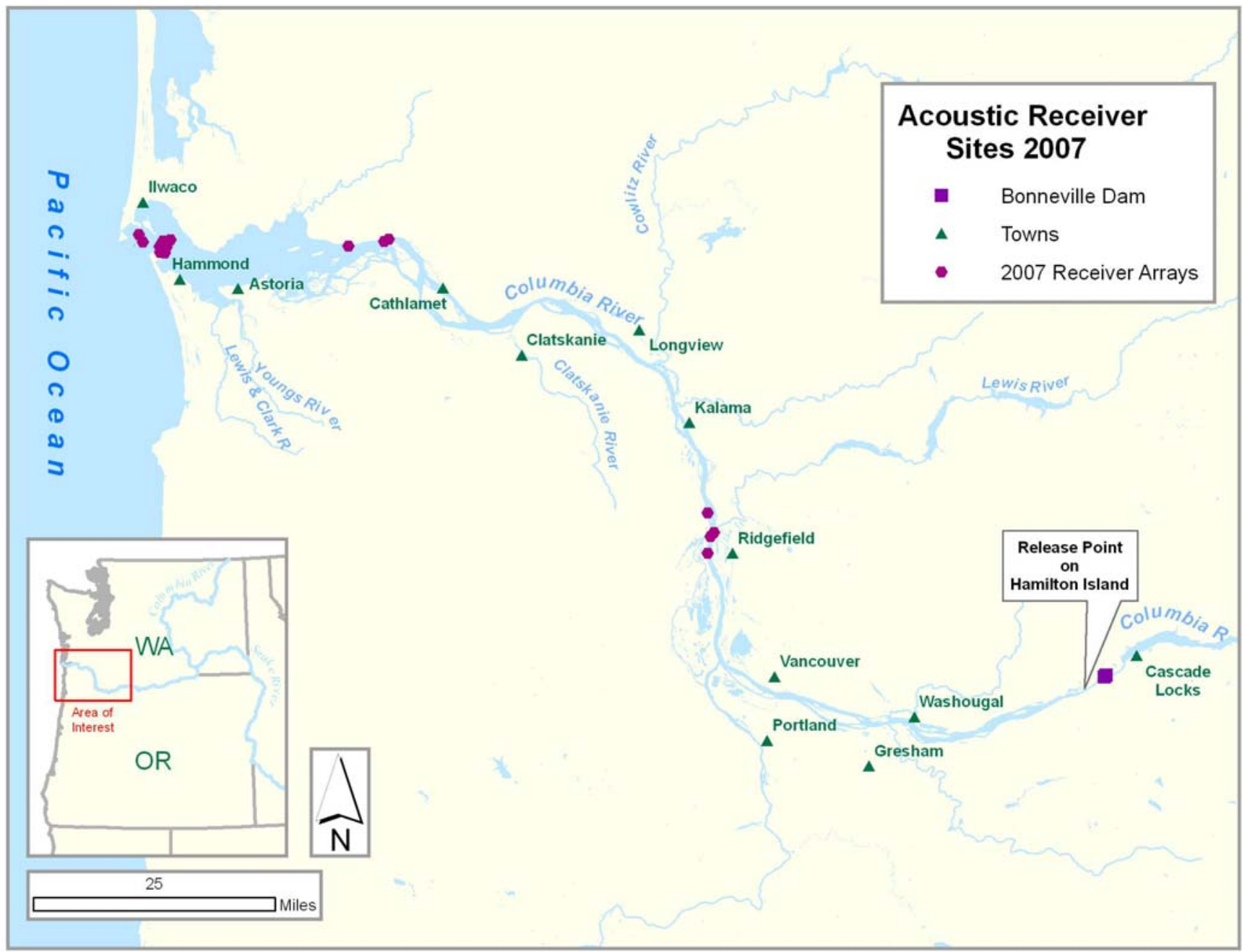

Figure 1. Array Sets for the Columbia River. 


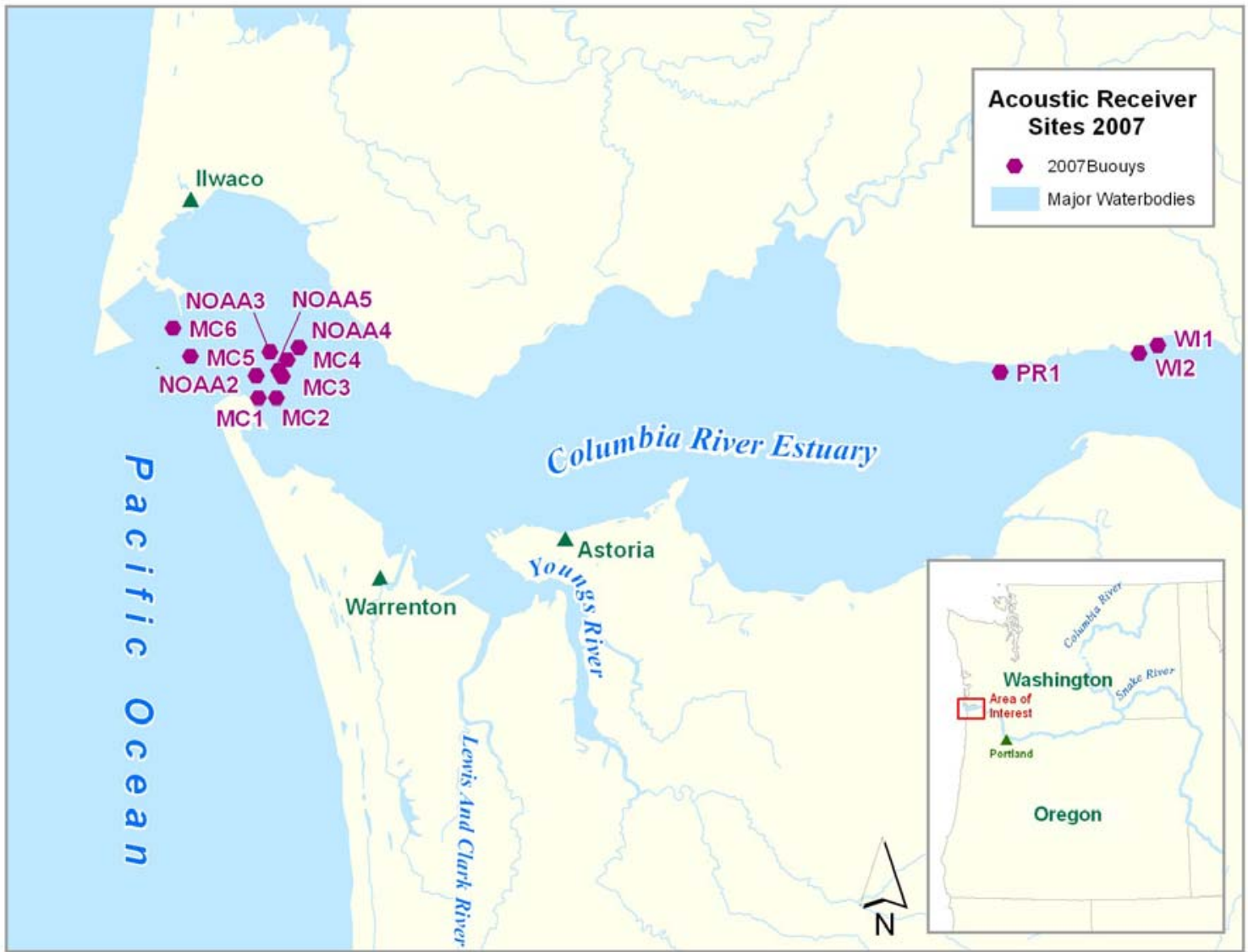

Figure 2. Estuary array sets rkm 43 and rkm 0. 


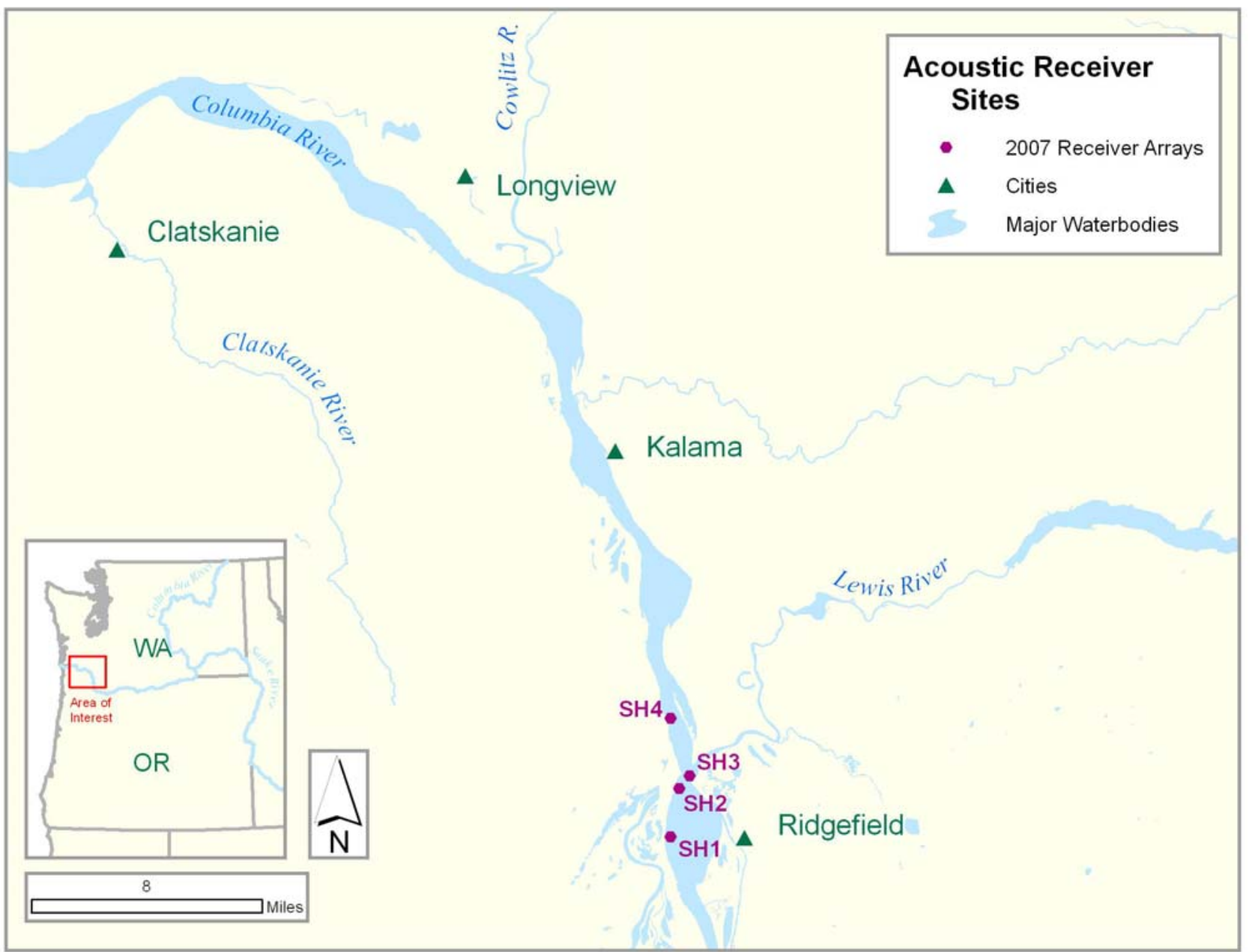

Figure 3. St Helens Array (rkm 138) 2008. 


\section{Appendix C: Likelihood functions of parameters}

For a tagged fish to be detected at receivers after release, the fish should not only survive to the receiver location but also be successfully detected by receivers. Thus, the number of fish detected in a location involves two parameters: fish survival and receivers' detection rate.

We describe estimation of parameters in a generalized setting where two detection locations are considered (Fig. 1). Even when there are more than two detection locations, the estimation principal remains the same. First, we arrange available data as in Table 1. In case of the experiment design in Fig. 1, numbers of fish released at stage 1 and then detected at stage 2 or 3 become multinomial random variables.

$$
\left(n_{g 12}, n_{g 13}\right) \sim \operatorname{Multinomial}\left(R_{g 1}, \boldsymbol{\theta}\right)
$$

where parameter vector $\boldsymbol{\theta}=\left(s_{g 1} p_{1}, s_{g 1}\left(1-p_{1}\right) s_{g 2} p_{2}\right)$. First element of vector $\boldsymbol{\theta}$ (i.e., $\left.\boldsymbol{\theta}_{(1)}=s_{g 1} p_{1}\right)$ means the probability that a fish from stage 1 survives to next stage, and also is detected at the next stage. The second element $\boldsymbol{\theta}_{\text {(2) }}\left(=s_{g 1}\left(1-p_{1}\right) s_{g 2} p_{2}\right)$ indicates the probability that a fish from stage 1 survives to stage 2, is not detected at stage 2, survives from stage 2 to stage 3 and finally is detected at stage 3 .

Also, when considering that the number of fish detected at stage 2 is the new release number, the number of fish detected at stage 2 being detected at stage 3 again becomes a binomial random variable.

$$
n_{g 23} \sim \operatorname{Binomial}\left(n_{g 12}, s_{g 2} p_{2}\right)
$$

where $s_{g 2} p_{2}$ means the probability that a fish from stage 2 survives to stage 3 and then is detected at stage 3. However, so-called success/failure probability in the binomial mass function in eq. 2 consists of two parameters of $s_{g 2}$ and $p_{2}$, and such two parameters cause an over-parameterization problem because a success/failure parameter in a binomial mass function is only one. That is, we cannot separately estimate $s_{g 2}$ and $p_{2}$ and thus express the product as one parameter, say $\lambda_{g}$ (Table 1). The expression of $\lambda_{g}$ is not problematic in this study, because our ultimate goals are to compare two fish groups (control vs. treatment) not to estimate receivers' detection rates. A difference in $\lambda_{g}$ between two fish groups is due to only fish survival $s_{g 2}$ not receivers' detection rate $p_{2}$ (Table 1 ). So, comparing two fish groups based on estimates of $\lambda_{g}$ is justifiable.

Further these multinomial and binomial events do not affect each other, so they are independent. That is, the probability of those two events is the product of the respective probabilities.

$$
\begin{aligned}
p\left(n_{g 12}, n_{g 13}, n_{g 23} \mid \theta, \lambda_{g}\right) & =p\left(n_{g 12}, n_{g 13} \mid \theta\right) \cdot p\left(n_{g 23} \mid \lambda_{g}\right) \\
& =\operatorname{Multinomial}\left(R_{g 1}, \boldsymbol{\theta}\right) \cdot \operatorname{Binomial}\left(n_{g 12}, \lambda_{g}\right)
\end{aligned}
$$

By definition, the likelihood function of parameters, $L\left(\boldsymbol{\theta}, \lambda_{g} \mid n_{g 12}, n_{g 13}, n_{g 23}\right)$ is eq. 3. Ignoring constants with respect to parameters, the likelihood function of parameters is

$$
L\left(\boldsymbol{\theta}, \lambda_{g}\right) \propto \boldsymbol{\theta}_{(1)}^{n_{g 12}} \cdot \boldsymbol{\theta}_{(2)}^{n_{g 13}} \cdot\left(1-\boldsymbol{\theta}_{(1)}-\boldsymbol{\theta}_{(2)}\right)^{R_{g 1}-n_{g 12}-n_{g 13}} \cdot \lambda_{g}^{n_{g 23}} \cdot\left(1-\lambda_{g}\right)^{n_{g 12}-n_{g 23}}
$$

Note that this likelihood function has three parameters as variables: $s_{g 1}, p_{1}$, and $\lambda_{g}$. For convenience of the calculation of maximum likelihood estimates (MLEs) of those three parameters and the variances, we take the natural logarithm for the likelihood function of 
eq. 4. The conversion to the log likelihood form is straightforward so we don't show it here. Finally, implementing the log likelihood function to software, Automatic Differentiation Model Builder (ADMB) (Fournier 2000), we differentiate the log likelihood function with respect to parameters to obtain the MLEs, and further calculate the Hessian matrix for calculation of the variances. We can provide our ADMB codes and executable file for the calculation of the MLEs and variances on request.

\section{Reference}

Fournier, D.A. 2000. An introduction to AD Model Builder version 4: For use in nonlinear modeling and statistics. Otter Research Ltd., Sidney, B.C., Canada.

Table 1. Notations. Release and detection stages are illustrated in Fig. 1.

\section{Index}

$g \quad$ Fish group (control or treatment).

$i, j \quad$ Stage index.

\section{Data}

$R_{g i} \quad$ The number of fish from group $g$ being released at stage $i$.

$n_{g i j} \quad$ The number of group $g$-fish being released at stage $i$ and then detected only at stage $j$. For example, $n_{g 13}=$ the number of group $g$-fish being released at stage 1 , and then detected not at stage 2 but at stage 3 .

\section{Parameters}

$s_{g i} \quad$ Probability of a fish from group $g$ surviving from stage $i$ to next stage $(i+1)$.

$p_{i} \quad$ Probability of a fish released from stage $i$ to be successfully detected at next stage $(i+1)$. Note that this parameter depends only on receivers' detection ability not on fish. So it does not have subscript, $g$. 
$\lambda_{g} \quad$ Product of $s_{g 2}$ and $p_{2}$ (i.e., $\lambda_{g}=s_{g 2} \times p_{2}$ ).

$1^{\text {st }}$ stage

$2^{\text {nd }}$ stage

\section{$3^{\text {rd }}$ stage}

Release
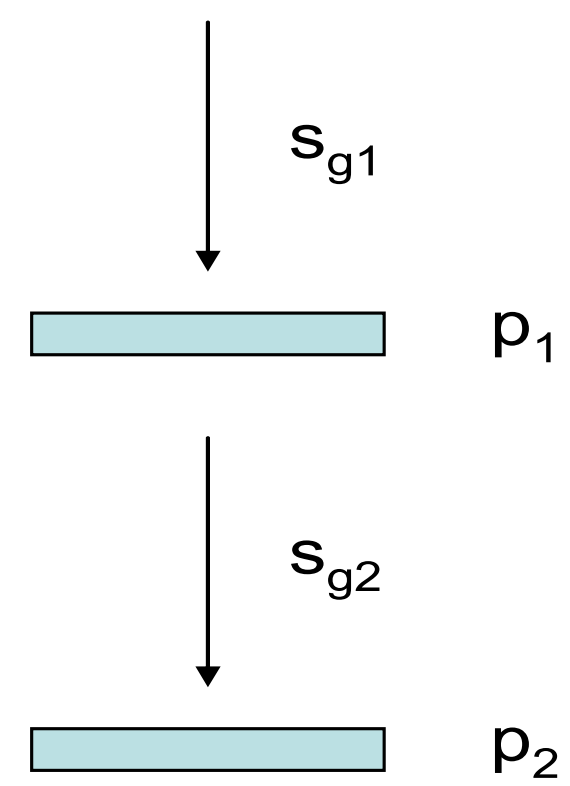

Figure 1. Parameters in the process of fish being released and detected in two different locations. A flat rectangle indicates a detection location. When there are two detection locations, four parameters of $s_{g 1}, p_{1}, s_{g 2}$, and $p_{2}$ are involved (Table 1). 
Appendix D. Detections History by Treatment and Release Year For

Yakima River Steelhead Kelt Releases.

Table 1: Yakima In River Releases and Returns.

\begin{tabular}{|c|c|c|c|c|}
\hline & & & & \\
Collection Year & In & Survived to Release & Returned to Bonneville & $\begin{array}{c}\text { Survived \& } \\
\text { Returned }\end{array}$ \\
\hline 2002 & -- & -- & -- & -- \\
\hline 2003 & -- & -- & -- & -- \\
\hline 2004 & -- & -- & -- & $4 \%$ \\
\hline 2005 & 67 & 67 & 3 & $2 \%$ \\
\hline 2006 & 52 & 52 & 3 & $3 \%$ \\
\hline 2007 & 53 & 53 & 3 & $4 \%$ \\
\hline 2008 & 88 & 88 & & \\
\hline $2005-08$ weighted average
\end{tabular}

Table 2: Collection and Return Migration History of No-term Yakama Releases

\begin{tabular}{|c|c|c|c|c|}
\hline Collection Year & In & $\begin{array}{c}\text { Survived to } \\
\text { Release }\end{array}$ & $\begin{array}{c}\text { Returned to } \\
\text { Bonneville }\end{array}$ & $\begin{array}{c}\% \text { Detected } \\
\text { Returning to } \\
\text { Bonneville }\end{array}$ \\
\hline 2002 & -- & -- & -- & -- \\
\hline 2003 & -- & -- & -- & -- \\
\hline 2004 & 75 & 63 & 5 & $7 \%$ \\
\hline 2005 & 98 & 96 & 1 & $1 \%$ \\
\hline 2006 & 55 & 49 & 2 & $4 \%$ \\
\hline 2007 & 43 & 38 & 0 & $0 \%$ \\
\hline 2008 & 100 & 100 & 2 & $2 \%$ \\
\hline 2005-08 weighted average & & & & $2 \%$ \\
\hline 2004-08 weighted average & & & & $3 \%$ \\
\hline
\end{tabular}


Table 3: Collection and Return Migration History of Short-term Reconditioned Yakama Releases

\begin{tabular}{|c|c|c|c|c|}
\hline Collection Year & In & $\begin{array}{c}\text { Survived to } \\
\text { Release }\end{array}$ & $\begin{array}{c}\text { \% Detected } \\
\text { Returning to } \\
\text { Bonneville }\end{array}$ \\
\hline 2002 & 479 & 334 & 43 & $9 \%$ \\
\hline 2003 & 208 & 187 & 8 & $4 \%$ \\
\hline 2004 & 105 & 83 & 0 & $5 \%$ \\
\hline 2005 & 106 & 96 & 0 & $0 \%$ \\
\hline 2006 & 56 & 50 & 1 & $0 \%$ \\
\hline 2007 & 40 & 38 & 6 & $3 \%$ \\
\hline 2008 & 108 & 100 & & $2 \%$ \\
\hline $2005-08$ weighted average & \multicolumn{3}{|l}{} \\
\hline 2002-08 weighted average
\end{tabular}

Table 4: Collection and Return Migration History of Long-term Reconditioned Yakama Releases

\begin{tabular}{|c|c|c|c|c|}
\hline Collection Year & In & $\begin{array}{c}\text { Survived to } \\
\text { Release }\end{array}$ & Mature @ Release & $\begin{array}{c}\% \text { Mature @ } \\
\text { Release }\end{array}$ \\
\hline 2000 & 512 & 91 & 42 & $8 \%$ \\
\hline 2001 & 551 & 197 & 108 & $20 \%$ \\
\hline 2002 & 420 & 140 & 76 & $18 \%$ \\
\hline 2003 & 482 & 298 & 254 & $53 \%$ \\
\hline 2004 & 662 & 253 & 216 & $33 \%$ \\
\hline 2005 & 386 & 86 & 75 & $19 \%$ \\
\hline 2006 & 279 & 85 & 79 & $28 \%$ \\
\hline 2007 & 422 & 221 & 202 & $48 \%$ \\
\hline 2008 & 472 & 266 & 263 & $56 \%$ \\
\hline $\begin{array}{l}2003-08 \text { weighted } \\
\text { average }\end{array}$ & & & $40 \%$ \\
\hline $2000-06$ weighted average & & & $31 \%$ \\
\hline
\end{tabular}




\section{Appendix E. First Time Spawner Analysis for Steelhead Captured at Parkdale 2008.}

Estimated Fertilization Rate: Based on keel presence/absence (approximately 10 sampled 2-weeks post-fertilization)

\begin{tabular}{|c|c|c|c|c|c|c|c|}
\hline Spawner \# & $\begin{array}{l}\text { Male } \\
\text { Group }\end{array}$ & $\begin{array}{c}\text { Keel } \\
\text { Success }\end{array}$ & Spawner \# & $\begin{array}{l}\text { Male } \\
\text { Group }\end{array}$ & $\begin{array}{c}\text { Keel } \\
\text { Success }\end{array}$ & Spawner \# & $\begin{array}{l}\text { Male } \\
\text { Group }\end{array}$ \\
\hline \multirow[t]{3}{*}{02828 / 02829} & A & $20 \%$ & 02834 / 02835 & A & $50 \%$ & 02843 / 02844 & A \\
\hline & B & $30 \%$ & & $\mathrm{~B}$ & $0 \%$ * & & $B$ \\
\hline & C & $20 \%$ & & $\mathrm{C}$ & $20 \%$ & & $\mathrm{C}$ \\
\hline \multirow[t]{3}{*}{$02701 / 02702$} & A & $20 \%$ & 02839 / 02840 & A & $40 \%$ & 02853 / 02854 & A \\
\hline & $B$ & $40 \%$ & & $B$ & $45 \%$ & & $B$ \\
\hline & C & $70 \%$ & & C & $0 \%$ * & & $\mathrm{C}$ \\
\hline \multirow[t]{3}{*}{$2831 ?$} & A & $10 \%$ & 02837 / 02838 & A & $36 \%$ & 02703 / 02704 & A \\
\hline & $B$ & $30 \%$ & & $B$ & $20 \%$ & & $B$ \\
\hline & C & $0 \% *$ & & C & $18 \%$ & & $\mathrm{C}$ \\
\hline \multirow[t]{3}{*}{52593 / 02858} & A & $70 \%$ & 52602 / 02864 & A & $60 \%$ & $02707 / 02708$ & A \\
\hline & $B$ & $10 \%$ & & $B$ & $30 \%$ & & $B$ \\
\hline & $\mathrm{C}$ & $60 \%$ & & $\mathrm{C}$ & $70 \%$ & & C \\
\hline \multirow[t]{3}{*}{02862 / 02863} & A & $50 \%$ & 02859 / 02860 & A & $40 \%$ & & \\
\hline & B & $30 \%$ & & B & $60 \%$ & & \\
\hline & C & $70 \%$ & & C & $40 \%$ & & \\
\hline
\end{tabular}

*This does not mean that there was no fertilization only that fertilization was extremely poor.

Actual Egg Survival: Based on counts eyed egg counts taken post cold shock

\begin{tabular}{|c|r|}
\hline FEMALE\# & \multicolumn{1}{l|}{ Survival } \\
\hline $2828 / 29 \mathrm{~A}$ & $53.6 \%$ \\
\hline $2828 / 29 \mathrm{~B}$ & $37.8 \%$ \\
\hline $2828 / 29 \mathrm{C}$ & $43.7 \%$ \\
\hline $2701 \mathrm{~A}$ & $33.2 \%$ \\
\hline $2701 \mathrm{~B}$ & $46.6 \%$ \\
\hline $2701 \mathrm{C}$ & $47.5 \%$ \\
\hline $2834 / 35 \mathrm{~A}$ & $33.0 \%$ \\
\hline $2834 / 35 \mathrm{~B}$ & $34.1 \%$ \\
\hline $2834 / 35 \mathrm{C}$ & $16.5 \%$ \\
\hline $2843 \mathrm{~A}$ & $54.6 \%$ \\
\hline $2843 \mathrm{~B}$ & $57.1 \%$ \\
\hline $2843 \mathrm{C}$ & $44.2 \%$ \\
\hline $2853 \mathrm{~A}$ & $14.1 \%$ \\
\hline $2853 \mathrm{~B}$ & $26.1 \%$ \\
\hline $2853 \mathrm{C}$ & $6.2 \%$ \\
\hline $2839 / 40 \mathrm{~A}$ & $33.8 \%$ \\
\hline $2839 / 40 \mathrm{~B}$ & $23.9 \%$ \\
\hline $2839 / 40 \mathrm{C}$ & $5.5 \%$ \\
\hline
\end{tabular}




\begin{tabular}{|c|r|}
\hline $2830 / 31 \mathrm{~A}$ & $14.4 \%$ \\
\hline $2830 / 31 \mathrm{~B}$ & $10.4 \%$ \\
\hline $2830 / 31 \mathrm{C}$ & $6.4 \%$ \\
\hline $2703 / 04 \mathrm{~A}$ & $50.4 \%$ \\
\hline $2703 / 04 \mathrm{~B}$ & $37.2 \%$ \\
\hline $2703 / 04 \mathrm{C}$ & $24.9 \%$ \\
\hline $2837 / 38 \mathrm{~A}$ & $60.0 \%$ \\
\hline $2837 / 38 \mathrm{~B}$ & $53.2 \%$ \\
\hline $2837 / 38 \mathrm{C}$ & $29.3 \%$ \\
\hline $529593 \mathrm{~A}$ & $37.5 \%$ \\
\hline $529593 \mathrm{~B}$ & $29.2 \%$ \\
\hline $529593 \mathrm{C}$ & $30.8 \%$ \\
\hline $52602 \mathrm{~A}$ & $53.5 \%$ \\
\hline $52602 \mathrm{~B}$ & $51.8 \%$ \\
\hline $52602 \mathrm{C}$ & $62.6 \%$ \\
\hline $2707 / 08 \mathrm{~A}$ & $34.9 \%$ \\
\hline $2707 / 08 \mathrm{~B}$ & $50.0 \%$ \\
\hline $2707 / 08 \mathrm{C}$ & $50.0 \%$ \\
\hline $2859 \mathrm{~A}$ & $32.2 \%$ \\
\hline $2859 \mathrm{~B}$ & $62.8 \%$ \\
\hline $2859 \mathrm{C}$ & $53.9 \%$ \\
\hline $2862 \mathrm{~A}$ & $46.4 \%$ \\
\hline $2862 \mathrm{~B}$ & $39.4 \%$ \\
\hline $2862 \mathrm{C}$ & $51.6 \%$ \\
\hline
\end{tabular}

Juvenile Growth. Sub-sampled (2 small hand nets) weekly over 10 -week period. Water temperatures $5.5^{0} \mathrm{C}\left(42^{0} \mathrm{~F}\right)$. Juvenile fish were hand fed every 2 hours approximately 2 grams of food. 

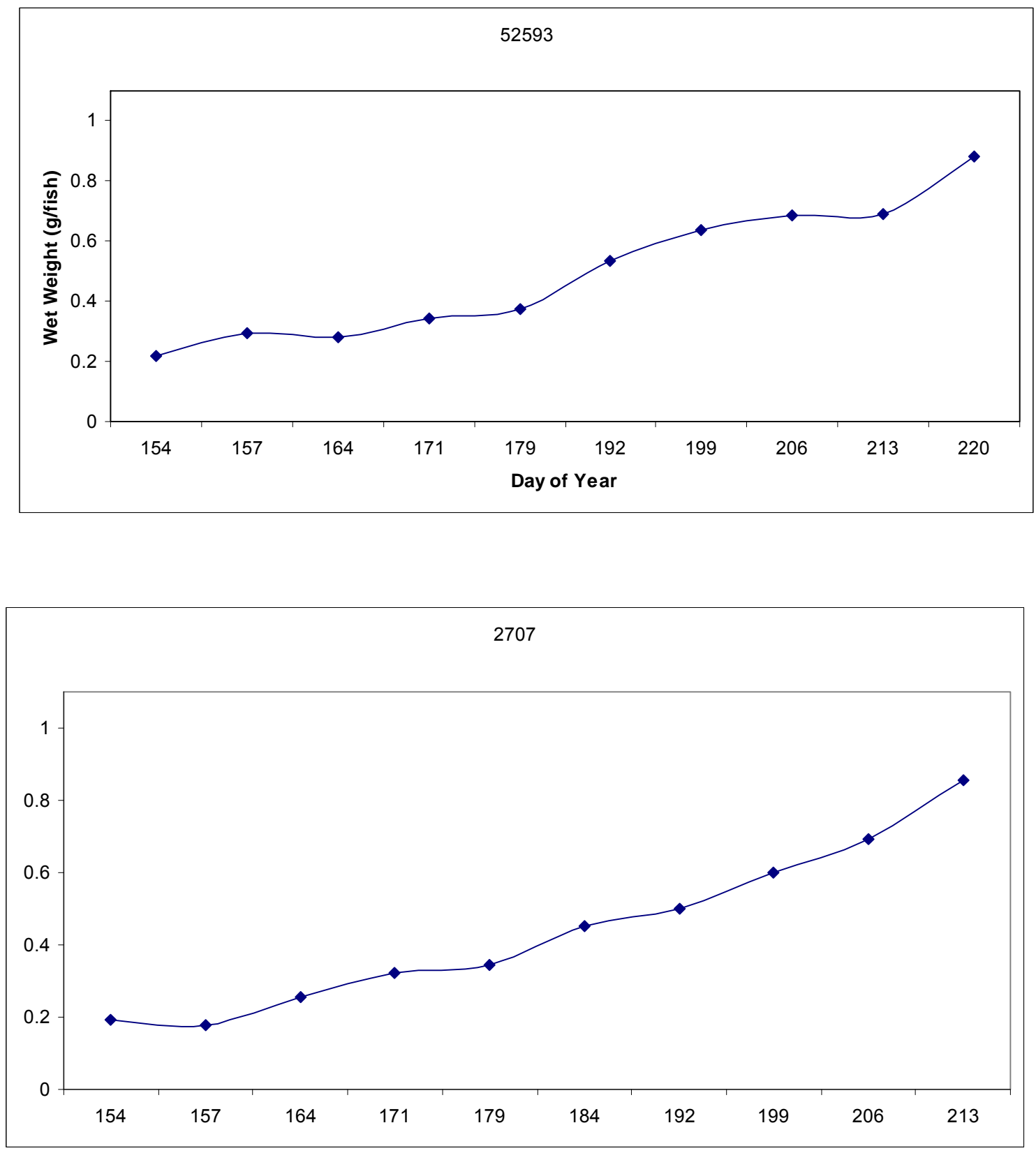

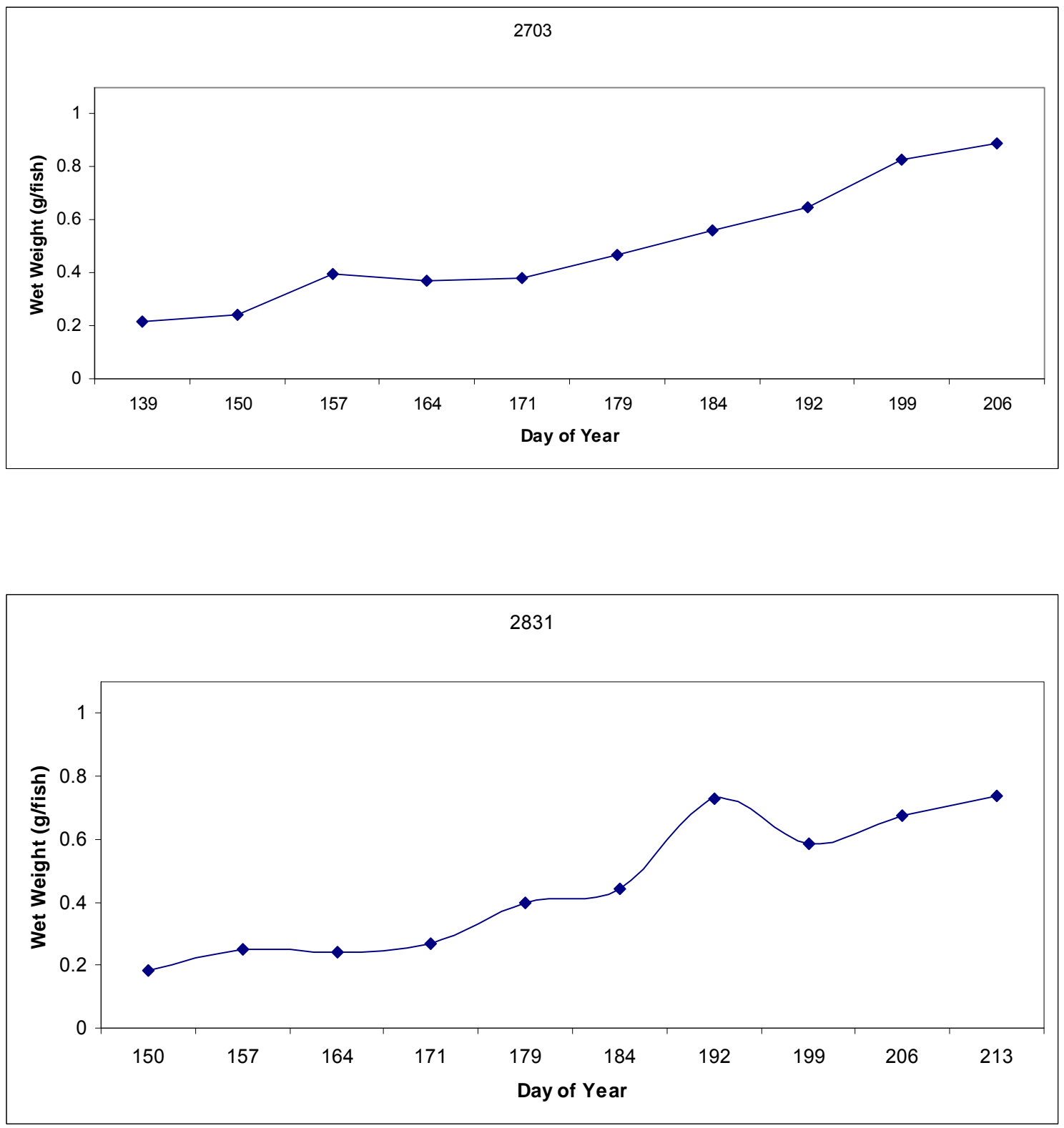

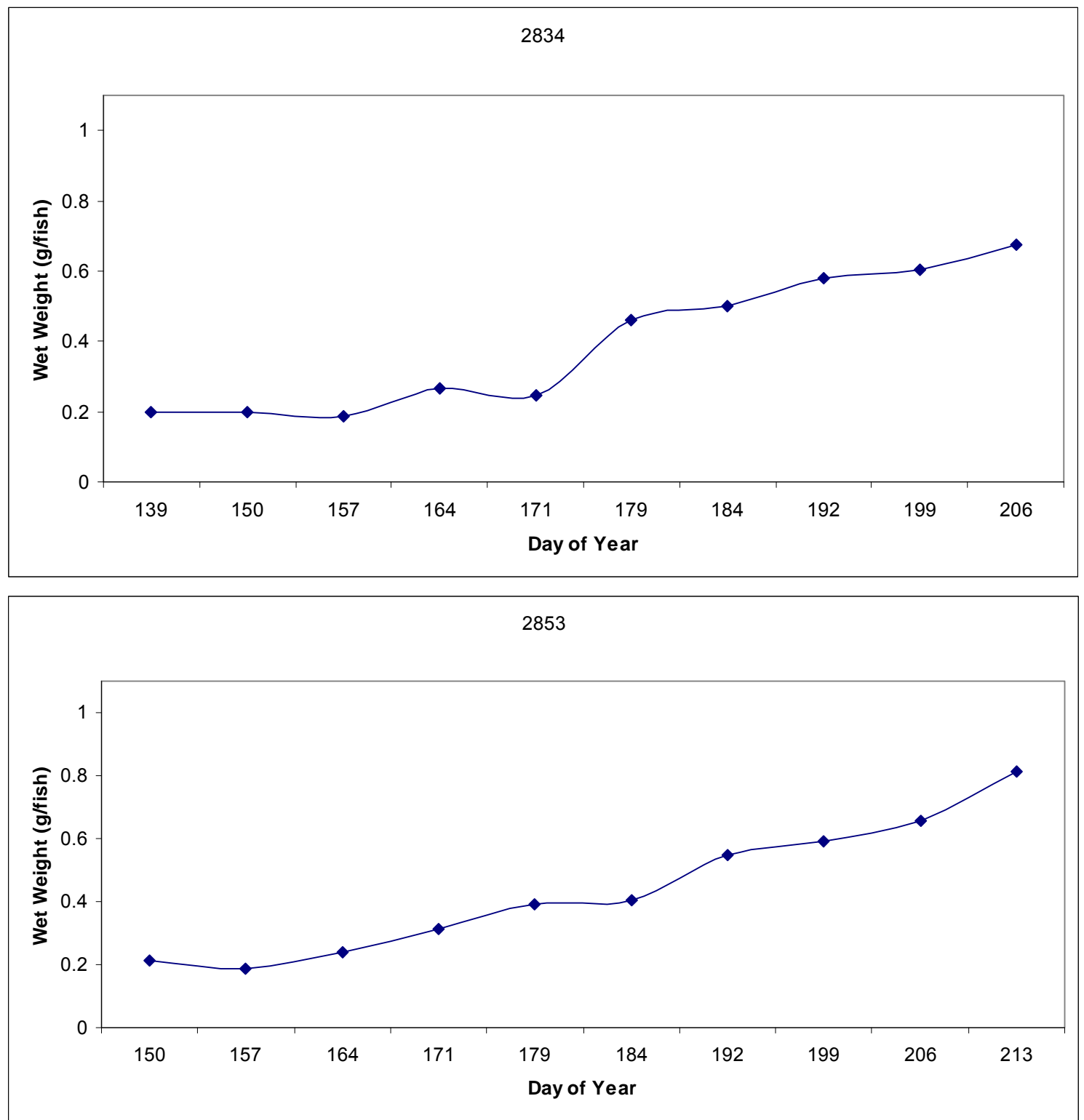

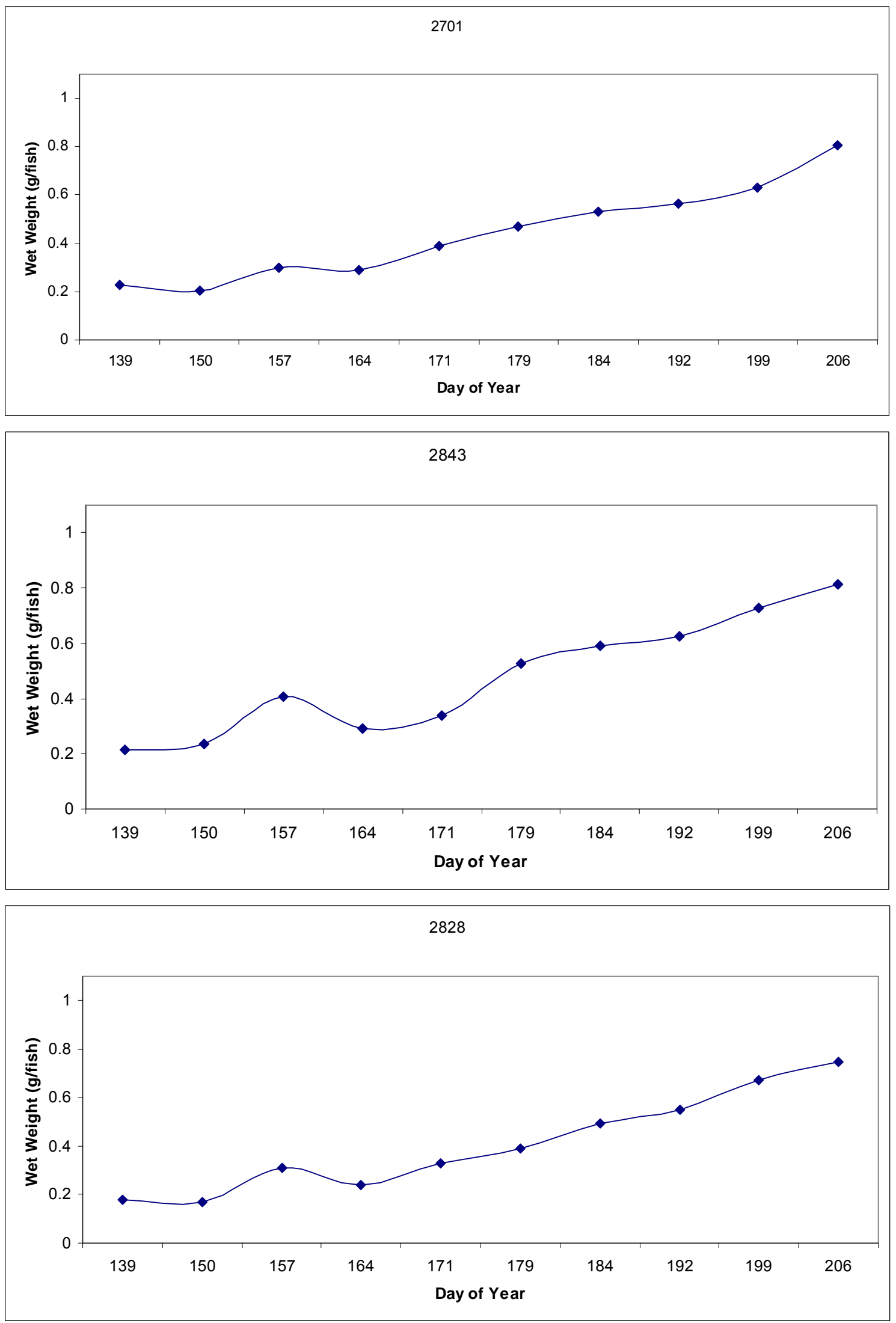

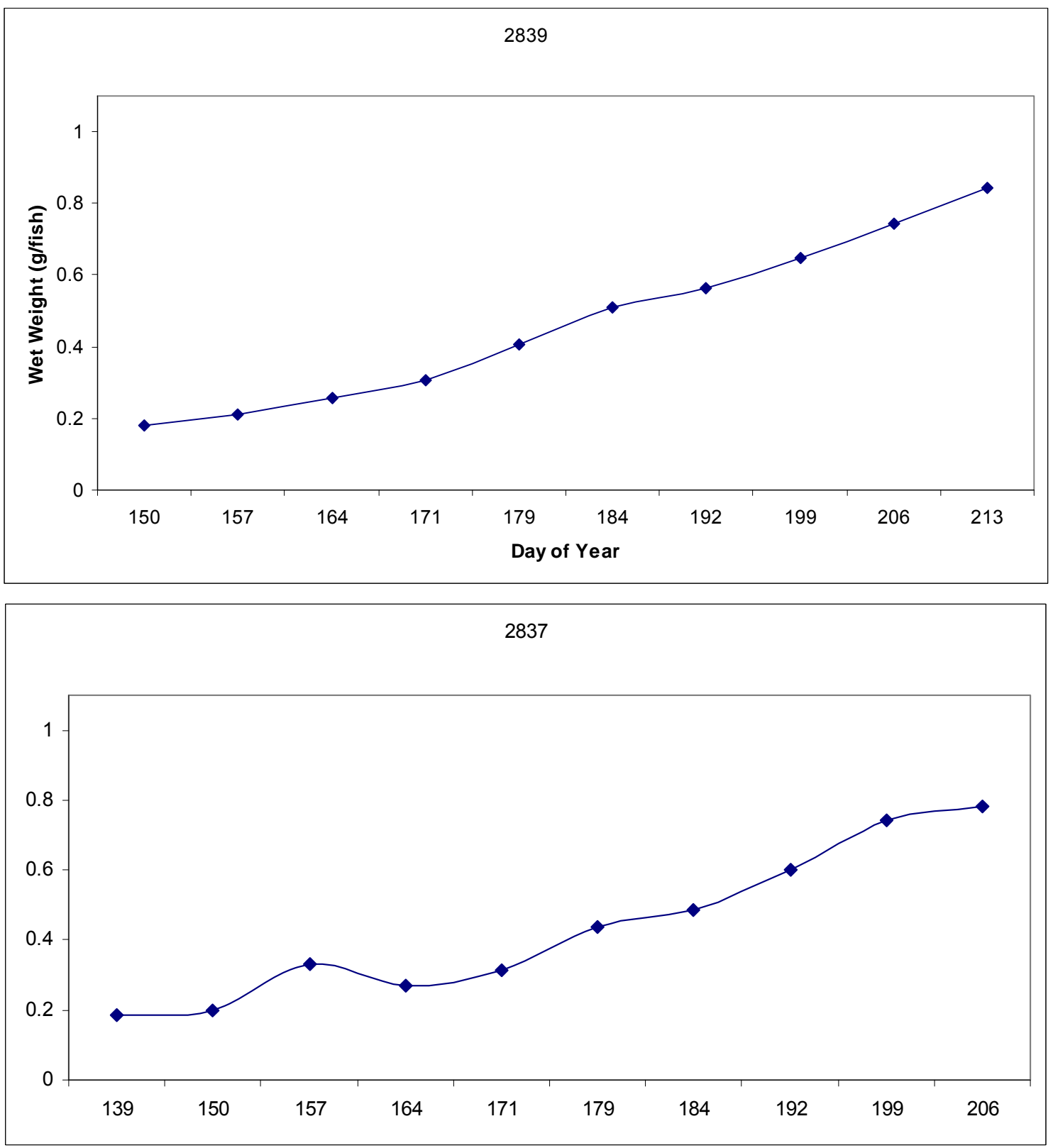


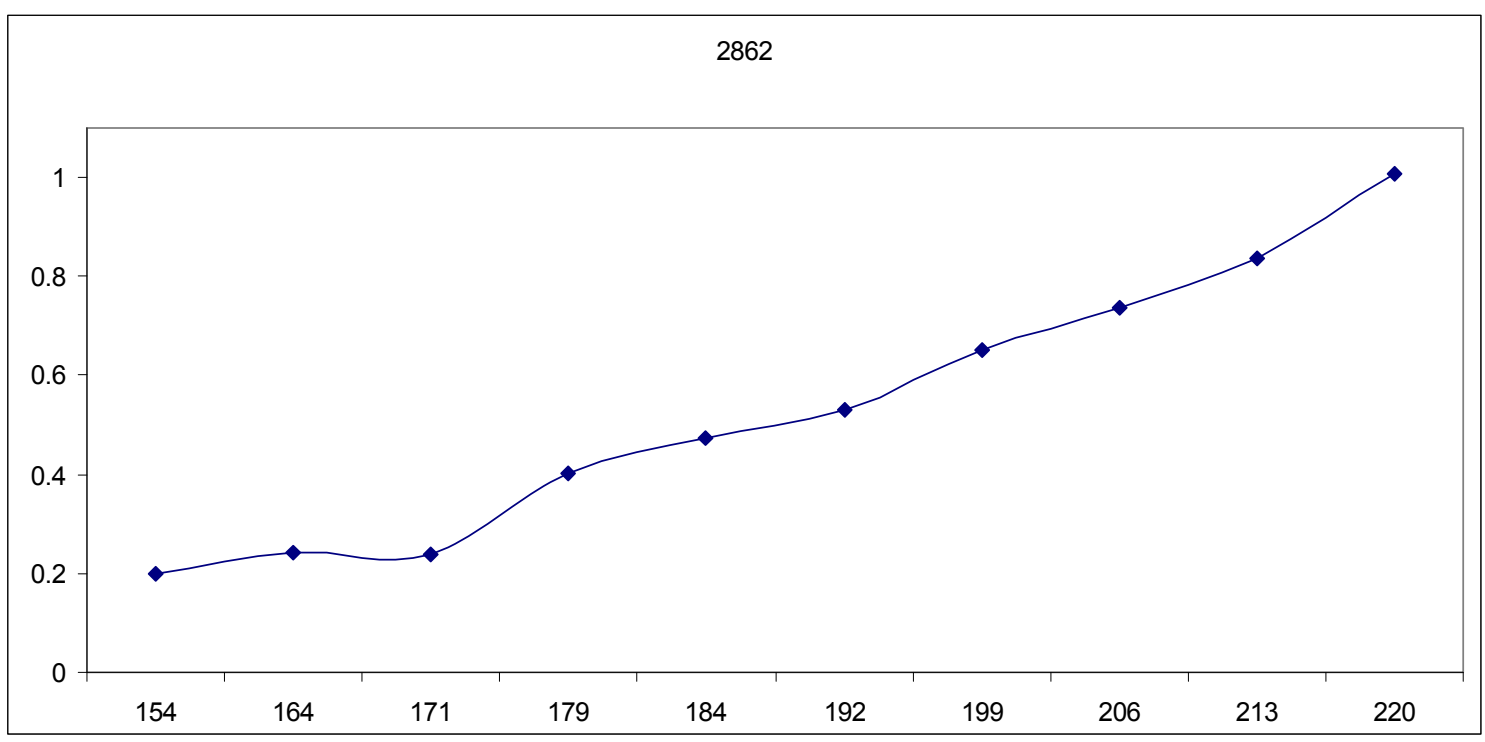

